\title{
The Role of Outer-Membrane Vesicles in Intercellular Communication in Pseudomonas aeruginosa
}

\author{
Euan Russell \\ 300221866 \\ February 2017
}

Submitted in fulfilment for the requirements of the degree Master of Biomedical Science

Victoria University of Wellington

Supervisor: Dr Darren J Day 


\section{Acknowledgements}

I would like to firstly thank my supervisor, Dr Darren Day. Thank you for talking me into coming back to research after working a soulless year at a bank and for all the guidance and words of wisdom you have shared with me. You taught me that science could be exciting and encouraged me to challenge myself. Although we may have differing opinions at times, I have a huge amount of respect for you as both a scientist, mentor and lastly, as a friend. I will be taking all the knowledge and lessons you have taught me over the past year to further build upon in my $\mathrm{PhD}$ studies.

I would also like to thank Dr Renee Goreham for both her expertise in electron micrograph imaging and the collaborations we have made on projects over the past year, I wish you all the best for your career in New Zealand.

To Dr Jeremy Owen \& fellow colleague Jennifer Soundy, thank you for taking the time to use your expertise in HPLC \& flow cytometry to help me in aspects of this study.

To fellow postgraduates who provided support and quality banter in the tough times, namely; Varun, Luke, Jack, Mitch, Alistair, Izzie, Orin, Jasmine \& Antoine. I wish you guys all the best for the remainder of your studies and subsequent careers, whether it be science-related or not.

To my close friends, Aaron, Ryan, Lee, Hamish, Adam, Patch \& Mel for encouraging me along this journey and for being understanding when I was too busy to be social. You guys have been a huge element in keeping me driven and making me see the light at the end of the tunnel.

To my partner and best friend, Charlotte Parson. I know it hasn't been easy dealing with me this year, we have experienced a lot of highs and lows together that come with research and you have been amazingly understanding when I have spent large amounts of time either in the lab or writing this thesis. I hope that I will be able to provide the same level of support as you did, through your studies to become a Teacher. 
Last but not least, my parents for both enabling me to do my masters by providing financial assistance and also for providing words of support and encouragement when times looked grim. The support you have provided throughout my university life has been immense and I hope that I will one day be able to repay you with the same kind of generosity. 


\section{$\underline{\text { Abstract }}$}

Gram-negative bacteria produce outer-membrane vesicles (OMVs) that have biological roles ranging from biofilm formation, modulation of host-cell interactions \& delivery of virulence factors. Several studies have shown a role for OMVs to act as intracellular signals to co-ordinate behaviour of bacteria. This study showed OMVs generated at sub-lethal ciprofloxacin concentrations were capable of programming naïve $P$. aeruginosa cultures resulting in premature entry into stationary-phase and a significantly lower final culture density reached after 14 hrs. Pyoverdine production was also initiated after $6 \mathrm{hrs}$ in cultures treated with OMVs.

Heat-inactivation of OMVs failed to impede OMV-mediated growth inhibition \& pyoverdine production. Chloroform-disruption of OMVs prevented OMV-mediated growth inhibition but did not inhibit OMV-induced pyoverdine production. It is likely that these effects are mediated by multiple signals as opposed to a single mechanism. This suggests that a protein is not responsible for OMV-mediated growth inhibition and an intact OMV lipid bilayer is required. Induction of pyoverdine production is likely due to a lipid (such as a homo-serine lactone) or small molecule present within OMVs.

Preincubation with OMVs for 2-4 hrs resulted in a substantial decrease in the final culture density from cultures that were exposed to OMVs during the course of growth. This suggests that OMV fusion is capable of programming naïve bacteria to set a predetermined division limit on subsequent daughter cells. We coin this as the 'Dayflick' limit due to the similarities of the Hayflick limit in eukaryotic cells.

This shows that OMVs act as intercellular messaging vehicles between bacteria that communicate and program naïve bacteria to adapt to the environment under which they were generated in, aiding survival in harsh environments. Further study is needed to determine what OMV components are responsible for initiating these responses and to determine how long the programming is stable. 


\section{Table of Contents}

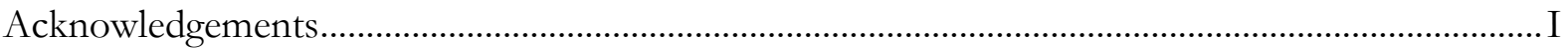

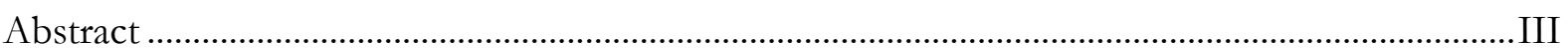

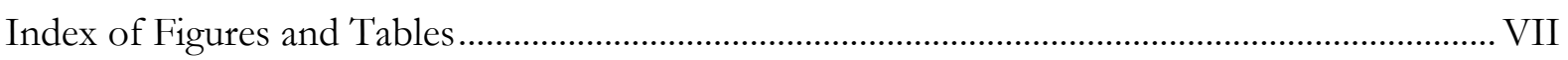

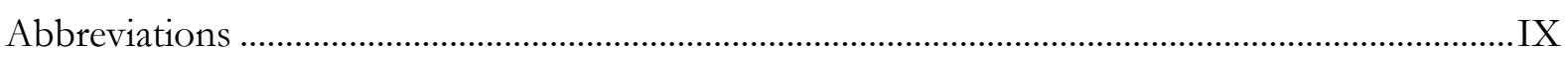

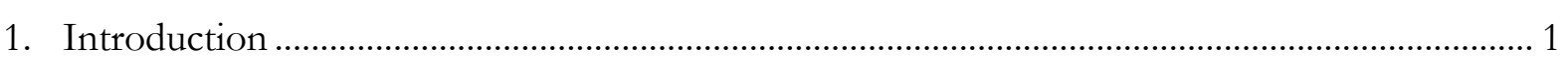

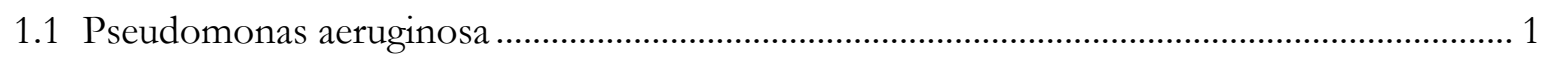

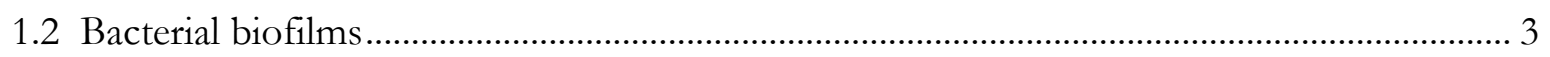

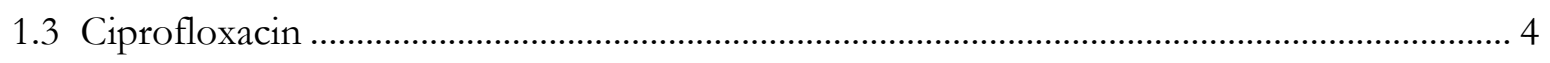

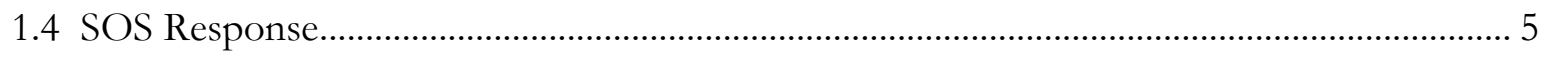

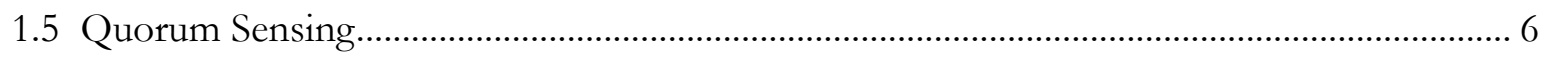

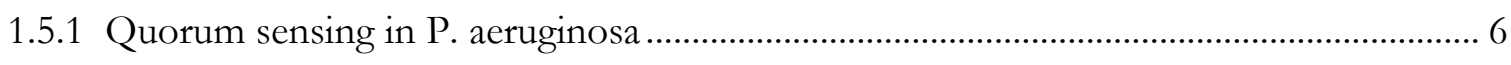

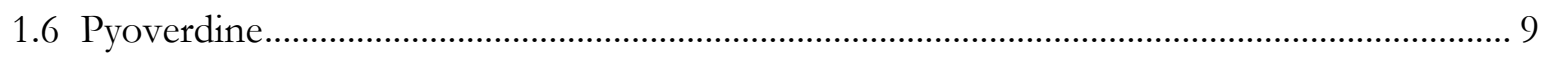

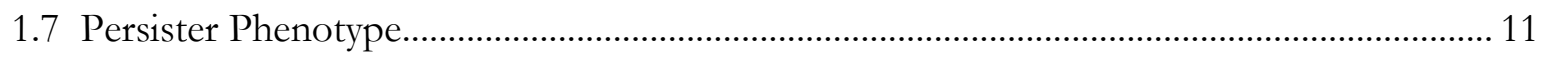

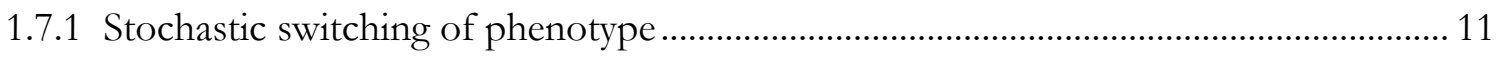

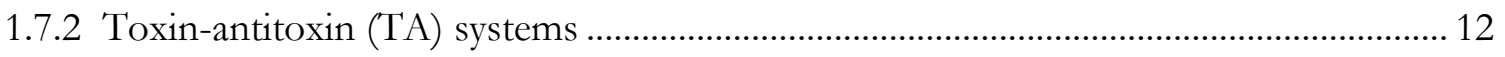

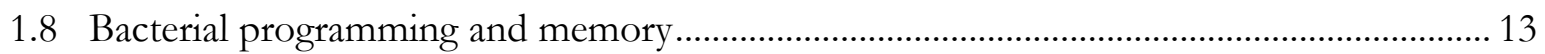

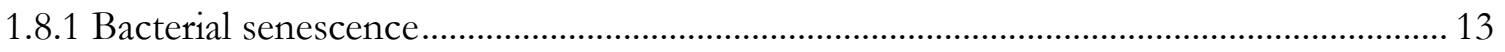

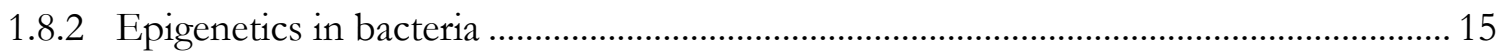

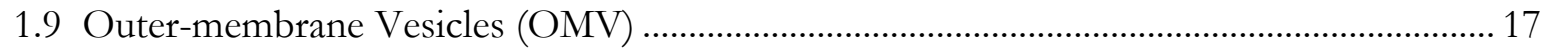

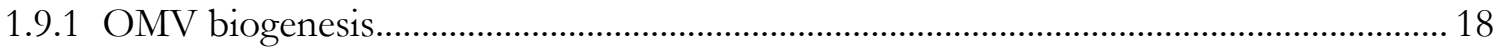

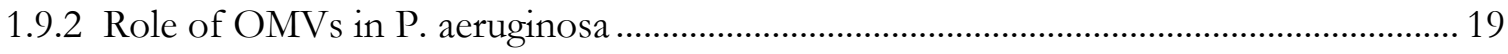

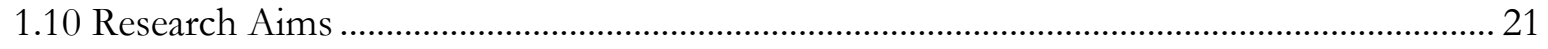

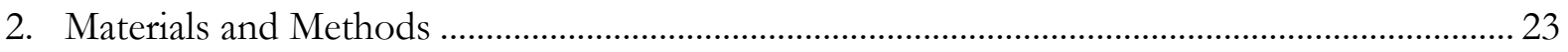

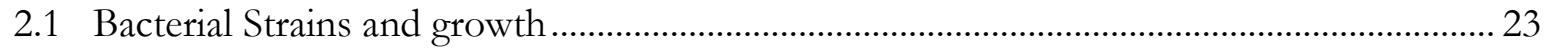

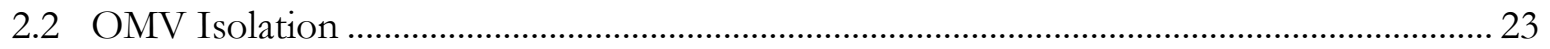

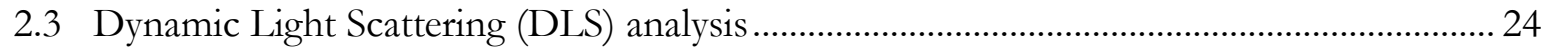

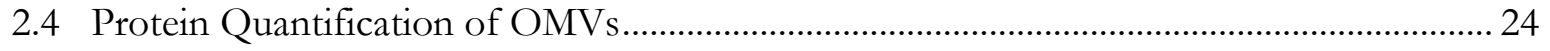

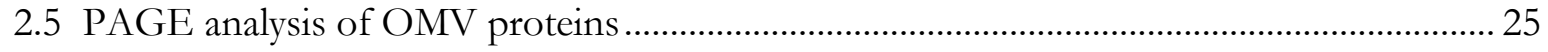

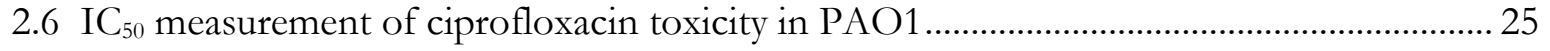

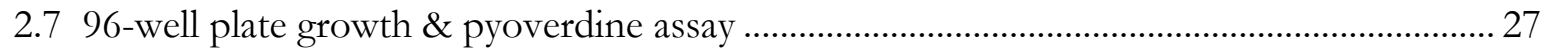

2.8 Modified Optical absorption spectral analysis .......................................................................... 27

2.9 Persister abundance CFU and colony morphology assay ........................................................ 28

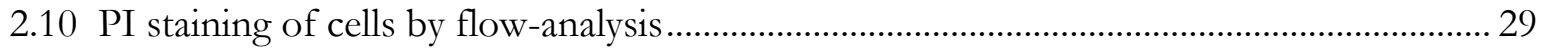

2.11 Transmission Electron Microscopy (TEM) images ................................................................. 29 


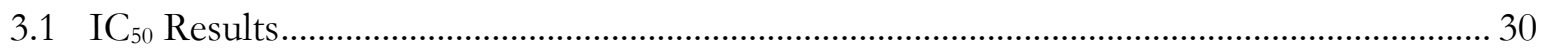

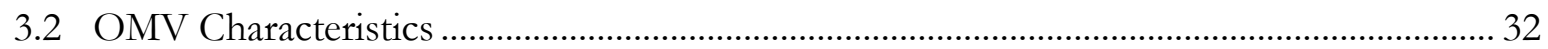

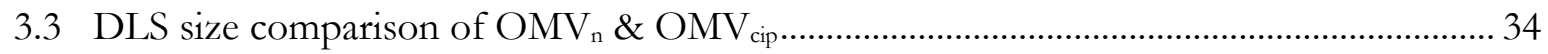

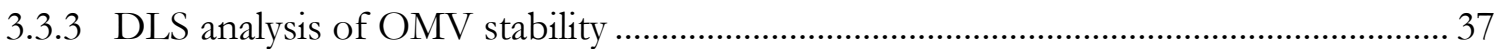

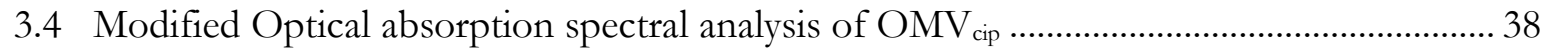

3.4 Electron Micrograph (EM) images of OMVs......................................................................... 41

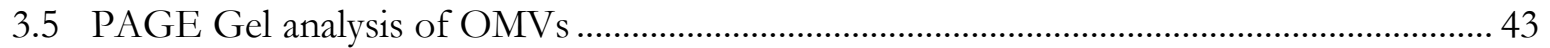

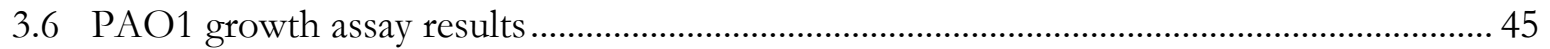

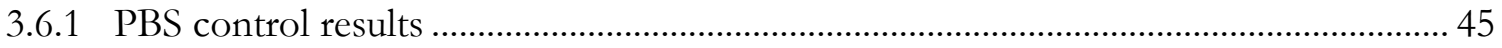

3.6.2 Effect of $\mathrm{OMV}_{\text {cip }}$ on PAO1 growth kinetics .................................................................... 47

3.6.3 Effect of $\mathrm{OMV}_{\text {cip }}$ on S.enterica growth kinetics.................................................................. 49

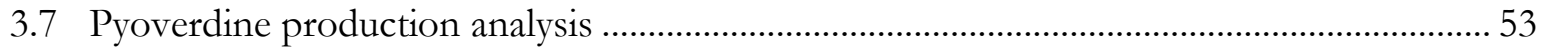

3.7.1 $\mathrm{OMV}_{\text {cip }}$ induction of pyoverdine production. .................................................................. 53

3.8 Ablation of $O M V_{\text {cip }}$-mediated effects by heat \& chloroform disruption............................... 57

3.9 Pre-incubation with $\mathrm{OMV}_{\text {cip }}$ effect on growth \& pyoverdine production.............................. 61

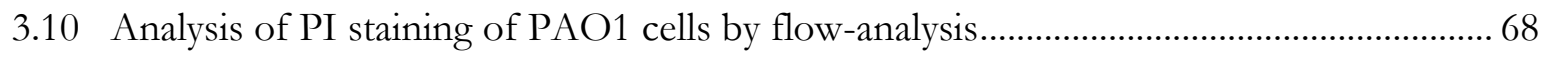

3.11 Analysis of $\mathrm{OMV}_{\text {cip }}$ treatment on PAO1 colony morphology and antibiotic tolerance.. 72

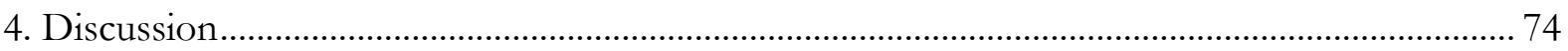

4.1 Optimization of OMV Isolation Protocol............................................................................ 74

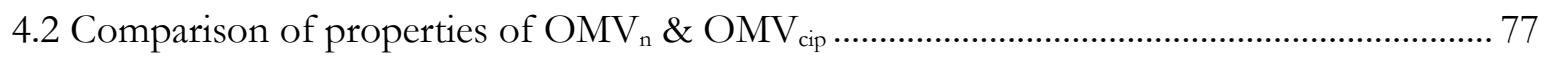

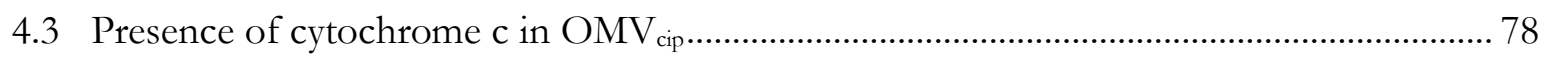

$4.4 \mathrm{OMV}_{\text {cip }}$ as a vehicle for intercellular communication ............................................................ 79

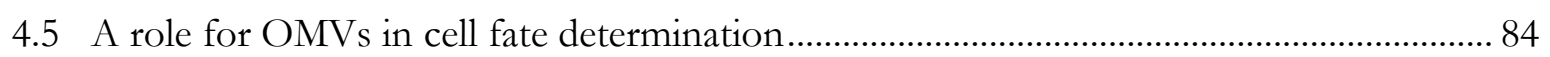

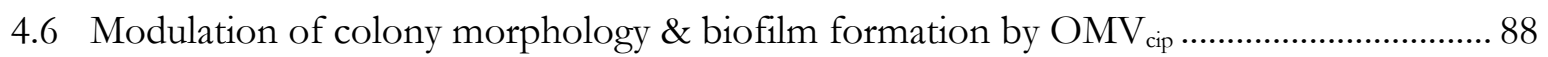

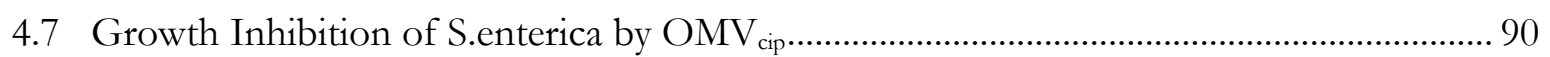

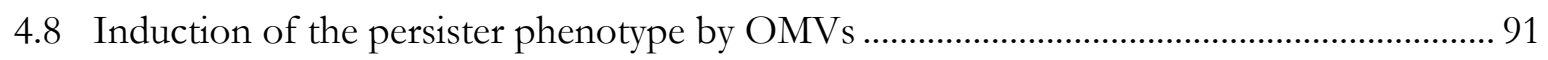

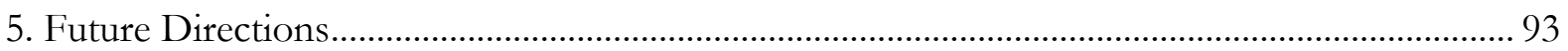

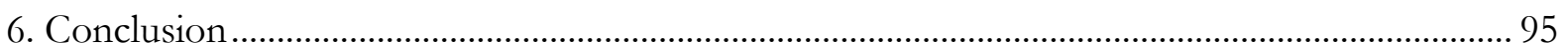

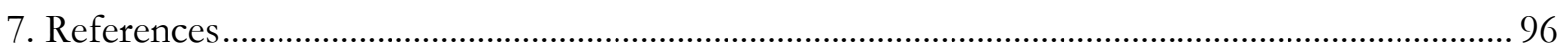

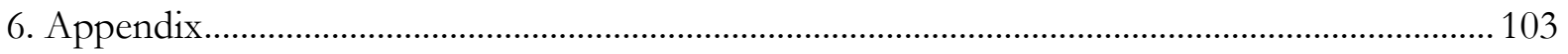

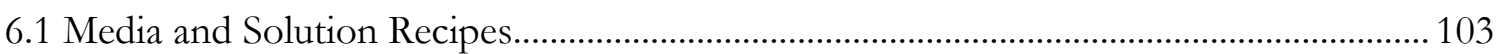

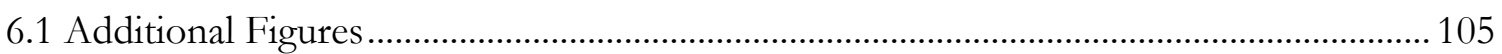




\section{$\underline{\text { Index of Figures and Tables }}$}

Figure 1: The 4 characteristic stages of biofilm formation in P.aeruginosa ......................................... 3

Figure 2: An overview of the P.aeruginosa quorum-sensing networks, las and $\mathrm{rhl}$............................ 7

Figure 3: Mechanisms of OMV biogenesis and cargo selection ...................................................... 18

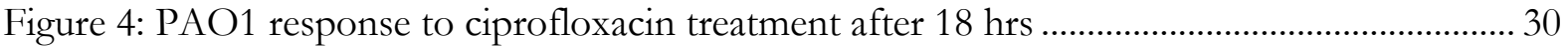

Figure 5: A visual comparison of ciprofloxacin treated PAO1 cultures ........................................... 33

Figure 6: Dynamic Light scattering analysis of OMV isolates ......................................................... 35

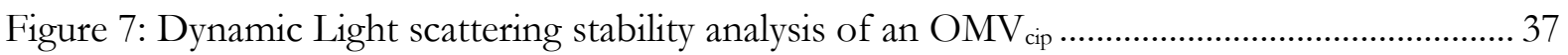

Figure 8: Analysis of $\mathrm{OMV}_{\text {cip }}$ absorbance spectra using an integrating sphere................................. 39

Figure 9: Analysis of cytochrome c oxidation in $\mathrm{OMV}_{\text {cip }}$ by APS from absorbance spectra ........ 40

Figure 10: Electron micrograph images of OMV isolates ................................................................. 42

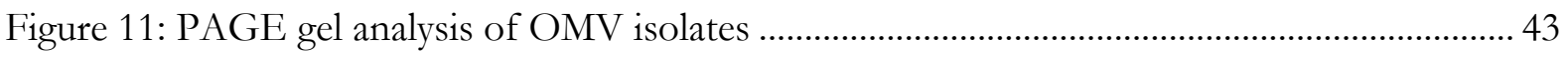

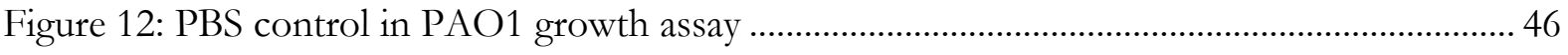

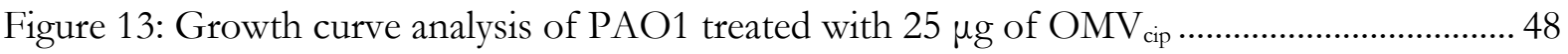

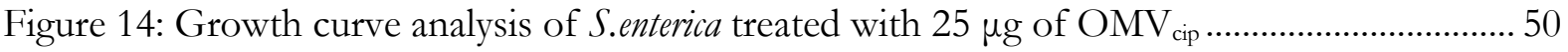

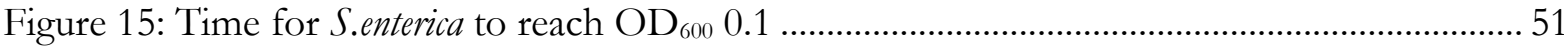

Figure 16: UV trans-illumination of a 96-well plate of PAO1 ………………................................. 53

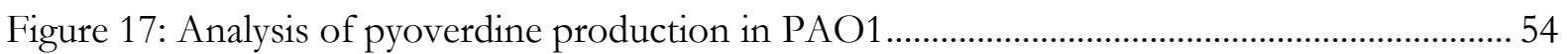

Figure 18: Analysis of Pyoverdine production \& Growth of PAO1 …………................................. 55

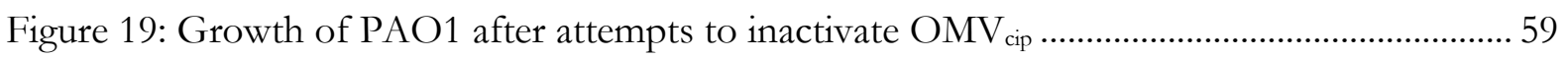

Figure 20: Pyoverdine production in PAO1 after attempts to inactivate $\mathrm{OMV}_{\text {cip }} \ldots . . . . . . . . . . . . . . . . . . . . .60$

Figure 21: Analysis of PAO1 growth after 4 hr pre-incubation ........................................................ 64

Figure 22: Analysis of PAO1 pyoverdine production after 4 hr pre-incubation............................... 65

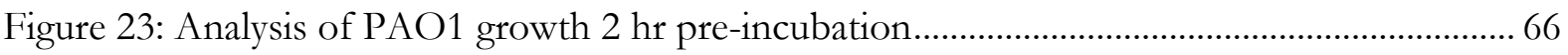

Figure 24: Analysis of PAO1 pyoverdine production after $2 \mathrm{hr}$ pre-incubation.............................. 67

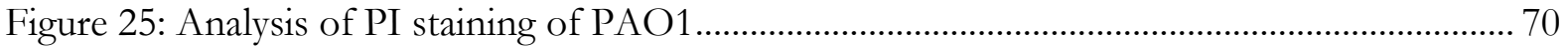


Figure 26: Proportion of PAO1 cells stained PI positive ……………............................................... 71

Figure 27: Comparison of colony morphology of PAO1 incubated for 2 hrs with $\mathrm{OMV}_{\text {cip }} \ldots . . . . . .73$

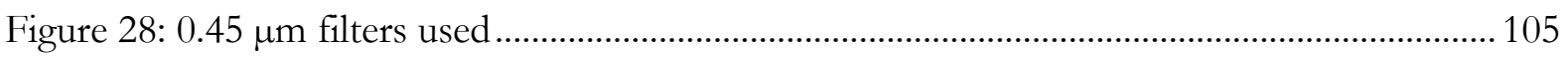

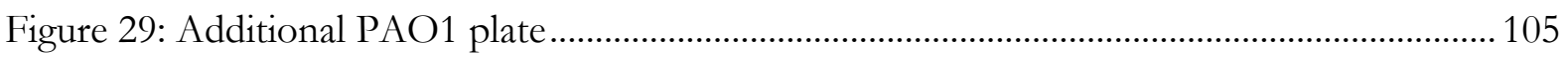

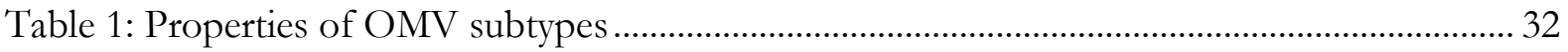




\section{$\underline{\text { Abbreviations }}$}

AHL $=$ Acyl Homoserine Lactone

APS $=$ Ammonium persulfate

BCA $=$ Bicinchoninic acid

BSA $=$ Bovine Serum Albumin

$\mathrm{CF}=$ Cystic Fibrosis

$\mathrm{CFU}=$ Colony Forming Units

Cyt c $=$ Cytochrome C

DLS $=$ Dynamic Light Scattering

DNA $=$ Deoxyribonucleic acid

ssDNA $=$ Single-stranded DNA

EPS $=$ Exopolysaccharide

HSL $=$ Homoserine-lactone

$\mathrm{IC}_{50}=50 \%$ Inhibition concentration

IPTG = Isopropyl $\beta$-D-1-thiogalactopyranoside

$\mathrm{LB}=$ Lieu broth media

Lpp $=$ Braun's lipoprotein

LPS = Lipopolysaccharide

MALDI = Matrix-assisted laser desorption/ionization

MIC $=$ Minimum inhibitory concentration 
$\mathrm{MV}=$ Microvesicle

NRPS $=$ Nonribosomal peptide synthetase

$\mathrm{OD}=$ Optical Density

OMV $=$ Outer-membrane Vesicle

$\mathrm{OMV}_{\text {cip }}=\mathrm{OMV}$ ciprofloxacin

$\mathrm{OMV}_{\mathrm{g}}=\mathrm{OMV}$ gentamicin

$\mathrm{OMV}_{\mathrm{n}}=\mathrm{OMV}$ native

PBS $=$ Phosphate Buffered Saline

PG = Peptidoglycan

PI = Propidium Iodide

$\mathrm{pmf}=$ proton-motive force

PQS = Pseudomonas quinone signal

$\mathrm{RT}=$ Room temperature

RNA $=$ Ribonucleic acid

$\mathrm{mRNA}=$ messenger $\mathrm{RNA}$

$\mathrm{t} \mathrm{RNA}=$ transporter $\mathrm{RNA}$

SDS-PAGE $=$ Sodium dodecyl Polyacrylamide Gel electrophoresis

$\mathrm{TA}=$ Toxin-antitoxin 


\section{Introduction}

\section{$\underline{1.1 \text { Pseudomonas aeruginosa }}$}

Pseudomonas aeruginosa is a rod-shaped, Gram-negative bacterium commonly found on the skin of humans and in the environment in water and soil. It is considered an opportunistic pathogen that thrives in a moist environment, making it a good bacterial colonizer of medical equipment such as urinary catheters. It is a highly adaptable organism that is of concern due to the role it plays in chronic recalcitrant infections in immunocompromised patients, burn victims and particularly suffers of Cystic Fibrosis (CF) (Van Delden \& Iglewski, 1998). P. aeruginosa is highly prevalent in suffers of CF, with studies showing $80 \%$ of CF patients have a $P$. aeruginosa infection by the age of 20 .

Genomic studies on $P$. aeruginosa have shown a high degree of allelic differences in genes involved with metabolic and regulatory processes. In addition to this, in chronic infections $P$. aeruginosa develops into multiple sub-phenotypic variants that co-exist and diversify in their antimicrobial susceptibility and virulence traits. All these factors contribute to the ability of $P$. aeruginosa to readily adapt to multiple environments (Silby et al, 2011).

P. aeruginosa is able to grow in both aerobic and anaerobic environments as well as utilize a variety of carbon sources including oil (Itah \& Essien, 2005). In the absence of oxygen, $P$. aeruginosa is able to use nitrate or nitrite as an electron acceptor to undergo respiration. If nitrate or nitrite are not present, it can still ferment arginine or pyruvate via substrate-level phosphorylation (Schobert \& Jahn, 2010). This ability allows it to use a variety of energy sources and is what contributes to the prevalence with which it is found in both natural and synthetic environments.

P. aeruginosa readily forms sessile bacterial communities by adhering to surfaces and forming an exopolysaccharide matrix, these are known as biofilms. Compared to planktonic or freeswimming bacteria, more bacteria exist within biofilm colonies. This allows the bacteria 
within these communities to be protected from adverse environmental conditions (such as antimicrobial agents). Cells can shed from the biofilm to become planktonic cells which are able to colonize and form new biofilms in other environments, allowing the bacterial population to expand and benefit further (Costerton et al, 1995). Through the use of flagella and type IV pili, $P$. aeruginosa is able to move in planktonic culture, with these components also being vital for biofilm formation (O'Toole \& Kolter, 1998). 


\section{$\underline{1.2}$ Bacterial biofilms}

Biofilms in their simplest form, exist as an exopolysaccharide (EPS) matrix which encloses the bacteria in an aqueous environment. Common EPS components can include cellulose, alginates, poly-N-acetylglucosamine, various proteins, extracellular RNA or DNA (Jolivet-Gougeon \& Bonnaure-Mallet, 2014).

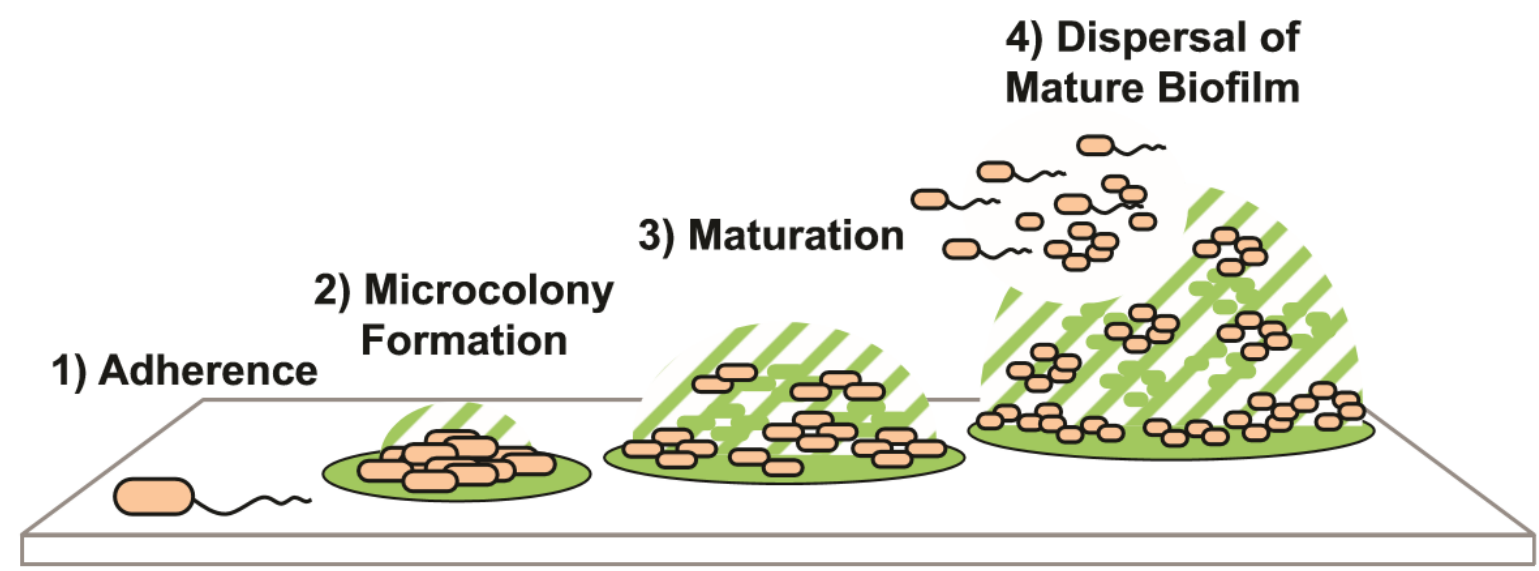

Figure 1: The 4 characteristic stages of biofilm formation in $P$. aeruginosa. Replicated with permission from Taylor et al, 2014.

In the initial stages of biofilm formation, a cell attaches to a substrate and this acts as a 'focus point' for the formation of the biofilm. Adherence stimulates a change in gene expression which is characterised by a down-regulation of polar flagella and an up-regulation of type IV pili.

In the second stage, a microcolony forms through successive rounds of cell divison. Secretion of extracellular matrix components provides a strong foundation for the bacteria to the bacteria and also cements the bacteria in close association with one another, protecting the colony from the external environment.

The third stage is characterised by continuous bacterial growth leading to development of a matured biofilm. Within the biofilm, subsets of cells develop specialized morphologies due to quorum sensing molecule \& nutrient gradients that form between the interior and exterior layers of the biofilm structure.

Dispersal is the final stage, whereby cells are shed from the outer surface of the biofilm due to a combination of quorum-sensing signaling, external stimulus or physical manipulation of the biofilm. These cells become motile and changes in gene expression occur, promoting reexpression of polar flagella. 


\section{$\underline{1.3 \text { Ciprofloxacin }}$}

First-generation quinone antibiotics such as nalidixic acid, had relatively low-potency due to extensive renal excretion but were found to be partially effective against Gram-negative bacteria (Emmerson \& Jones, 2003). Discovery of the fluroquinone antibiotic Norfloxacinin in 1979, led to the development of other fluroquinone antibiotics due to the discovery that including a fluorine atom in the quinone ring moiety, led to vastly increased potency as an antibiotic (Khan et al, 1982). Ciprofloxacin was discovered as a result of a fluroquinolone development program implemented by Bayer (Petersen et al, 1985). The structure of Ciprofloxacin is identical to Norfloxacin except for the presence of one additional carbon atom in Ciprofloxacin. This alteration increased the potency of the fluroquinone 16-fold against $P$. aeruginosa compared to Norfloxacin (Bauernfeind \& Petermüller, 1983) making it a common first-line treatment for $P$. aeruginosa infections.

Ciprofloxacin is a broad-spectrum antibiotic (i.e targets both Gram-positive \& Gram-negative bacteria) and primarily operates as topoisomerase IV/DNA gyrase inhibitor preventing introduction and removal of supercoiling of DNA, required for cellular replication and some transcriptional processes (Drlica \& Zhao, 1997). DNA and DNA gyrase act to form a cleavage complex during replication and it is at this stage that Ciprofloxacin (and other quinolone compounds) act, trapping the gyrase-DNA cleavage complex. This causes ssDNA to form, initiating the SOS response in bacteria (Drlica \& Zhao, 1997). In higher concentrations ciprofloxacin can cause disassociation of the gyrase protein complex, causing double-stranded breaks which are lethal to the bacterium. 


\subsection{SOS Response}

The SOS Response is a survival response which is induced in bacteria when DNA is damaged causing a halting of the cell cycle and initiating DNA repair mechanisms \& mutagenesis. Under normal growth conditions, SOS genes are negatively regulated by the LexA repressor protein.

LexA binds to a consensus sequence called the SOS box in the SOS genes. SOS genes are activated after DNA damage occurs from the accumulation of single-stranded DNA (ssDNA) products at DNA replication forks, causing stalling of DNA polymerase. RecA is stimulated by the presence of ssDNA and forms a nucleoprotein filament upon the ssDNA. Formation of this nucleoprotein filament, activates RecA to interact as a co-protease with LexA, causing autocatalytic cleavage of LexA from the operator region. LexA concentrations decrease, stimulating expression of SOS genes (Maredia et al., 2012).

Different binding affinities for LexA to the SOS box exist and as such, LexA can sequentially activate SOS genes in a specific manner. Low levels of DNA damage will stimulate genes that have weak SOS box affinities, allowing DNA damage to be corrected without induction of an all-out SOS response (Janion, 2001). 


\subsection{Quorum Sensing}

Many species of bacteria communicate intracellularly to determine their relative cellular populations through a system known as quorum sensing. Quorum sensing bacteria both secrete and respond to signalling molecules (known as autoinducers) which are constitutively produced by the bacteria. As the bacterial population expands, the relative concentration of signal molecules increases which then in turn causes changes in gene expression patterns once the minimum stimulatory threshold is met (Miller \& Bassler, 2001).

Quorum sensing systems are highly conserved amongst bacteria and it is likely they play a vital role in the survival of many bacterial species as they allow microbes to 'sense' changes in their environment associated with nutrient scarcity and relative cell density and respond appropriately by initiating transcriptional changes which induce functions such as biofilm formation, secretion of toxins/virulence factors or by altering growth rate (Venturi, 2006).

\section{$\underline{\text { 1.5.1 Quorum sensing in P.aeruginosa }}$}

A large number of genes in $P$. aeruginosa are under direct control through quorum-sensing regulatory elements. Studies have shown that at least 300 genes $(\sim 6 \%$ of the total genome) in $P$. aeruginosa, are influenced by quorum sensing (Schuster et al, 2003; Wagner et al, 2003). These genes play a number of roles when expressed but most notably, the majority were found to be involved in processes mediating secretion of factors such as toxins, alginate \& enzymes or involved in metabolic regulation (Schuster \& Greenberg, 2006), indicating an important role for quorum sensing in $P$. aeruginosa for both virulence \& the notorious adaptability of $P$. aeruginosa which allows it to tolerant a range of harsh conditions. 

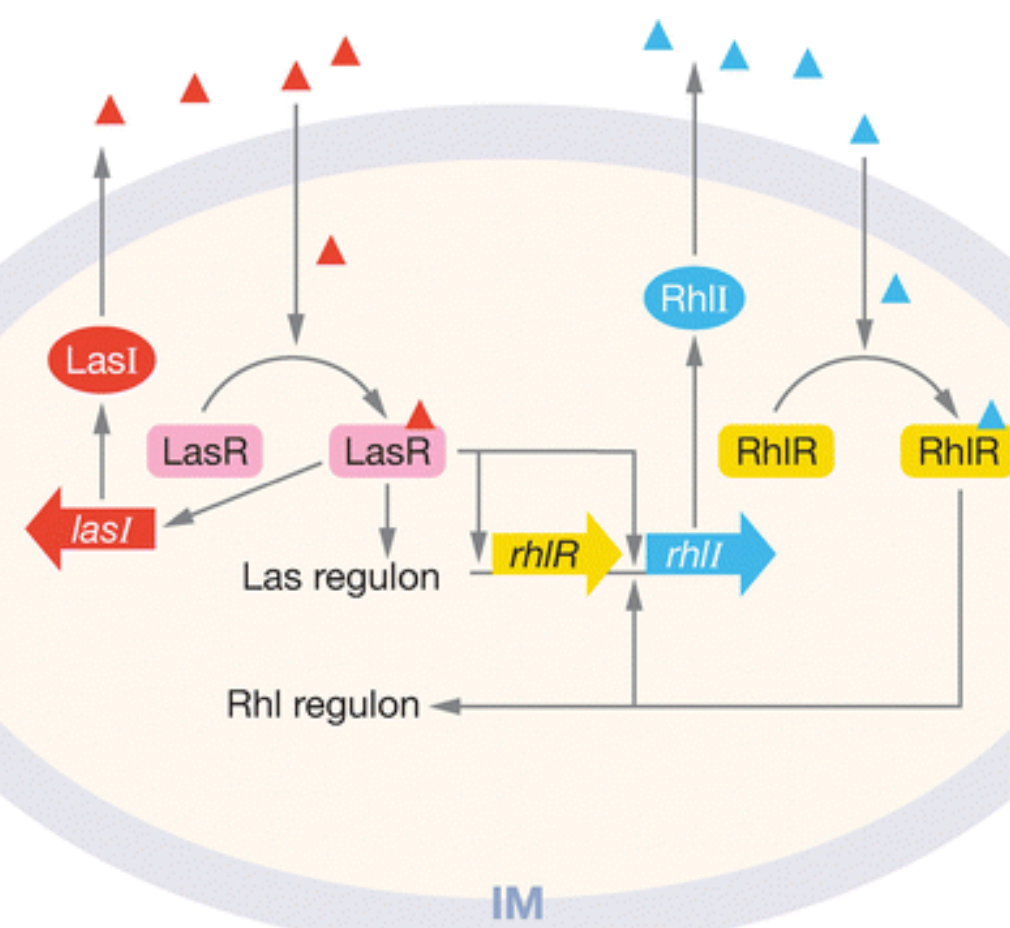

Waters CM, Bassler BL. 2005.

Annu. Rev. Cell Dev. Biol. 21:319-46

Figure 2: An overview of the P. aeruginosa quorum-sensing networks, las and $r h l$. Replicated from Waters \& Bassler, 2005

Quorum-sensing responses in P. aeruginosa are primarily under control by two main regulatory networks, las and $r b l$ (Fig 2). In the las system, activation of the gene lasl, induces production of 3OC12-homoserine lactone (3OC12-HSL) that is secreted (Pearson et al, 1995). When 3OC12HSL enters a $P$. aeruginosa bacterium, it then binds to the LasR element to form a complex. This acts in a positive feedback loop, further activating the las system.

The LasR complex activates expression of genes under control of the Las regulon to co-ordinate a quorum-sensing mediated response (Waters \& Bassler, 2005). In addition to this, the LasR complex also induces expression of the genes $r b / R$ and $r b l l$. These genes are involved in a secondary quorum-sensing network that produce and respond to another autoinducer element, AHL C4-homoserine lactone (C4-HSL). 
RhlL produces C4-HSL which is then secreted. As concentrations of C4-HSL increase, accumulation occurs within the cell and C4-HSL becomes bound to the regulatory element, RhlR and forms a complex that then goes on to activate/induce expression of genes under control of the Rhl regulon (Pearson et al., 1995).

A number of autoinducers in $P$. aeruginosa have been identified but the most well-characterised are 3OC12-HSL, C4-HSL and 2-heptyl-3-hydroxy-4-quinolone (also known as Pseudomonas quinone signal or PQS) (Pesci et al., 1999). 


\section{$\underline{1.6 \text { Pyoverdine }}$}

Iron is required as a co-factor for many biological processes and as such, is a vital element for bacterial growth. In many environments it is the limiting nutrient due to scarcity and poor solubility (Andrews et al, 2006). To overcome the issue of iron scarcity, many bacteria have evolved biosynthesis pathways that produce iron-scavenging compounds known as siderophores. One such siderophore of significance is pyoverdine.

Pyoverdine is an iron-chelating siderophore produced by bacteria of the Pseudomonas genus. The level of pyoverdine produced by pseudomonads is inversely correlated to the extracellular iron concentration (i.e. production of pyoverdine is increased in low-iron environments) (Totter \& Moseley, 1953). This response allows Psendomonads to sequester iron from the surrounding environment which could otherwise be utilized by other organisms.

The pyoverdine biosynthesis pathway has been well-characterised and is made up of a number of key genes/enzymes. Firstly, biosynthesis begins with the synthesis of the pyoverdine backbone in the cytoplasm by a number of non-ribosomal peptide synthetases (NRPS) and other associated enzymes. The enzymes PvdA, PvdF and PvdH modify the amino acids required for the peptide moiety of pyoverdine. PvdL attaches a fatty acid (usually myristic acid or myristoleic acid) to the glutamine of the peptide backbone. The peptide-fatty acid conjugate is then transported to the periplasm where the fatty acid portion is cleaved by the acylase, PvdQ. The chromophore moiety is then formed by condensation of the tyrosine residue and 2,4-diaminobutyrate (DAB) by PvdN, PvdO and PvdP before being secreted by the ATP-dependent efflux pump PvdRT-OpmQ (Schalk \& Guillon, 2013).

Previous studies have shown pyoverdine to be essential for virulence in $P$. aeruginosa as pyoverdine-deficient mutants display growth inhibition when cultured in media containing the iron-transport protein, transferrin (present in human serum) (Meyer et al, 1996). This model reflects the competition for iron-resources encountered in vivo 
between $P$. aeruginosa and the host cells in an infection. Without the ability to sequester iron, growth would be limited. P. aeruginosa strains deficient in pyoverdine production show an increase in time taken to kill the host in a waxworm infection model and also displayed a reduction in the bacterial load present (indicating a reduction in growth) (Harrison et al, 2006). Furthermore, $P$. aeruginosa strains deficient in pyoverdine production produce a low mortality rate in mice compared to pyoverdine-producing strains (Minandri et al., 2016).

Pyoverdine abundance can be obtained by measuring the florescence at an excitation wavelength of $405 \mathrm{~nm}$ and reading the subsequent emission wavelength at $455 \mathrm{~nm}$ (Dao et al, 1999) 


\subsection{Persister Phenotype}

\subsubsection{Stochastic switching of phenotype}

Stochastic switching of bacterial phenotypes is a phenomenon that is common in bacteria that experience fluctuating environmental conditions. By generating genetically identical but phenotypically variable offspring, the bacterium will inevitably produce some offspring that are maladapted to the current environment but will in addition produce offspring that are more adapted to the environment, thus ensuring a higher chance of survival in the future (Rainey et al., 2011). This can be seen when bacteria are exposed to a sufficiently high concentration of antibiotic, most of the population will die but a small fraction will survive. The cells have not acquired antibiotic resistance genes in the short time span that the antibiotic was applied as the new population is still sensitive to the antibiotic if it were to be exposed to it again (Balaban et al, 2004).

Activation of stochastic switching can lead to the development of bacterial cells which exhibit a high level of antibiotic resistance, as well as a lower basal metabolic rate. These viable cells are known as 'persisters' and can serve as a reservoir of cells that can re-populate the environment when the conditions are appropriate. This ability for them to survive high doses of antibiotic treatment and re-grow once conditions become favourable, makes them responsible for chronic recalcitrant infections that are extremely difficult to treat (Fauvart et al, 2011). The stochastic nature of persister development is underpinned by multiple mechanisms, such as the toxinantitoxin system. 


\section{$\underline{\text { 1.7.2 Toxin-antitoxin (TA) systems }}$}

TA loci in bacteria commonly encode two or more components; a toxin that causes growth inhibition and decreases metabolic activity and an anti-toxin that regulates toxin activity through inhibition of the toxin (Gerdes \& Maisonneuve, 2012).

Three main types of TA systems have so far been identified in bacteria. Types I TA systems regulate toxin activity through base-pairing of anti-sense RNA (antitoxin) to mRNA which encodes the toxin thus inhibiting production of the toxin (Brantl, 2012). Type I TA toxins are usually small hydrophobic proteins (Van Melderen \& Saavedra De Bast, 2009) that increase cell membrane permeability.

Type II TA systems are regulated by production of a unstable protein (antitoxin) which binds to the more stable antitoxin protein (F. Hayes, 2003). The antitoxin protein is degraded by host cell enzymes at a greater rate than the toxin protein and thus the antitoxin protein is required to be constitutively produced to inhibit toxin action (F. Hayes, 2003).

Type III TA systems are less understood but are regulated through interaction of an RNA antitoxin and the toxin protein. In this system the RNA directly binds to the toxin preventing action of the toxin (Labrie et al, 2010). 


\section{$\underline{1.8 \text { Bacterial programming and memory }}$}

Many bacteria such as Escherichia coli and P. aeruginosa exhibit hallmarks of bacterial programming or memory. This occurs through epigenetic changes such as methylation or acetylation of specific genes in response to a stressor. This results in a general reduction in transcription or translation, leading to the induction of variable phenotypes under these conditions (Veening et al, 2008) which can be stochastic in nature. There is increasing evidence, that phenotypic changes can be passed on from one generation to a next via transmission of stable intracellular proteins/ metabolites (Gerdes \& Maisonneuve, 2012).

\subsubsection{Bacterial senescence}

Senescence is defined as a reduction in a cell's ability to carry out normal biological processes or in its ability to survive due to the accumulation of effects associated with subsequent divisions (aging). This is easily characterised in eukaryotes by irreversible growth arrest and the inability to re-enter the growth cycle even in the presence of mitogens (Campisi, 1999).

Replicative senescence occurs due to a combination of chromosomal and DNA architecture, ultimately leading to a reduction in telomere length with each subsequent mitotic division. Cell growth is halted once the telomere reaches a critical length, as a means of preventing both the accumulation of mutations from reaching a dangerous point, and to prevent disruption to genes that exist below the telomeres. This pre-determined number of cellular divisions is known as the 'Hayflick limit' and acts as a molecular longevity index to protect cells against developing aberrations in otherwise normal metabolic and physiological processes (Shay \& Wright, 2000).

Cells that escape replicative senescence in mammals display high levels of genetic abnormalities and dysregulation of normal cell cycle processes that can allow cellular growth to remain unchecked and ultimately develop into cancer (Hensler \& Pereira-Smith, 1995). Evolution has selected for senescence by favouring survival of the whole organism over allowing cells to continue growth unchecked and thus it is easy to see why this phenomenon is present in 
eukaryotic cells. What is less understood however, is why some species of bacteria exhibit elements of replicative senescence as survival of the bacteria does not depend on the collective cellular population like in eukaryotes but rather any one bacterium is capable of re-establishing the population.

The Gram-negative bacterium Caulobacter crescentus, found frequently in fresh water environments, starts off as a motile, swarmer bacterium. At this point in its lifecycle it is nonreproductive but eventually differentiates into a sessile cell, which takes on a stalk-like appearance and becomes reproductively active. To reproduce it undergoes asymmetric division which allows the stalk to be retained and produce more free-swimming cells (Tsokos \& Laub, 2012). In experiments conducted by Ackerman et al, groups of $C$. crescentus cells were followed for 300 hours and rated for their age-specific reproductive age by the number of progeny produced per individual. Although some cells produced up to 130 progeny in 300 hours, it was noted that many divided slowly or stopped dividing all together with increasing age (Ackermann et al, 2003).

This study showed that some bacteria were not exempt from experiencing replicative senescence, however it was thought that this was due to asymmetric replication nature of $C$. crescentus and therefore would not apply to bacteria that reproduce by binary fission such as E. coli and P. aeruginosa which are largely thought of to be more or less 'immortal'.

The existence of TA systems as described in section 1.6.3 challenge this notion, as accumulation of the toxin component in a cell will cause growth arrest. If production of the antitoxin is not resumed, the cell is effectively senescent and eventually experience cell death. The chromosome of E.coli encodes the TA loci mazEF. The TA loci is made up of the genes mazE (antitoxin) and $m a z F$ (toxin) and is located downstream from the operon $r e l A$, which is activated as part of the stringent response (Aizenman et al, 1996).

Overproduction of mazF reduces the level of viable bacteria and increases in ppGpp levels cause reduced transcription of mazEF, causing the levels of the less stable MazE antitoxin to fall, 
allowing the MazF toxin to act (Aizenman et al, 1996). When the concentration of amino acids is low, the presence of uncharged tRNAs (i.e. tRNA that lacks amino acid) in E. coli stimulates Rel A activity to synthesize ppGpp (Dalebroux \& Swanson, 2012). This implies that when conditions of starvation are encountered, mą $E F$ acts to cause growth arrest. Aizenman $e t$ al suggested that by a proportion of cells entering growth arrest in nutrient poor conditions, this provides an altruistic function for the bacteria whereby the sacrifice of a few may enable the population to survive.

\subsubsection{Epigenetics in bacteria}

Epigenetic inheritance is the heritable transfer of a phenotype from one generation to another without changes to the genomic DNA sequence. Epigenetic modifications to DNA occur primarily through methylation or acetylation mechanisms and these changes can be stably transferred from one generation to another, altering the phenotype expressed through modulating gene expression (Casadesús \& Low, 2006). In addition to this, epigenetic inheritance can occur during cellular division when components such as proteins, RNA and other factors are partitioned between the two daughter cells. This can alter the fate of the next generation and asymmetric partitioning of these components can occur, producing two genetically identical daughter cells that exhibit different phenotypes (Veening et al., 2008).

One of the first epigenetic systems discovered in bacteria was the lac operon in E. coli. The lac operon encodes proteins that are involved in the uptake and utilization of lactose sugars and is activated in the presence of allolactose. Studies investigating the epigenetic heritability of the lac operon, cultured E. coli in the presence of the allolactose analogue, isopropyl-D-thio- $\beta$ galactopyranoside (IPTG). This induces the production of permease protein which becomes translocated to the cell membrane. Cultures that were treated with high concentrations of IPTG had high levels of permease protein present on the cell membrane, whilst those that received low concentrations had cell membranes in which permease was absent. Re-culturing of these cells 
caused the resulting populations to either have high or low lac expression respective to the conditions upon which it received initially (Veening et al., 2008) and thus displays the characteristics of a heritable epigenetic trait which could be interpreted as a form of bacterial memory.

Although the exact mechanisms which cause bacteria such as E. coli and P. aeruginosa to stochastically exhibit a persister phenotype are unknown, it is possible the fluctuations in gene expression responsible for inducing the persister phenotype is due to an accumulation of factors through subsequent divisions which has been observed in the yeast, Saccharomyces cerevisiae (Kaufmann et al, 2007). 


\subsection{Outer-membrane Vesicles (OMV)}

Outer-membrane Vesicles (OMVs) are small membrane vesicles primarily produced by Gramnegative bacteria that are approximately 50-300 $\mathrm{nm}$ in size. They are composed of outermembrane components (such as LPS, various phospholipids and protein) and may in addition, contain periplasmic components (Klimentová \& Stulík, 2015). There is evidence that some species of Gram-positive bacteria produce microvesicles (MVs) (Rivera et al., 2010) but these are less well-characterised.

They were a bone of contention for biologists for a long time as many argued that they were a biological artefact of bacterial membrane shedding and served no significant biological purpose. In fact, initial discoveries of OMVs in the early 1990's were incorrectly described as 'nanobacteria' due to their similarity in composition to bacteria and small size and were often found alongside much larger 'true' bacteria (Folk, 1993). However, studies have consistently shown that OMVs play an integral role in Gram-negative bacteria survival.

Many functional roles have been described ranging from delivery of virulence factors (Bomberger et al., 2009) \& attenuation of host-immune system responses (Bielig et al, 2011) to intracellular communication (Schertzer \& Whiteley, 2013) \& nutrient sequestering (Kulp \& Kuehn, 2010).

As OMV biology is a new and rapidly advancing field with more functions being described it appears that what was previously thought as being a biological artefact, is in fact an integral part of the biology of the whole organism. 


\subsubsection{OMV biogenesis}

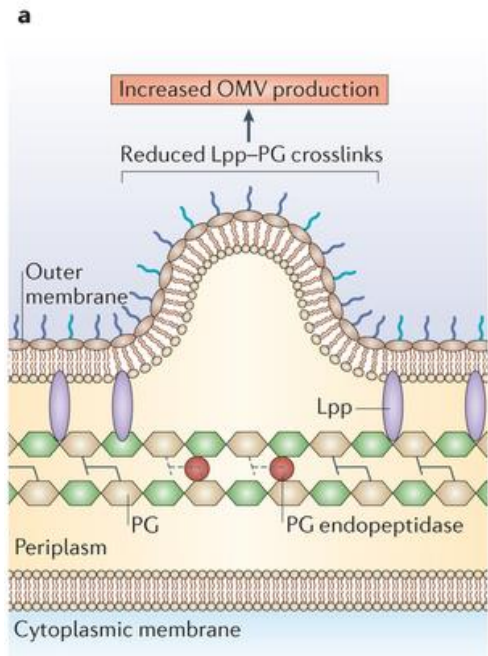

d

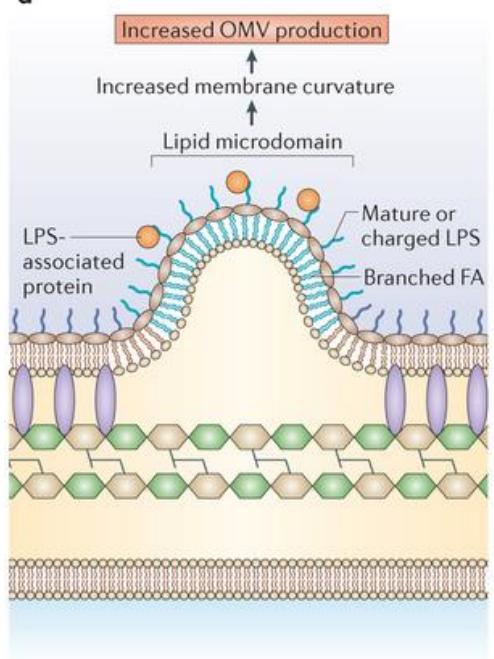

b
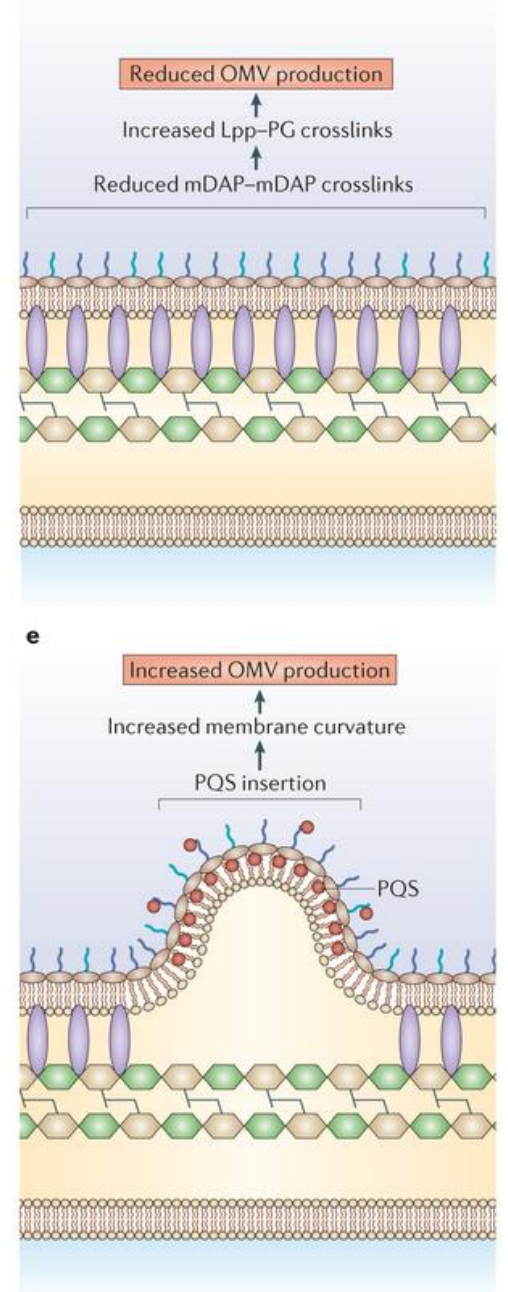

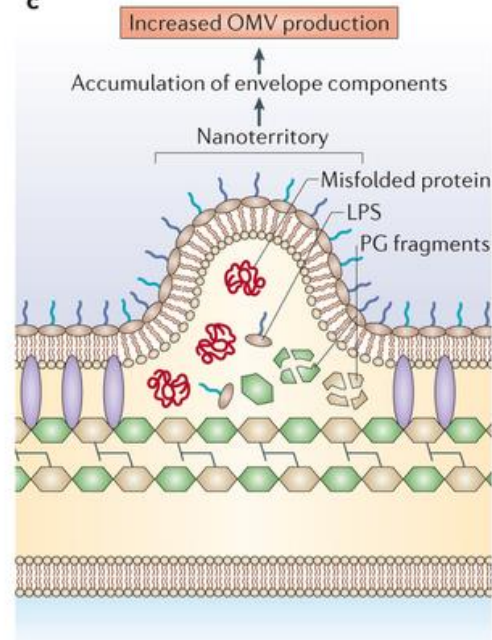

f

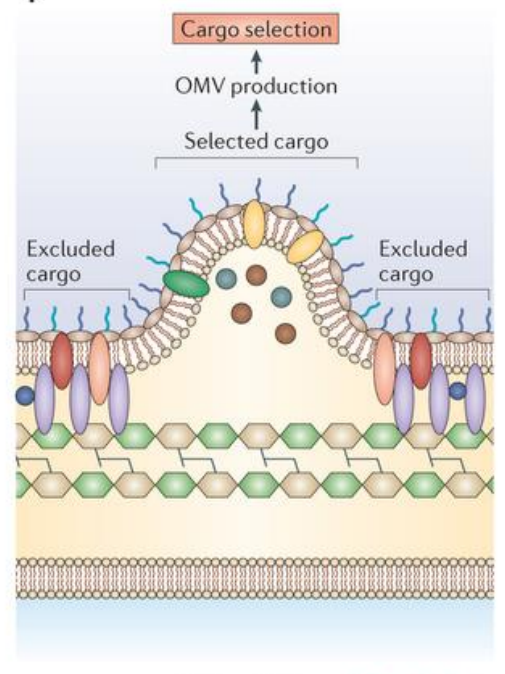

Nature Reviews | Microbiology

Figure 3: Mechanisms of OMV biogenesis and cargo selection replicated with permission from Schwechheimer \& Kuehn, 2015.

a. Peptidoglycan (PG) endopeptidases regulate PG breakdown and therefore the ability to form crosslinks between Braun's lipoprotein (Lpp) and PG. OMV production is increased in regions of the cell that have reduced Lpp-PG crosslinks. b. Inversley, an increase in Lpp-PG crosslinks cause a reduction in OMV formation. This can occur due to a reduced amount of mDAP-mDAP crosslinks in the PG, allowing for more Lpp-PG crosslinks to occur. c. Misfolded proteins or outer-membrane fragments accumulate in a region of cell displacing the crosslinks, causing bulging of the outer-membrane leading to an increase in OMV biogenesis. d. Enrichment of the outer-membrane with specific types of LPS or phospholipid components can cause the outer-membrane to bulge outwards due to a change in the charge of these molecules or increase membrane fluidity, stimulating OMV production. e. Due to the hydrophobic nature of PQS, it becomes inserted in the outer leaflet of the outer-membrane. PQS induces curvature of the outer-membrane, stimulating OMV production. f. Specific envelope components can become enriched in OMVs through interactions with membrane components. 


\subsubsection{Role of OMVs in P. aeruginosa}

To date, the majority of studies on P. aeruginosa OMVs have largely focused on the offensive role OMVs play in bacteria-host pathogenicity, bacterial competition and the proteomic/lipidomic analysis of the OMVs.

P. aeruginosa can produce OMVs in response to a stimulus from a mammalian host (e.g. the prescence of mucosal fluid or lysozyme) and these act to prime bacterial adhesion to the host cells (Metruccio et al, 2016) thus promoting biofilm formation. In addition to this, P. aeruginosa OMVs are capable of modulating the host immune response to promote the production of proinflammatory cytokines (Zhao et al, 2013) causing increased capillary leakiness in the host, allowing $P$. aeruginosa to acquire nutrients from the plasma and potentially invade deeper into the tissues. Induction of the SOS response in P. aeruginosa by ciprofloxacin treatment, has been shown to greatly increase OMV production through stimulation of LexA (Maredia et al., 2012). This suggests a possible advantage to $P$. aeruginosa in producing OMVs under antibiotic treatment, although this has not been studied.

Upon membrane fusion with host cells, $P$. aeruginosa OMVs deliver multiple virulence factors such as CFTR inhibitory factor (Cif), $\beta$-lactamase, alkaline phosphatase $\&$ haemolytic phospholipase C, inducing impaired cell function and cell death (Bomberger et al., 2009). The unique protein and lipid composition induces a cytokine profile that cannot be replicated using whole cells or purified antigen as the OMV components act in synergy to produce a unique immune response (Ellis et al, 2010) and as such, reflect the complex role they play in modulating the host immune system.

Multiple studies support a potential role of P. aeruginosa OMVs in mediating cell-aggregation and subsequent biofilm formation (Schooling \& Beveridge, 2006; Schooling et al, 2009) and OMVs are abundantly present within the extracellular matrix of 
biofilms (Toyofuku et al, 2012). Thus, it is apparent that OMVs are involved in co-ordinating biofilm formation in P. aeruginosa.

In competing bacterial species $P$. aeruginosa OMVs have been shown to induce cell wall lysis (Kadurugamuwa \& Beveridge, 1996), disrupt biofilm formation, and swarming behaviour (Fernández-Piñar et al, 2011) of other bacteria.

P. aeruginosa OMVs are also capable of killing other Gram-negative bacteria as well as Grampositive bacteria (Kadurugamuwa \& Beveridge, 1996).

As $P$. aeruginosa OMVs are largely composed of B-band lipopolysaccharide (LPS) which is normally present in minor quantities in the outer-membrane (Kadurugamuwa \& Beveridge, 1996; Li et al, 1998), this indicates that OMV biogenesis is not the result of random membrane fragmentation. Furthermore, proteomic analysis shows enrichment of specific proteins within OMVs that changes depending on whether OMVs were generated in a planktonic culture or a biofilm (Park et al., 2015) thus implying a putative role within the environment under which it was generated in. 


\section{$\underline{1.10 \text { Research Aims }}$}

The aim of this study will be to elucidate what role outer-membrane vesicles play in intercellular communication in the opportunistic pathogen P. aeruginosa and whether OMV production could confer a survival advantage in the presence of a stressor.

Firstly, comparison of the properties of natively-produced OMVs and stress-induced OMVs was conducted to determine whether OMVs produced under ciprofloxacin treatment are significantly different to natively-produced OMVs. This was investigated using polyacrylamide gel electrophoresis (PAGE) gels, allowing for comparison of protein bands between different OMV subtypes. Dynamic Light Scattering (DLS) will be used to validate whether isolations are successful as well as to evaluate whether OMV subtypes differ in size. Transmission Electron Microscopy (TEM) was utilized to observe any obvious physical difference between OMV subtypes. Protein quantification through bicinchonic acid (BCA) assay was used to determine relative OMV production/yield under various conditions.

Secondly, this study investigates the potential of OMVs functioning as an intercellular communication mechanism for en mass programming of bacterial populations. This was explored using growth assays measuring the optical density at $600 \mathrm{~nm}$ as a measure of cell density. Changes in both the growth kinetics and in endpoint final optical density were observed for perturbations differing from that of normal growth. Pyoverdine production over the course of growth was monitored by excitation of the culture at $405 \mathrm{~nm}$ and recording the resulting emission at $455 \mathrm{~nm}$.

Using the standard bacterial methodology of counting colony forming units (CFU) on agar plates to determine the number of viable bacteria, was used to determine whether OMVs can program P. aeruginosa cells to become persisters. This was achieved through implementation of a high-dose ciprofloxacin challenge following incubation with OMVs before cultures are plated 
out. Flow analysis using propidium iodide (PI) was also be performed to determine whether OMVs cause a decrease in the proton-motive force (pmf) or induce cell death.

Finally, investigation of a possible signalling mechanism wias explored through attempts to inactivate the OMVs. Any effect OMVs have on P. aeruginosa cultures will be abalated through various attempts at inactivating the active signalling constituent through heat-inactivation or chloroform-mediated OMV disruption. By systematically evaluating which methods cause the OMV-mediated effect to be lost, will shed light on potential cellular mechanisms through which OMVs transduce their signalling properties.

We hypothesized that OMVs produced in the presence of a sub-lethal stressor (i.e. ciprofloxacin) are distinctly different than OMVs produced as part of the normal growth phase in $P$. aeruginosa. These stress-induced OMVs will vastly differ in both their lipid and protein composition, reflecting a possible biological function in defence of such a stressor.

Due to the strong link between SOS response induction and a corresponding increase in OMV production seen in previous studies, we hypothesize that OMVs act as an intercellular communicator mechanism capable of programming $P$. aeruginosa populations, altering either growth kinetics or metabolism of the population to cause $P$. aeruginosa to become antibiotictolerant. 


\section{Materials and Methods}

\subsection{Bacterial Strains and growth}

Pseudomonas aeruginosa strain PAO1 (ATCC 15692) and Salmonella enterica strain CDC 6516-60

(ATCC 14028) were obtained from Washington State University (Pullman, Washington, USA).

Bacteria were cultured in standard $\mathrm{LB}$ medium at $37^{\circ} \mathrm{C}$ for $18 \mathrm{~h}$ with aeration in large conical flasks. Overnight cultures were diluted 1:100 in fresh LB and grown for 4 hours to allow them to reach exponential phase prior to use.

\subsection{OMV Isolation}

An overnight culture of $P$. aeruginosa was diluted to an $\mathrm{OD}_{600}$ of 0.01 in $\mathrm{LB}$ and grown with aeration at $37^{\circ} \mathrm{C}$ for $24 \mathrm{hrs}$. A cell-free supernatant was obtained by centrifugation at $10,000 \mathrm{xg}$ for 30 mins followed by filtration through a $0.45 \mu \mathrm{m}$ HDVP filter (Millipore, Merck). OMVs were harvested from this solution by centrifugation at $100,000 \mathrm{xg}$ at $4^{\circ} \mathrm{C}$ for $1 \mathrm{hr}(\mathrm{L} 100 \mathrm{XP}$, Beckman Coulter). The resulting pellet of OMVs was washed with phosphate-buffered saline (PBS) and resuspended before being centrifuged again at 100,000 $\mathrm{g}$ at $4^{\circ} \mathrm{C}$ for $1 \mathrm{hr}$. The washed OMV pellet was then resuspended in PBS at a ratio of $1 \mathrm{~mL}$ of PBS per $200 \mathrm{~mL}$ of original culture volume. The OMV suspension was then filtered through a $0.45 \mu \mathrm{m}$ syringe filter to ensure sterility prior to storage at $4^{\circ} \mathrm{C}$. For OMVs isolated from ciprofloxacin-treated cultures, cultures were inoculated as described above but after 4 hrs of growth, ciprofloxacin was added to a final concentration of $0.3 \mu \mathrm{g} / \mathrm{mL}$ and the culture allowed to grow for a further $20 \mathrm{hrs}$ at $37^{\circ} \mathrm{C}$ before harvesting as described above. 


\subsection{Dynamic Light Scattering (DLS) analysis}

Size distribution of OMVs was determined using a Malvern Zetasizer Nano-ZS. OMV isolates were diluted 1 in 10 in sterile $0.22 \mu \mathrm{m}$ filtered PBS solution. $500 \mu \mathrm{L}$ total volume was analysed in semi-micro curvette with a path length of $10 \mathrm{~mm}$. Measurements were taken at $3.0 \mathrm{~mm}$. DLS data was collected by fifteen $5 \mathrm{~s}$ acquisitions at $25^{\circ} \mathrm{C}$. Three reads per sample were taken and averaged. Data was displayed using the Malvern Zetasizer software.

\subsection{Protein Quantification of OMVs}

A $100 \mu \mathrm{L}$ sample of OMV suspension was mixed with $1 \mathrm{~mL}$ of methanol and vortexed, before $250 \mu \mathrm{L}$ of chloroform was added and the solution was vortexed further. $750 \mu \mathrm{L}$ of $\mathrm{ddH}_{2} \mathrm{O}$ was then added and the solution vortexed to cause the protein to precipitate out and form crystals. The protein suspension was then centrifuged at 16,000 $\mathrm{x}$ for $1 \mathrm{~min}$, causing the protein precipitate to condense into a flake at the interphase. The aqueous phase was discarded before 1 $\mathrm{mL}$ of methanol was added. The mixture was then vortexed and spun for a further $20 \mathrm{~min}$ at $16,000 \mathrm{x} g$ to pellet the protein. The supernatant was then removed and the pellet was allowed to air-dry before being resuspended in $100 \mu \mathrm{L}$ of Tris-EDTA (TE) buffer with $0.1 \%$ sodium dodecyl sulfate (SDS). Protein samples were then quantified using the bicinchoninic acid (BCA) assay (Pierce BCA Protein Assay kit, Thermo Scientific) following the manufacturer's instructions. Bovine Serum Albumin (BSA) was used as protein standard. 


\section{$\underline{\text { 2.5 PAGE analysis of OMV proteins }}$}

OMV samples were diluted in MilliQ water and $5 \mathrm{x}$ reducing buffer containing $10 \% \beta$ mercaptoethanol to a total volume of $70 \mu \mathrm{L}$. The final protein concentration of each sample was $160 \mathrm{ng} / \mu \mathrm{L}$. Samples were then boiled for $5 \mathrm{~min}$ at $95^{\circ} \mathrm{C}$ before being cooled on ice. A $25 \mu \mathrm{L}$ sample was then loaded into a lane of a $1.5 \mathrm{~mm}$ thick $10 \%$ polyacrylamide separating gel (BioRad) with a 6\% polyacrylamide stacking gel. A protein marker ladder (Dual colour Precision Plus, Bio-Rad laboratories) ( $2 \mu \mathrm{L}$ ) wa s also loaded for size comparison of proteins. The gel was run for $1 \mathrm{hr} 20 \mathrm{~min}$ at $120 \mathrm{~V}$ in Tris Glycine SDS-PAGE buffer.

Upon completion of electrophoresis, gels were removed and stained with a $1 \%$ brilliant blue coomassie solution for $1 \mathrm{hr}$. The gel was then allowed to de-stain for $48 \mathrm{hrs}$ in de-staining solution before being scanned in a Fujifilm scanner.

\subsection{IC 50 measurement of ciprofloxacin toxicity in PAO1}

To determine the concentration of ciprofloxacin required to inhibit $50 \%$ of $P$. aeruginosa growth $\left(\mathrm{IC}_{50}\right)$, a $18 \mathrm{hr}$ end-time point $\mathrm{OD}_{600}$ assay was used. This assay determines the amount of bacterial growth (relative to a control). $100 \mu \mathrm{L}$ of LB was added to each well except starting wells \& blank wells (blanks contained $200 \mu \mathrm{L}$ LB). Ciprofloxacin was then added at twice the starting concentration (i.e. $10 \mu \mathrm{g} / \mathrm{mL}$ ) in the starting wells before performing a 2 -fold serial dilution across the plate. An overnight culture of $P$. aeruginosa was diluted to an $\mathrm{OD}_{600}$ of 0.01 in LB. 100 $\mu \mathrm{L}$ of this was added to each well. The plate was then incubated at $37^{\circ} \mathrm{C}$ for $18 \mathrm{hrs}$ before the $\mathrm{OD}_{600}$ absorbance was read. Cell growth was quantified as a percentage of the control wells using the equation: $[\%$ of control $=($ Sample absorbance - Blank absorbance $) /($ Average control absorbance - Blank absorbance) X 100].

SigmaPlot 10.0 (Systat Software Inc.), was used to construct a four-parameter logistic curve to 
obtain the IC50. The IC50 was calculated from the concentration-response curve using the equation:

$$
y_{i j}=p \max _{j}+\frac{\max _{j}(1-p)}{1+\exp \left\{\beta\left(\log \left(x_{j}\right)-\log \left(\mathrm{IC}_{50}\right)\right)\right\}}
$$

In which $\beta$ is the slope of the concentration-response curve, $y_{\mathrm{ij}}$ corresponds to the response in well $i$ to drug concentration $x_{j}, \max _{i}$ is the maximal response in well $i$ and $p$ is the ratio of maximum to minimum responses, which is assumed to be constant for each drug concentration over all wells (Field, 2009). 


\subsection{6-well plate growth \& pyoverdine assay}

Growth assays were performed using a plater reader to track $P$. aeruginosa growth by $\mathrm{OD}_{600}$ measurement in a 96-well plate. A starting inoculum of an $\mathrm{OD}_{600} 0.005$ of exponentially growing PAO1 was plated into each well. Control wells received no OMV treatment and blank wells contained only LB. The plate was then read continuously for 15-18 hrs on an automated multiwell plate reader at $600 \mathrm{~nm}$ (for growth), with the chamber being temperature controlled at $37^{\circ} \mathrm{C} . \mathrm{OD}_{600}$ values from each time point were compared and tested for significance using student's t-test.

To assess relative pyoverdine production during growth, wells were excited at $405 \mathrm{~nm}$ and the corresponding emission wavelength, $455 \mathrm{~nm}$ was recorded. All wells were background corrected from the blank wells. SigmaPlot 10.0 (Systat Software Inc.), was used to graph all growth and pyoverdine data.

\section{$\underline{2.8 \text { Modified Optical absorption spectral analysis }}$}

OMV sample was diluted 5-fold in PBS before undergoing white-light illumination to obtain an absorbance spectrum ranging from $400-700 \mathrm{~nm}$ through use of an integrating sphere to obtain an absorption spectrum as described by Darby et al 2016. Data was graphed using a python script. 


\subsection{Persister abundance CFU and colony morphology assay}

An Overnight culture of P. aeruginosa were diluted to an $\mathrm{OD}_{600}$ of 0.01 in LB. $1 \mathrm{~mL}$ of this solution was added to sterile borosilicate test-tubes. OMVs were added at a concentration of 125 $\mu \mathrm{g} / \mathrm{mL}$ for those receiving OMV treatment. Control groups received an equivalent volume of PBS as the OMVs, to account for any nutrient scarcity due to dilution of LB. A $10 \mu \mathrm{L}$ sample was retained from each well for comparison of CFU prior to antibiotic challenge and plated as described below. The tubes were incubated for $4 \mathrm{hrs}$ at $37^{\circ} \mathrm{C}$ before ciprofloxacin was added at a final concentration of $5 \mu \mathrm{g} / \mathrm{mL}$ ( $5 \mathrm{x}$ MIC). The plate was then incubated for a further hour at $37^{\circ} \mathrm{C}$. A $100 \mu \mathrm{L}$ sample was taken from each well and aliquoted into a fresh eppendorf. Samples were spun at 10,000 x $\mathrm{g}$ for 10 mins before the supernatant was discarded. Samples were resuspended in sterile PBS solution before being spun down again at 10,000 x g for 10 mins. PBS washes were repeated once more before samples were initially diluted ten-fold before being serially diluted two-fold with $10 \mu \mathrm{L}$ of each dilution plated onto a lysogeny broth (LB) Agar plate. $\mathrm{LB}$ plates were then incubated for $12 \mathrm{hrs}$ at $37^{\circ} \mathrm{C}$ before being colonies were counted and recorded. Photos were also taken at this point for data analysis purposes. 


\section{$\underline{2.10 \text { PI staining of cells by flow-analysis }}$}

An Overnight culture of $P$. aeruginosa were diluted to an $\mathrm{OD}_{600}$ of 0.01 in $\mathrm{LB}$ and allowed to incubate at $37^{\circ} \mathrm{C}$ with sufficient aeration. At each time-point, an aliquot of the culture was taken and diluted in $\mathrm{LB}$ to an $\mathrm{OD}_{600}$ of 0.01 in a volume of $1 \mathrm{~mL}$ before OMVs were added. Cultures were then incubated at $37^{\circ} \mathrm{C}$ with $200 \mathrm{rpm}$ constant shaking. Samples were prepared by a 1 in 100 dilution in sterile PBS of each culture in a $15 \mathrm{~mL}$ falcon flow tube of each culture, before addition of propidium iodide (PI) to a final concentration of $1 \mu \mathrm{g} / \mathrm{mL}$. Samples were incubated for 5 min at RT before being flow analysed by FACS (BD FACSCanto II, BD Biosciences). Operation of BD FACSCanto II was kindly performed by fellow colleague, Jennifer Soundy.

\subsection{Transmission Electron Microscopy (TEM) images}

Copper TEM grids were cleaned by use of glow-discharge for 5 mins before $5 \mu \mathrm{L}$ of isolated OMVs were spotted onto the TEM grid. 1\% Uranyl acetate was added for negative-staining and was incubated for 5 min at RT before having the excess solution removed by blotting with a kimwipe. Samples were then allowed to air-dry for 5 min at RT before being carbon-coated. Digital images were taken on TEM (JEM-2100F, Jeol). All samples were kindly imaged by VUW Postdoctoral fellow, Renee Goreham. 


\section{$\underline{\text { 3. Results }}$}

\section{$\underline{3.1 \quad \mathrm{IC}_{50}} \underline{\text { Results }}$}

To stimulate OMV production in PAO1 using ciprofloxacin, a sub-lethal dose would need to be used. To determine the concentration of ciprofloxacin that would be sub-lethal to PAO1, an $\mathrm{IC}_{50}$ was conducted using a 2-fold serial dilution of ciprofloxacin in duplicate. $\mathrm{OD}_{600}$ was measured after $18 \mathrm{hrs}$ and graphed as a percentage of control cells.

Determination of $\mathrm{IC}_{50}$ of ciprofloxacin for $P$. aeruginosa strain PAO1 (18 hr)

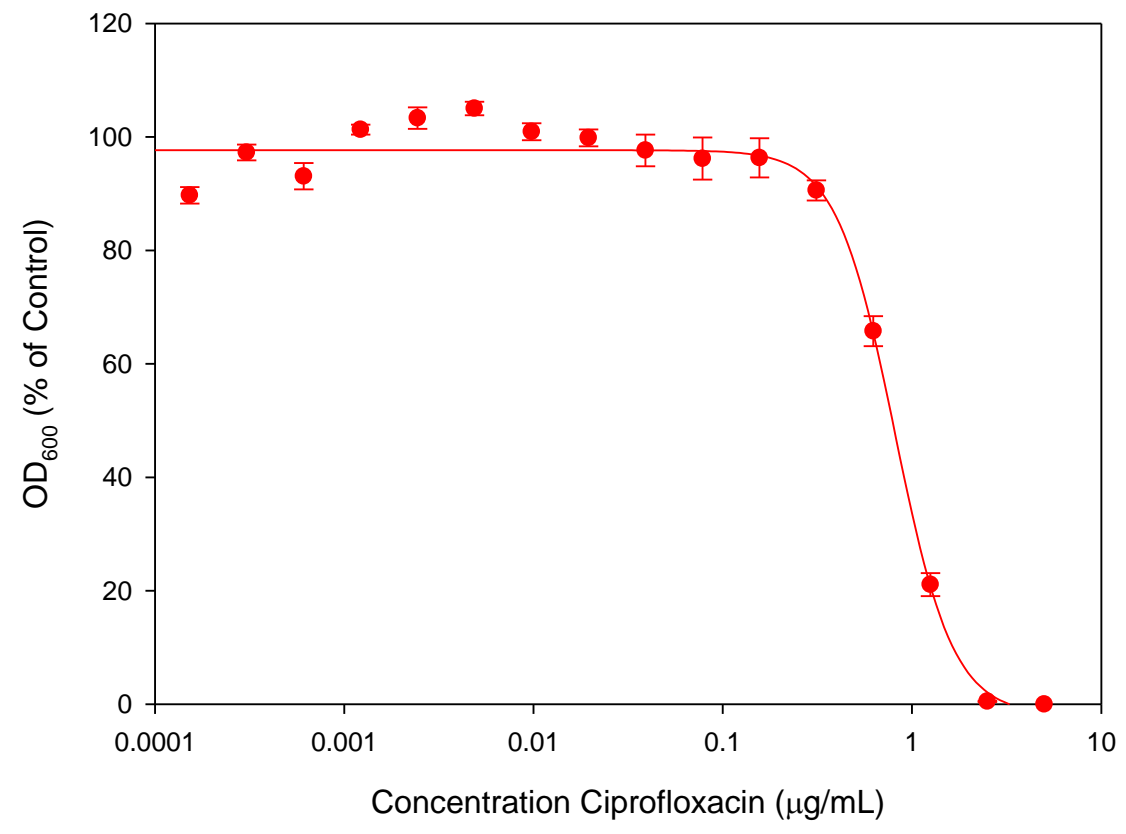

$$
\begin{array}{ll}
\text { PAO1 } \\
-\mathrm{IC}_{50}: 0.81 \mu \mathrm{g} / \mathrm{mL}
\end{array}
$$

\section{Figure 4: PAO1 response to ciprofloxacin treatment after $18 \mathrm{hrs}$}

Ciprofloxacin was serially diluted 2-fold in a 96-well plate before addition of PAO1 cells, and allowed to incubate at $37^{\circ} \mathrm{C}$ for $18 \mathrm{hrs}$ before the absorbance at $600 \mathrm{~nm}$ was measured. The $\mathrm{OD}_{600}$ was then expressed as a percentage of the $\mathrm{OD}_{600}$ control cells and from this the $\mathrm{IC}_{50}$ was then modelled using a four-parameter logistic curve which determined the $\mathrm{IC}_{50}$ of ciprofloxacin in PAO1 to be $0.81 \mu \mathrm{g} / \mathrm{mL}$. As $0.31 \mu \mathrm{g} / \mathrm{mL}$ of ciprofloxacin caused little effect on growth inhibition, a concentration of $0.3 \mu \mathrm{g} / \mathrm{mL}$ of ciprofloxacin was chosen for use as a sub-lethal stressor to stimulate OMV production. Result shown is from a single experiment conducted in triplicate with error bars representing SD. 
PAO1 susceptibility to ciprofloxacin treatment was measured by determination of the $\mathrm{IC}_{50}$ value after incubation with ciprofloxacin for $18 \mathrm{hrs}$ (Fig 4). PAO1 response to ciprofloxacin was found to have a $\mathrm{IC}_{50}$ value of $0.81 \mu \mathrm{g} / \mathrm{mL}$. From this response curve we can see complete growth inhibition occurs around $2.5 \mu \mathrm{g} / \mathrm{mL}$ whilst $0.31 \mu \mathrm{g} / \mathrm{mL}$ of ciprofloxacin has little effect on cell growth after $18 \mathrm{hrs}$ as the growth of cultures at this concentration of ciprofloxacin achieved a final $\mathrm{OD}_{600}$ comparable to untreated (control) cells. As such, future experiments aiming to stress PAO1 with a sub-lethal dose of ciprofloxacin for stimulating OMV production in treatedcultures, used a ciprofloxacin concentration of $0.3 \mu \mathrm{g} / \mathrm{mL}$ in the growth media. 


\section{$\underline{3.2}$ OMV Characteristics}

OMVs have been shown to both change significantly in both size, composition \& yield when produced under differing conditions (Kulp \& Kuehn, 2010). Upon harvesting cultures for OMVs after a $24 \mathrm{hr}$ incubation period, the $\mathrm{OD}_{600}$ was recorded to assess whether the sub-lethal ciprofloxacin treatment caused growth inhibition. The amount of protein present in each OMV isolate was also recorded to give a yield (Table 1). In addition, any distinct characteristics of the OMVs observed during the isolation process were noted.

\begin{tabular}{|c|c|c|c|c|}
\hline $\begin{array}{c}\text { OMV Isolate } \\
\text { type }\end{array}$ & \multicolumn{2}{|c|}{$\begin{array}{c}\text { Protein Yield } \\
\text { ( } \mu \text { g per mL of Culture) }\end{array}$} & Lipid Properties \\
\hline OMV $_{\mathrm{n}}$ & 0.55 & 0.56 & 0.35 & $\begin{array}{c}\text { Pale yellow in colour. Low adherence to plastic. } \\
\text { Extreme difficulty in obtaining an even suspension in } \\
\text { PBS. High retention on membrane filter }\end{array}$ \\
\hline OMV & 6.81 & 8.20 & 14.7 & $\begin{array}{c}\text { Dark orange/brown in colour. Highly adherent } \\
\text { to plastic. Comes off in sheets when removed } \\
\text { from centrifuge tube. }\end{array}$ \\
\hline
\end{tabular}

\section{Table 1: Properties of OMV subtypes isolated from 3 independent isolations}

Protein yields from $O M V$ native $\left(\mathrm{OMV}_{\mathrm{n}}\right) \& \mathrm{OMV}$ ciprofloxacin $\left(\mathrm{OMV}_{\text {cip }}\right)$ were $0.49 \pm 0.07 \&$ $9.90 \pm 2.43 \mu \mathrm{g}$ per $\mathrm{mL}$ of original culture respectively ( $\mathrm{n}=3$, mean $\pm \mathrm{SEM}$ ). OMV yields based on protein show a 20 -fold increase in yield when PAO1 cultures are stimulated with $0.3 \mu \mathrm{g} / \mathrm{mL}$ ciprofloxacin.

Whilst treatment with a sub-lethal ciprofloxacin concentration $(0.3 \mu \mathrm{g} / \mathrm{mL})$ in PAO1 did not significantly affect the cell culture density when cultures were harvested for OMVs after 24 hrs (OD 600 values at 24 hrs were not significantly different, data not shown), it did alter the appearance of the resulting OMVs compared to that obtained from untreated cultures. The $\mathrm{OD}_{600}$ difference between the cultures at the time of harvest was $0.05 \pm 0.02(\mathrm{n}=3$, mean \pm SEM). Table 1 shows that protein yields from each OMV subtype isolation differed significantly with $\mathrm{OMV}_{\text {cip }}$ having an average increase in yield of $9.42 \pm 2.50 \mu \mathrm{g}$ of protein per $\mathrm{mL}$ of original culture volume $(n=3, \pm S E M)$. This represents roughly a 20 -fold increase in the amount of protein present in the $\mathrm{OMV}_{\text {cip }}$ isolation which assumes a corresponding increase in the amount of OMVs present. 


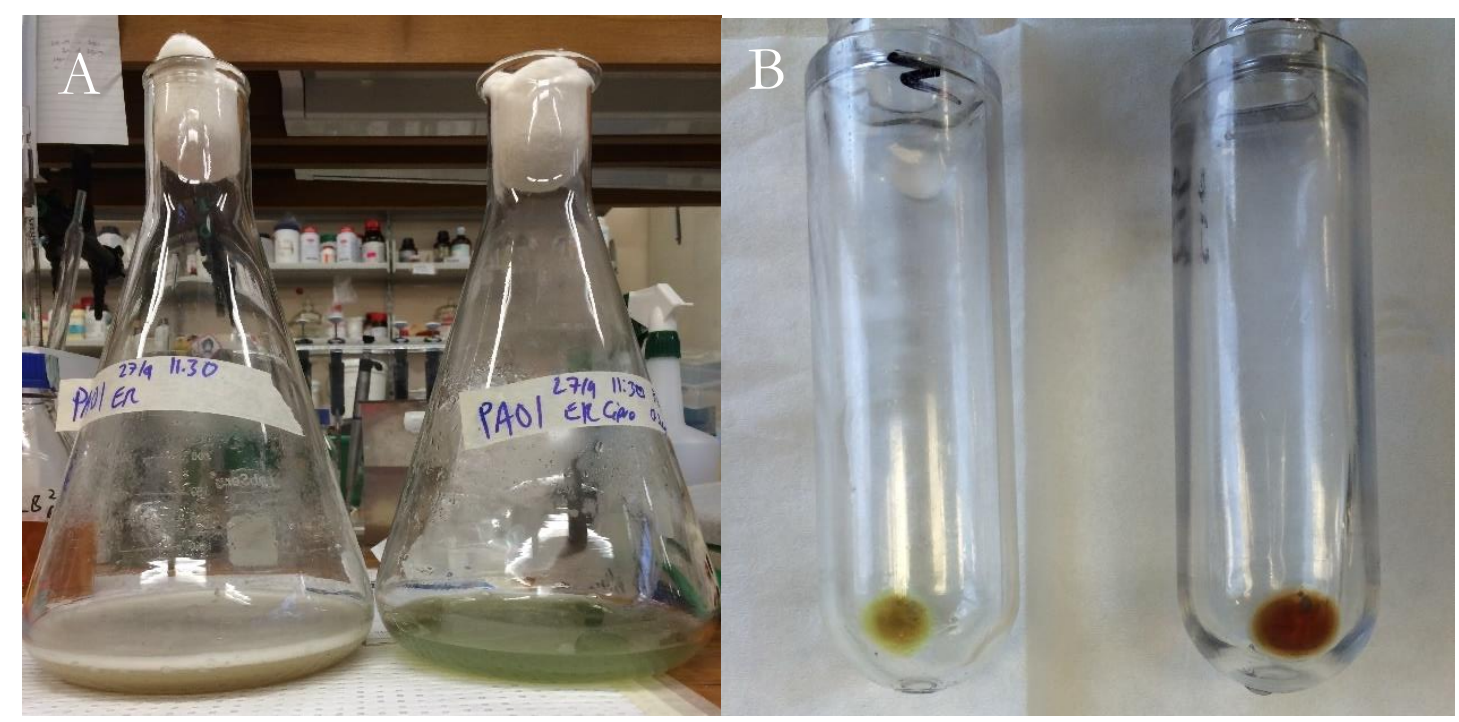

Figure 5: A visual comparison of ciprofloxacin treated PAO1 cultures and the resulting isolate OMVs, compared with a non-ciprofloxacin treated culture

A: Left-hand culture after $24 \mathrm{hrs}$ that was used to generate $O M V_{\mathrm{n}}$. The culture on the right has been treated with $0.3 \mu \mathrm{g} / \mathrm{mL}$ of ciprofloxacin which was used to generate $\mathrm{OMV}_{\text {cip. }}$ $\mathrm{B}$ : OMV isolates were processed as described in methods. Tube on the left is a typical $\mathrm{OMV}_{\mathrm{n}}$ isolate. Tube on the right is a typical $O M V_{\text {cip }}$ isolate.

Figure 5A shows two PAO1 cultures that are either untreated (left) or ciprofloxacin-treated (right), prior to harvesting for OMV isolation. The ciprofloxacin-treated culture has a distinct blue/green colour due to an increase in pyocyanin/pyoverdine production compared to the untreated control. Figure 5B shows two OMV isolations that were derived from untreated (left) or ciprofloxacin-treated (right) cultures. The OMVs isolated from ciprofloxacin-treated cultures have a distinct brown appearance and were difficult to remove from the sides of the tube but easily formed a uniform suspension in PBS. OMVs from untreated cultures were pale yellow in appearance and although were easily removed from the tube, formed aggregates in PBS and had high retention in the $0.45 \mu \mathrm{m}$ syringe filters used in the final sterilization step (See Appendix). 


\section{$\underline{3.3 \text { DLS size comparison of OMV }} \underline{\underline{n}} \underline{\text { \& } O M V} \underline{\underline{c i p}}$}

Dynamic Light Scattering (DLS) is a method which measures the intensity with which small particles in solution cause light scattering over time (Goldburg, 1999). It is possible to accurately measure particle size in solution through the correlation between intensity at which the light is scattered and particle movement (Brownian motion) by taking measurements over a time course. DLS has previously been used to determine the size of vesicles and in particular, OMVs (Hallett, Watton, \& Krygsman, 1991; Lee et al., 2009; Park et al., 2010). DLS size analysis of OMV isolates diluted 1 in 10 in PBS was conducted to analyse the size of OMVs produced with or without sub-lethal ciprofloxacin treatment.

DLS analysis of the OMV isolates was used to determine the effect of sub-lethal ciprofloxacin treatment in PAO1 on OMV size compare to natively produced OMVs. OMV $\mathrm{Cip}_{\text {cip }} \mathrm{OMV}_{\mathrm{n}}$ were characterised by DLS as previous studies had described particles in the size range from 20-300 $\mathrm{nm}$ in size (Nguyen, Saxena, \& Beveridge, 2003; Schooling \& Beveridge, 2006) with the distribution changing with growth conditions, such as antibiotic stress (Fulsundar et al., 2014; Nguyen et al., 2003). 

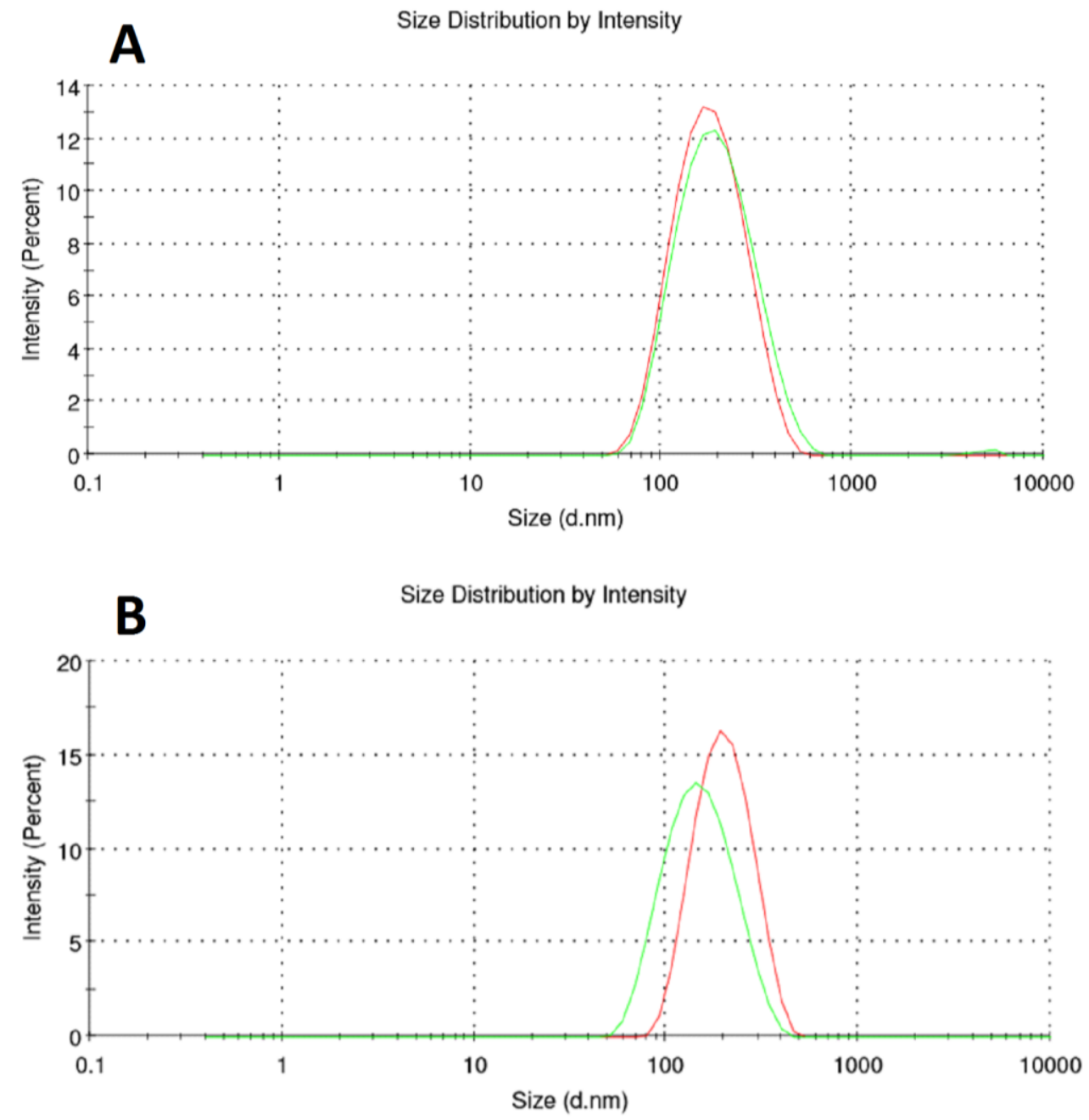

Figure 6: Dynamic Light scattering analysis of OMV isolates derived from PAO1 culture supernatants obtained from filtration using either $0.22 \mu \mathrm{m}$ or $0.45 \mu \mathrm{m}$ membrane filters.

Green $=\mathrm{OMV}_{\mathrm{n}}, \mathrm{Red}=\mathrm{OMV}_{\mathrm{cip}}$

A are OMVs that have been isolated as described in methods, utilising $0.22 \mu \mathrm{m}$ filter membranes.

$\mathrm{B}$ are OMVs that have been isolated as described in methods, utilising $0.45 \mu \mathrm{m}$ filter membranes.

OMVs processed through $0.22 \mu \mathrm{m}$ filters do not show any significant difference in size.

OMVs processed through $0.45 \mu \mathrm{m}$ filters show a significant difference in size with $\mathrm{OMV}_{\mathrm{n}}$ having an average diameter of $134.9 \mathrm{~nm}$ and a peak diameter of $157.6 \mathrm{~nm}$. Compared to $O M V_{\text {cip }}$ which had an average diameter of $183.6 \mathrm{~nm}$ with a peak diameter of $206.1 \mathrm{~nm}$. This shows a $36 \%$ increase in size with sub-lethal ciprofloxacin treatment. 
Panel A (Fig 6) shows that both $\mathrm{OMV}_{\mathrm{n}} \& \mathrm{OMV}_{\text {cip }}$ show no significant difference in size when $0.22 \mu \mathrm{m}$ filters are utilised for the isolation. Both OMV subtypes had average diameters of $\sim 175$ $\mathrm{nm} \&$ a peak diameter of $\sim 200 \mathrm{~nm}$.

In panel B (Fig 6), use of $0.45 \mu \mathrm{m}$ filters in the isolation protocol yielded OMVs with differing sizes. $O M V_{\text {cip }}$ isolates had an average diameter of $183.9 \mathrm{~nm}$ which compared to $\mathrm{OMV}_{\mathrm{n}}$, which had an average diameter of $134.9 \mathrm{~nm}$. This shows a 36\% increase in OMV size upon treatment of PAO1 with ciprofloxacin. The distribution of the curves shows a much greater size variance amongst $\mathrm{OMV}_{\mathrm{n}}$ derived OMVs compared to $\mathrm{OMV}_{\text {cip }}$ when the gradients of the two peaks are compared. Comparison of panel A to panel B (Fig 6) showed a reduction in OMV size of $\mathrm{OMV}_{\text {cip }}$ and this is likely due to $O M V_{\text {cip }}$ having a size greater than $200 \mathrm{~nm}$ and were either deformed or excluded when subjected to $0.22 \mu \mathrm{m}$ filtration. 


\section{$\underline{3.3 .3}$ DLS analysis of OMV stability}

To determine the stability of the prepared OMVs, a variety of storage conditions were tested to determine optimal conditions that would maintain the integrity of the preparations after storage for 96 hrs, was enabled by DLS. OMV $\mathrm{c}_{\text {cip }}$ were diluted 100-fold in PBS and stored for 96 hrs at either RT, $4{ }^{\circ} \mathrm{C},-20{ }^{\circ} \mathrm{C},-80{ }^{\circ} \mathrm{C}$ (Fig 7). OMVs were found to be most stable when stored at either at $4^{\circ} \mathrm{C}$ or $-20^{\circ} \mathrm{C}$ with much of the OMVs remaining at the expected sized of $50-300 \mathrm{~nm}$ range. At either room temperature or $-80^{\circ} \mathrm{C}$, coalescing or fragmentation of the OMVs occurred. It was decided that $4{ }^{\circ} \mathrm{C}$ was best for storage conditions as storage at $-20^{\circ} \mathrm{C}$ would require repeat freezing/thawing cycles that may potentially denature proteins present within the OMVs.

\section{Size Distribution by Volume}

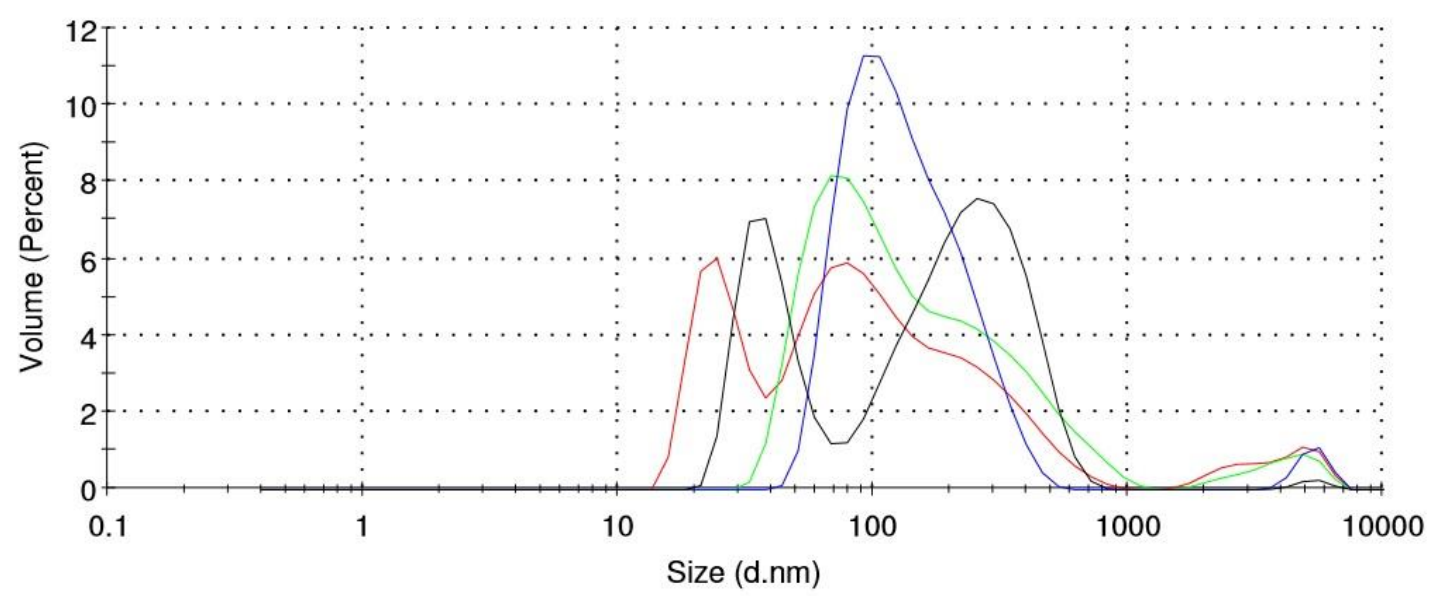

Figure 7: Dynamic Light scattering stability analysis of an OMV cip isolate derived from PAO1 cultures

Red Curve $=$ OMVs stored for 96 hrs at Room Temperature $\left(\sim 25^{\circ} \mathrm{C}\right)$

Green Curve $=$ OMVs stored for $96 \mathrm{hrs}$ at $4{ }^{\circ} \mathrm{C}$

Blue Curve $=$ OMVs stored for 96 hrs at $-20{ }^{\circ} \mathrm{C}$

Black Curve $=$ OMVs stored for 96 hrs at $-80{ }^{\circ} \mathrm{C}$

Multiple peaks are present in OMVs stored at either room temperature or $-80{ }^{\circ} \mathrm{C}$, indicating either coalescing or fragmenting of the OMVs. 


\subsection{Modified Optical absorption spectral analysis of OMV}

Absorption spectroscopy utilizing modified optics \& an integrating sphere can be used to obtain an absorbance spectrum of turbid solutions by accounting for scattering, making it an ideal technique to analyse complex biological samples (i.e. OMVs). As turbidity causes light scattering, absorption values become erroneously high in samples that have high turbidity and thus use of an integrating sphere allows 'true' absorption to be measured by eliminating the interference from scattering and thus it is possible to accurately measure small absorption values (Darby et al., 2016).

$\mathrm{OMV}_{\text {cip }}$ was diluted in PBS before undergoing white-light illumination to obtained an absorbance spectrum ranging from $400-700 \mathrm{~nm}$ (Fig 8). The absorbance spectrum yielded two characteristic peaks present at roughly $520 \& 550 \mathrm{~nm}$.

These absorbance peaks are characteristic of the electron-transfer protein, cytochrome c (cyt c) (Pettigrew \& Moore, 1987). To further elucidate whether these peaks were due to the presence of cyt c, the strong oxidant ammonium persulfate (APS) was added (Fig 9). Oxidation of cyt c causes a decrease in the peak absorbance at $550 \mathrm{~nm}$ (Pettigrew \& Moore, 1987; Vandewalle \& Petersen, 1987) and thus addition of APS should cause a corresponding decrease in absorbance if cyt $\mathrm{c}$ is present.

Analysis of the absorbance spectrum obtained upon addition of APS to the OMV cip sample, shows a decrease in peak intensity at both $520 \& 550 \mathrm{~nm}$ (Fig 9). This effect becomes more pronounced if readings are taken 10 mins after the addition of APS. The reduction of the $520 \&$ $550 \mathrm{~nm}$ peaks, confirms the presence of cyt $\mathrm{c}$ in $\mathrm{OMV}_{\text {cip. }}$ 


\section{Modified absorption spectra of $O M V_{\text {cip }}$}
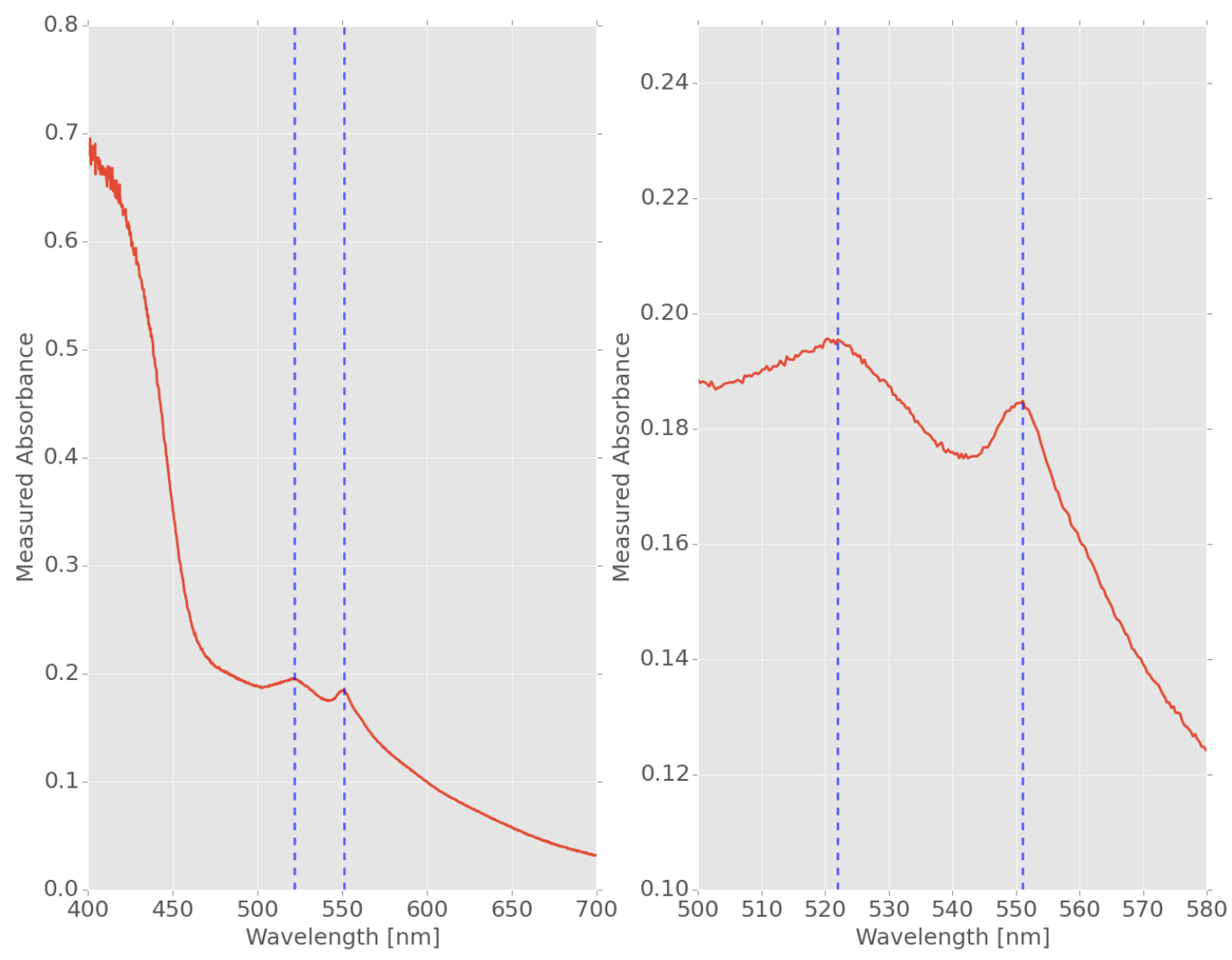

Figure 8: Analysis of $\mathrm{OMV}_{\text {cip }}$ absorbance spectra using an integrating sphere

A sample of $O M V_{\text {cip }}$ was diluted 1 in 5 in sterile PBS in a cylindrical glass tube before being subjected to white-light illumination. Spectra acquired were averaged from 10,000 1ms reads. Two minor peaks are present at $\sim 520 \mathrm{~nm} \& 550 \mathrm{~nm}$. The presence of these two peaks indicates the presence of the redox-active enzyme, cytochrome c. 


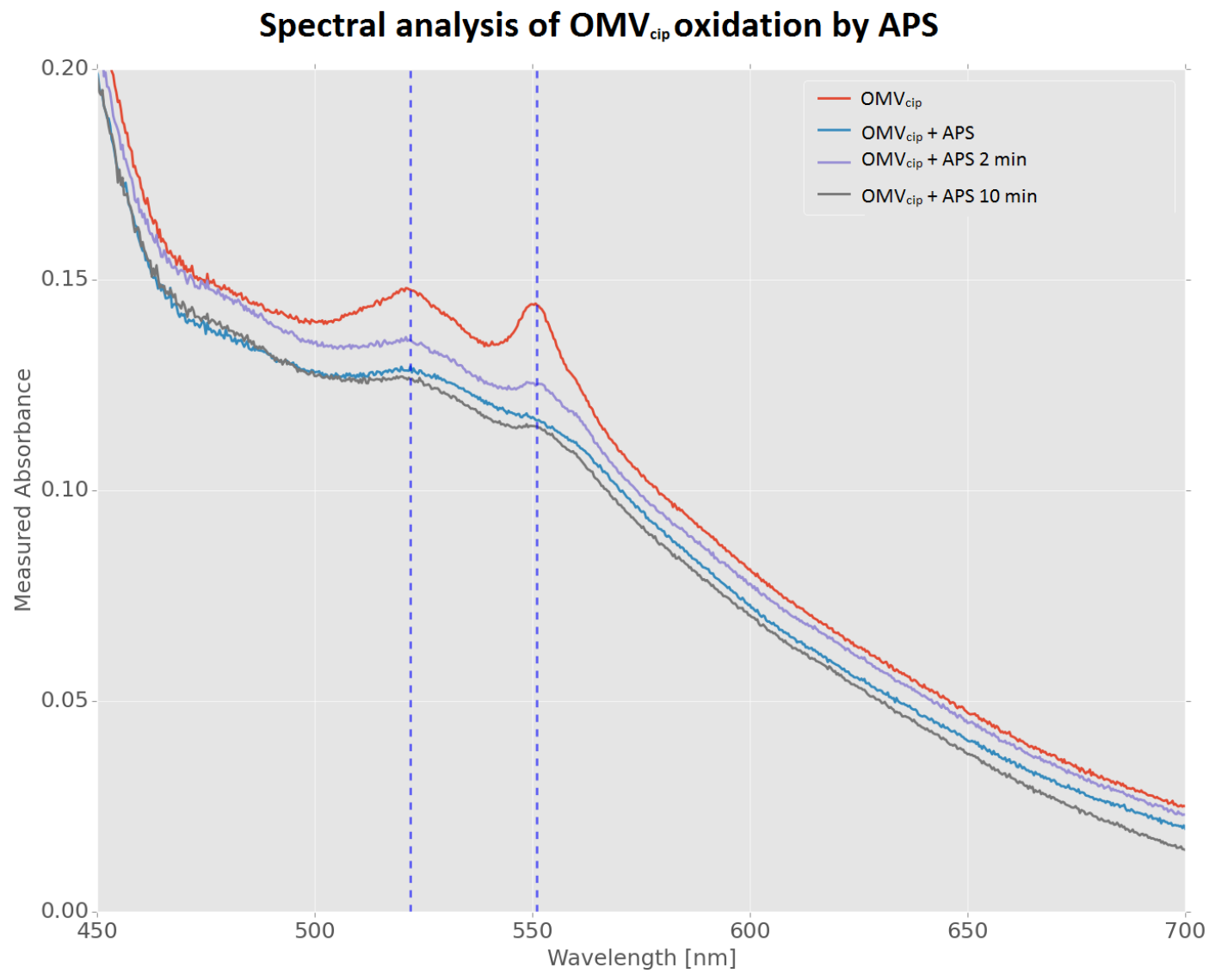

Figure 9: Analysis of cytochrome c oxidation in $\mathrm{OMV}_{\text {cip }}$ by APS from absorbance spectra using modified absorption spectroscopy

A sample of OMV cip was diluted 1 in 5 in sterile PBS in a cylindrical glass tube before being subjected to white-light illumination. Spectra acquired were averaged from 10,000 1ms reads. The oxidizing agent ammonium persulfate (APS) was added to oxidize cytochrome c present. Comparison of the unoxidized OMV $\mathrm{V}_{\text {cip }}$ absorption spectra (Red) to the spectra obtained 10 mins after the addition of APS shows decreased absorption at $520 \& 550 \mathrm{~nm}$, indicating oxidation of cytochrome c. 


\section{$\underline{3.4 \text { Electron Micrograph (EM) images of OMVs }}$}

To further characterize the OMV isolates, EM images were acquired of each OMV subtype. This would also further serve to detect contaminates present such as bacteria or bacterial components that may not have been detected by DLS previously in the study. Previous studies have shown the presence of other large proteins present in isolated OMV pellets, such as flagella (Bauman \& Kuehn, 2006).

Imaging of the OMV isolates showed a distinct physical appearance between $O M V_{n} \& O M V_{\text {cip }}$ (Fig 10). $\mathrm{OMV}_{\mathrm{n}}$ (Fig 10, A,B,C) appeared generally smaller in size and varied more in size between OMVs present in the images. OMV cip (Fig 10, D,E,F) were much larger and had a distinct appearance to the outer-membrane leaflet, which appeared to have a 'fuzzy' appearance. In all OMV isolates imaged there was the presence of bacterial components such as flagella (Fig 10, B \& E) \& suspected matrix components (Fig 10, A \& F). The marked difference in outermembrane appearance between OMV subtypes, is indicative of a difference in lipid composition when OMVs are generated under ciprofloxacin treatment. 

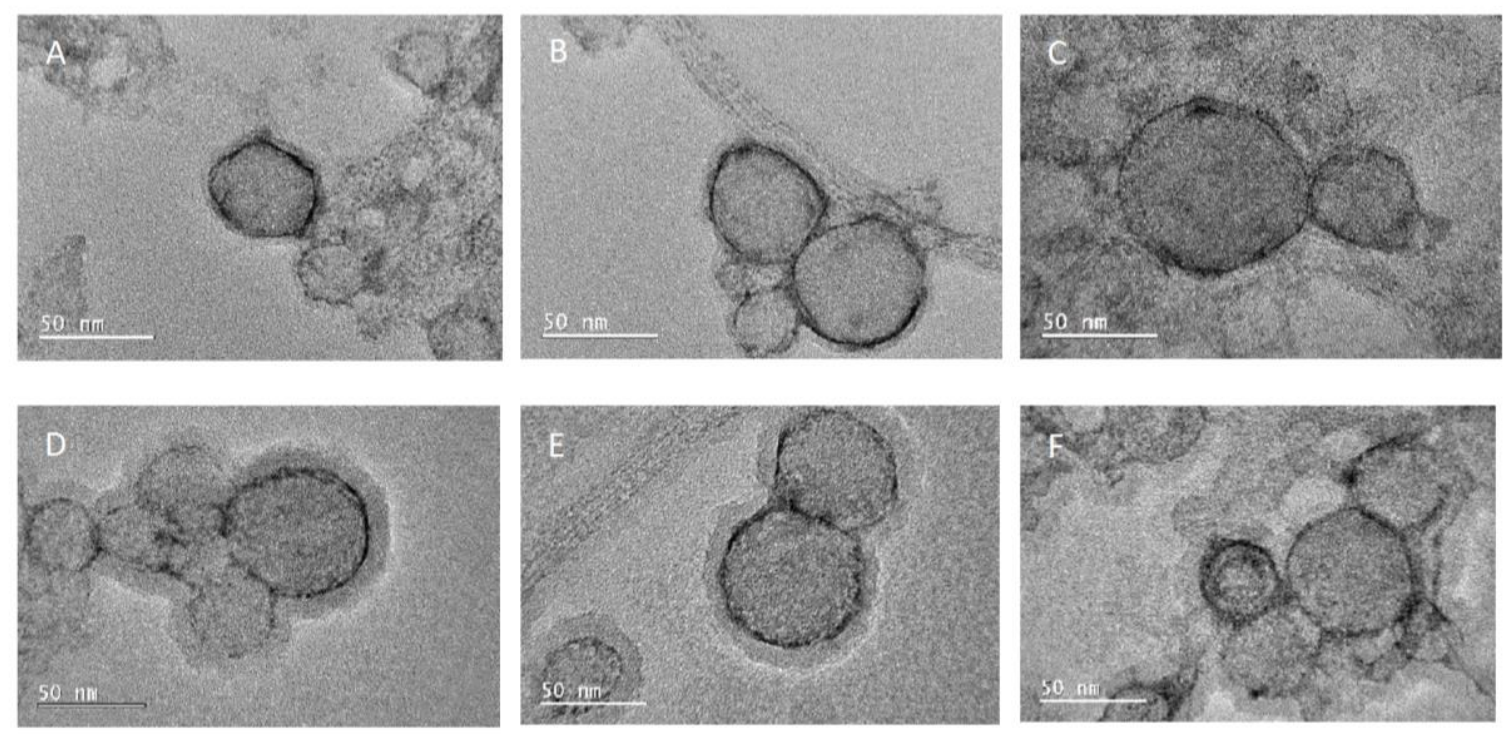

Figure 10: Electron micrograph images of OMV isolates used in this study.

$\mathrm{A}, \mathrm{B}, \mathrm{C}=\mathrm{OMVn}$
$\mathrm{D}, \mathrm{E}, \mathrm{F}=\mathrm{OMVcip}$

Images are representative of 3 independent OMV isolations for each OMV subtype. 


\subsection{PAGE Gel analysis of OMVs}

Samples of OMV isolates were separated by sodium dodecyl sulphate-polyacrylamide gel electrophoresis (SDS-PAGE) to examine whether any significant difference in protein expression profiles of the OMVs existed between $O M V_{n}$ and $O M V_{\text {cip. }}$.

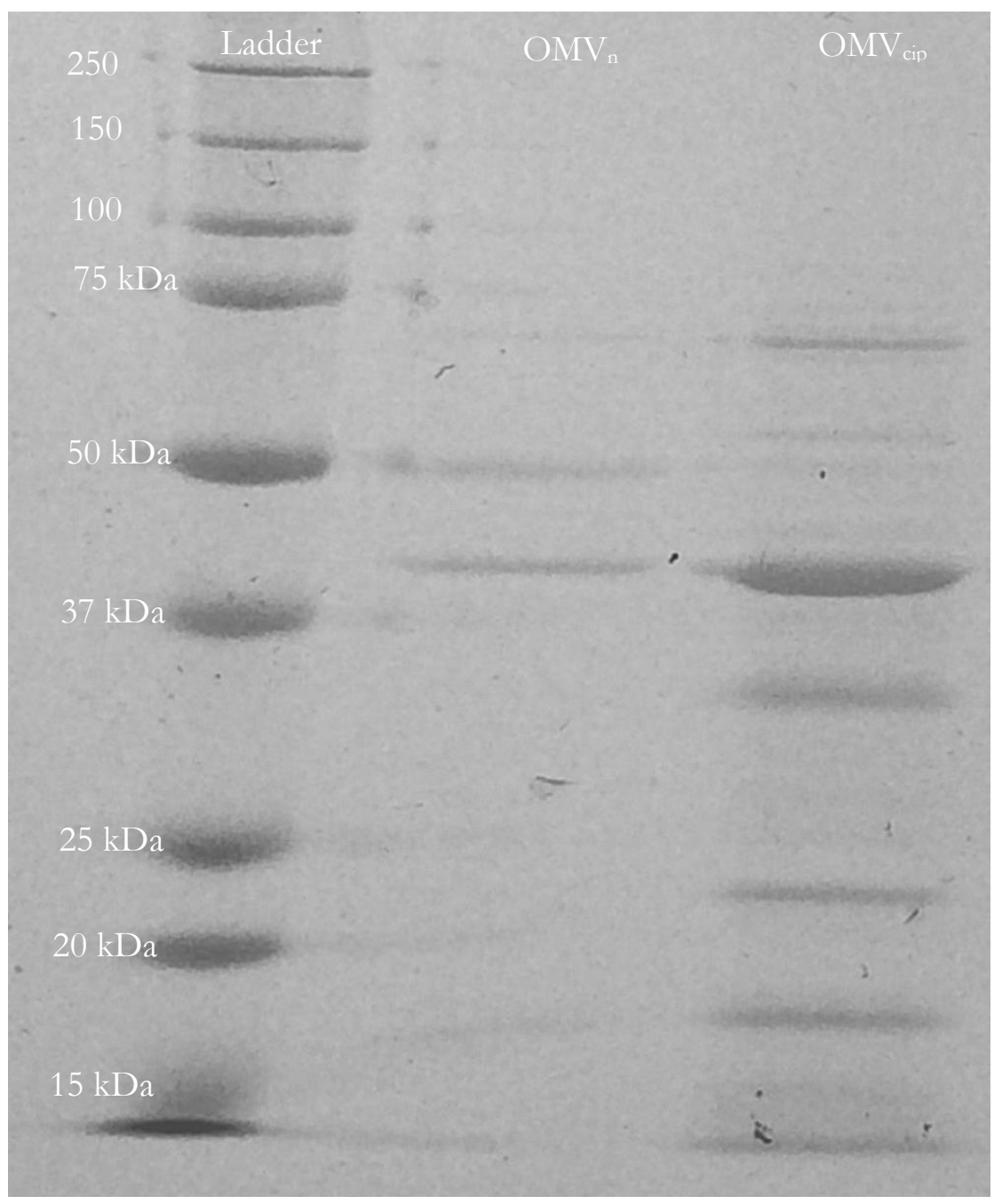

\section{Figure 11: PAGE gel analysis of OMV isolates}

Approximately $4 \mu \mathrm{g}$ of protein from each OMV subtype was loaded and Precision Plus Protein $^{\text {TM }}$ ladder was used for a size reference. PAGE analysis was conducted twice from two independent OMV preperations, this is a typical result shown. 
PAGE gel analysis of $\mathrm{OMV}_{\mathrm{n}}$ (Fig 11) showed a lack of staining although the amount of protein loaded was equivalent to that of $\mathrm{OMV}_{\text {cip }}$. Upon staining with coomassie blue a lack of staining is present in lanes containing $O M V_{n}$. However, a small amount of protein did stain as seen by a band faintly present in the $50 \mathrm{kDa}$ region when compared to the protein ladder .

Analysis of lanes containing samples of $O M V_{\text {cip }}$ show a number of distinct bands present. The highest molecular weight band present is around $75 \mathrm{kDa}$, with a couple of faint bands existing between the $50-75 \mathrm{kDa}$ range. A highly dense band is present with a molecular weight just over $37 \mathrm{kDa}$ indicating a high abundance of this protein present in OMVs generated during ciprofloxacin treatment. Three further bands are present with molecular weights of around 20-25 $\mathrm{kDa},<15 \mathrm{kDa}$ and $>10 \mathrm{kDa}$ respectively. 


\section{$\underline{3.6}$ PAO1 growth assay results}

\subsubsection{PBS control results}

It was necessary to determine the largest fraction of PBS that could be added to a P. aeruginosa culture without altering the growth kinetics, as varying volumes of OMVs suspended in PBS were planned to be used in future experiments.

The addition of up to $25 \%$ of PBS (a quarter of the well volume used in the assay) did not significantly alter growth kinetics or end-point optical density after 15 hrs (Fig 12). However, variability amongst replicates increases with addition of $25 \%$ of PBS. A small increase in the final $\mathrm{OD}_{600}$ value reached is seen in a dose-dependent manner with PBS and is possibly due to the additional phosphate from the PBS. 
PAO1 Growth assay assesment of PBS control

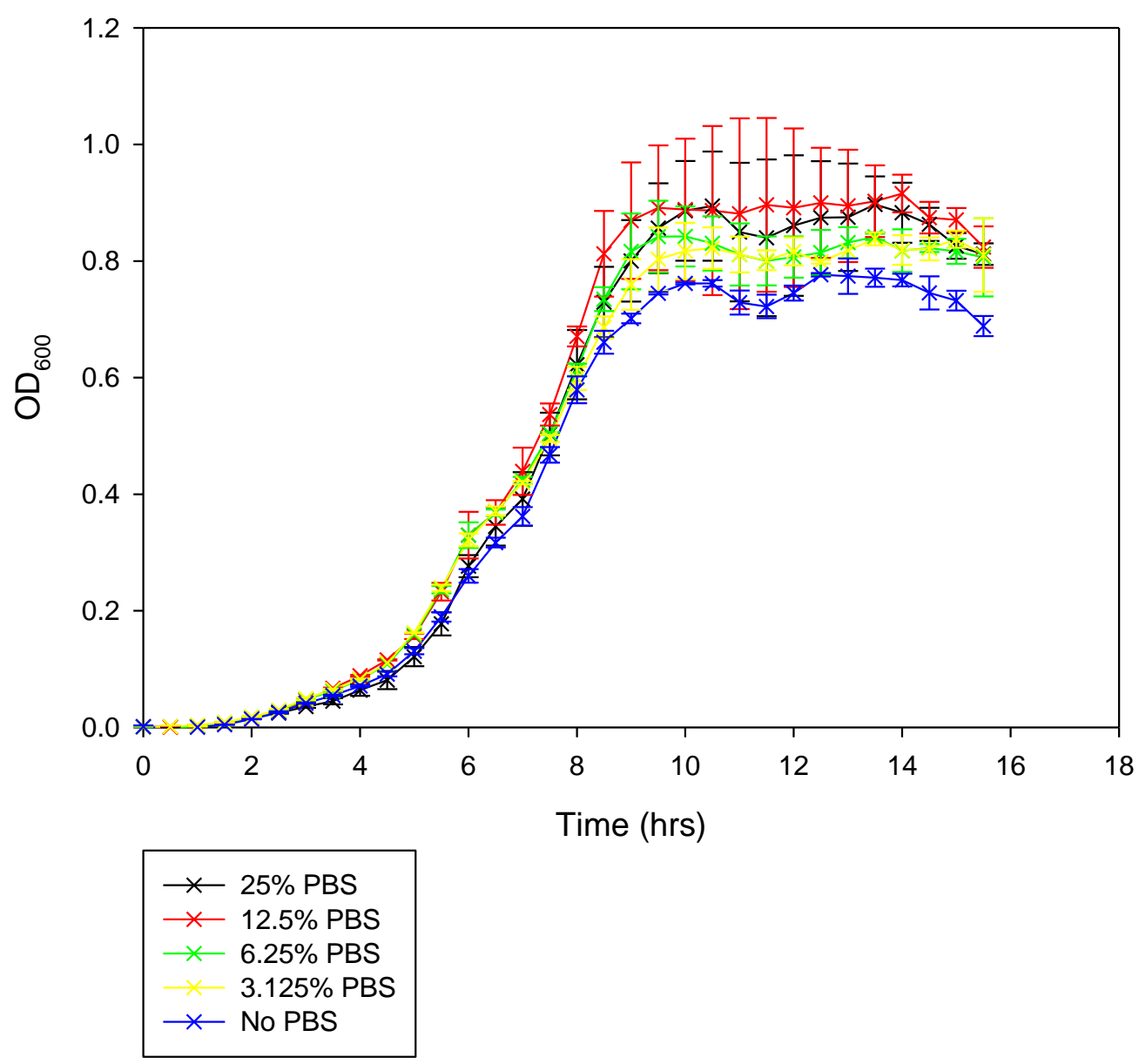

Figure 12: PBS control in PAO1 growth assay to assess growth effects associated with large volumes of PBS in place of $\mathrm{LB}$

P. aeruginosa was grown in LB supplemented with PBS at concentrations ranging from $25 \%$ to $3.125 \% .5$ different concentrations of PBS were tested in triplicate and OD $_{600}$ was tracked as a measure of bacterial growth. Result is from one experiment conducted in triplicate. 


\section{$\underline{\text { 3.6.2 Effect of OMV }}$ cip on PAO1 growth kinetics}

To determine whether OMVs generated under ciprofloxacin treatment caused any deviations from normal PAO1 growth, $25 \mu \mathrm{g}$ of $\mathrm{OMV}_{\text {cip }}$ (as determined by protein content from BCA assay) was added to a total culture volume of $250 \mu \mathrm{L}$ on a 96-well plate in triplicate and absorption at $600 \mathrm{~nm}$ tracked during growth. An equivalent volume of PBS was added to control wells.

Analysis of the growth kinetics of PAO1 upon treatment with $25 \mu \mathrm{g}$ of $\mathrm{OMV}_{\text {cip }}$ caused no significant deviations in the initial growth rate from that of the control up to $8.5 \mathrm{hrs}$ post inoculation (Fig 13). Upon reaching the $8.5 \mathrm{hr}$ mark, a significant difference in the $\mathrm{OD}_{600}$ between the control \& OMV treatment groups was evident and subsequently confirmed by student's t-test $(\mathrm{P}<0.05)$. The average $\mathrm{OD}_{600}$ at this time-point for the control groups and $\mathrm{OMV}$ treatment groups were $0.698 \pm 0.0280$ and $0.589 \pm 0.0289$ respectively $(\mathrm{n}=5$, mean \pm SEM). Control groups at the $8.5 \mathrm{hr}$ mark were higher in $\mathrm{OD}_{600}$ value by 0.109 compared to groups treat with OMVs, indicating a reduction in the growth rate at this time. 


\section{Effect of $\mathrm{OMV}_{\text {cip }}$ treatment on PAO1 growth kinetics}

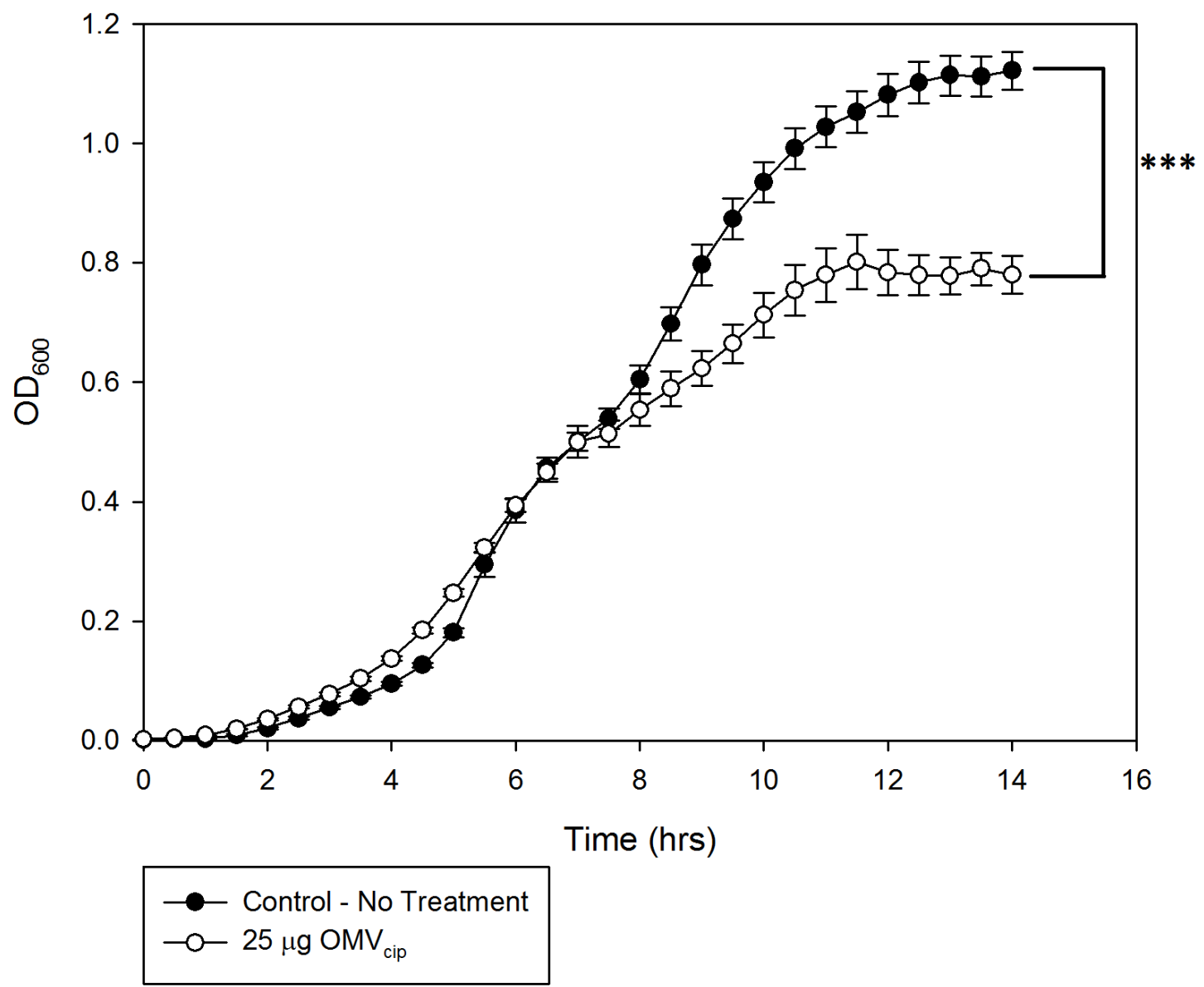

Figure 13: Growth curve analysis of PAO1 treated with $25 \mu \mathrm{g}$ of $\mathrm{OMV}_{\text {cip }}$

Treatment with $25 \mu \mathrm{g}$ of $\mathrm{OMV}_{\text {cip }}$ altered growth kinetics of PAO1, resulting in a decrease in growth rate occurring 9 hrs post inoculation compared to control. End-point $\mathrm{OD}_{600}$ values for controls were $1.122 \pm 0.0317\left(n=5\right.$, mean \pm SEM) \& treatment with $25 \mu$ g of $O M V_{\text {cip }}$ were $0.780 \pm 0.0319(\mathrm{n}=5$, mean \pm SEM).

Students t-test analysis of end-point OD600 amongst groups determined that the difference was highly statistically significant $(\mathrm{P}<0.001)$ with a 95\% CI of the difference between means $0.250-0.434$.

Students t-test analysis performed on individual time points indicated that the difference of OD600 values first becomes statistically significant $(\mathrm{P}<0.05)$ at the $8.5 \mathrm{hr}$ time point, with subsequent time points becoming highly significant $(\mathrm{P}<0.001)$ after 9 hrs. Results shown are from 5 independent experiments conducted in triplicate using multiple $O M V_{\text {cip }}$ isolations. 


\section{$\underline{\text { 3.6.3 Effect of OMV }}$ cip on S.enterica growth kinetics}

Previous studies reported a bacteriolytic effect from P. aeruginosa-derived OMVs, on other bacteria species (Kadurugamuwa \& Beveridge, 1996) and thus a growth assay using S. enterica was conducted to verify this. We were also interested to examine whether $P$. aeruginosa-derived OMVs could attenuate growth in other species.

S. enterica growth assays were prepared in the same manner to growth assays performed earlier in this thesis (Section 3.6.2). 


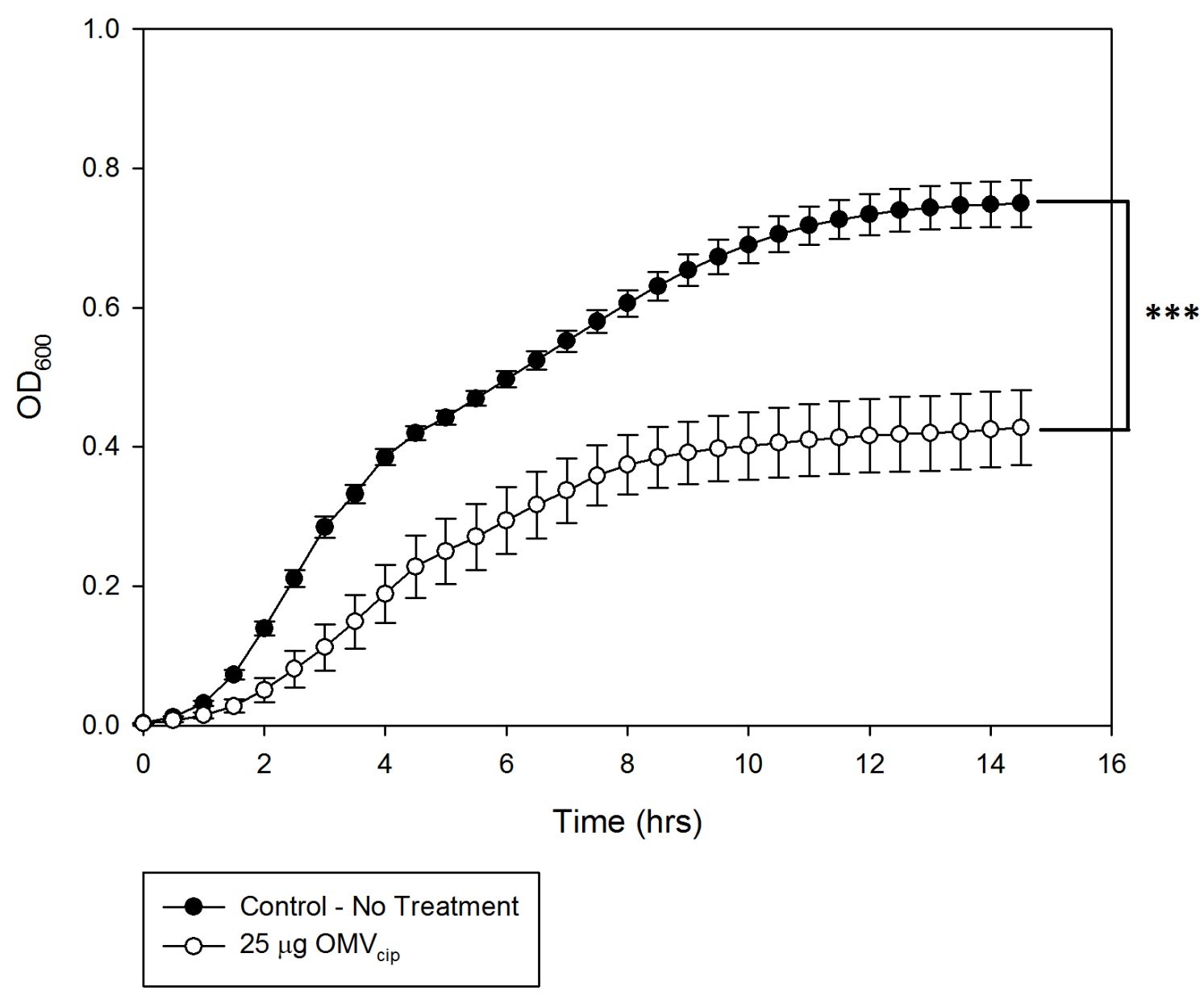

Figure 14: Growth curve analysis of $S$. enterica treated with $25 \mu \mathrm{g}$ of $\mathrm{OMV}_{\text {cip }}$

Treatment with $25 \mu \mathrm{g}$ of $\mathrm{OMV}_{\text {cip }}$ altered growth kinetics of $S$. enterica resulting in an increase in the lag phase as well as reaching a lower $\mathrm{OD}_{600}$ than that of the control. End-point $\mathrm{OD}_{600}$ values for controls were $0.750 \pm 0.034(\mathrm{n}=3$, mean $\pm \mathrm{SEM})$ and treatment with $25 \mu \mathrm{g}$ of $\mathrm{OMV}_{\text {cip }}$ were $0.428 \pm 0.054$ ( $\mathrm{n}=3$, mean $\pm \mathrm{SEM}$ ). Students t-test analysis of $\mathrm{OD}_{600}$ values determined that a significant difference in growth is first detected after $2.5 \mathrm{hrs}$ and becomes highly significant after $3.5 \mathrm{hrs}$.

Students t-test analysis of end-point $\mathrm{OD}_{600}$ amongst groups determined that the difference was highly statistically significant $(\mathrm{P}<0.001)$ with a 95\% CI of the difference between means $0.187-0.457$. Data shown is from 3 independent experiments done in triplicate using multiple independent $\mathrm{OMV}_{\text {cip }}$ isolates. 
S.entrica growth analysis of time taken to reach $\mathrm{OD}_{600}$ of 0.1

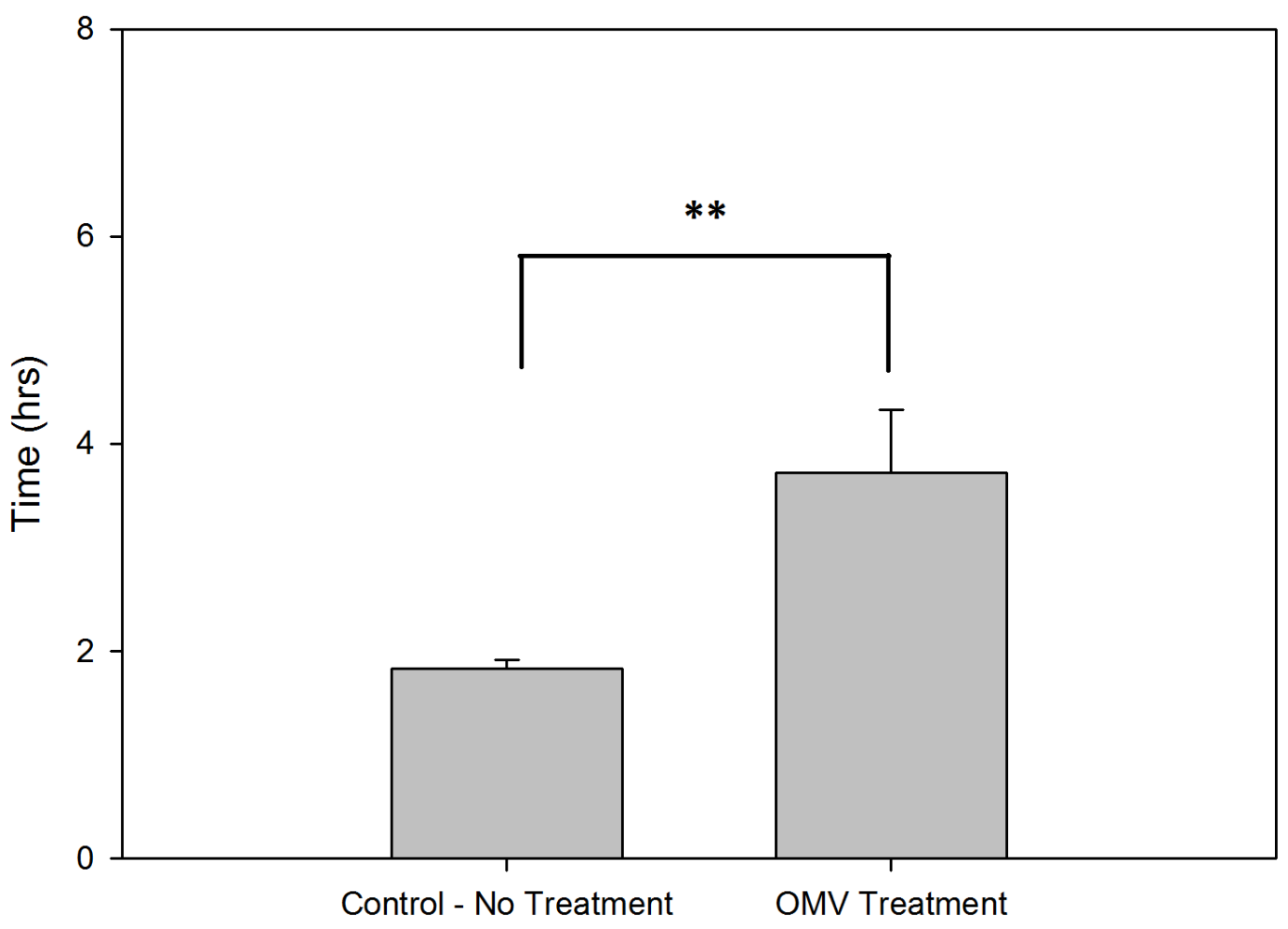

Figure 15: Time for $S$. enterica to reach $\mathrm{OD}_{600} 0.1$

Treatment with $25 \mu \mathrm{g}$ of $\mathrm{OMV}_{\text {cip }}$ in $S$. enterica increased the time taken for the culture to reach an OD600 of 0.1. Average time at which cultures reached an OD600 of 0.1 for controls were $1.8 \pm 0.083 \mathrm{hrs}(\mathrm{n}=3$, mean \pm SEM) compared to OMV treated cultures which took an average of $3.7 \pm 0.61 \mathrm{hrs}(\mathrm{n}=3$, mean \pm SEM).

Student's t-test was performed on the time point at which the cultures crossed the threshold OD600 of 0.1 between the two groups. Difference between groups was statistically significant $(\mathrm{P}<0.01)$. Data shown is from 3 independent experiments done in triplicate using multiple independent $\mathrm{OMV}_{\text {cip }}$ isolates. 
Treatment of $S$. enterica cultures with $\mathrm{OMV}_{\text {cip }}$ caused a decrease in growth rate (Fig 14) compared to control cultures indicating growth inhibition. Further examination by comparing at the time-point at which the culture crossed a threshold $\mathrm{OD}_{600}$ value of 0.1 (Fig 15) shows an increase in the time taken to reach this threshold by $1.9 \mathrm{hrs}$ in OMV treated cultures. This increase was statistically significant $(\mathrm{P}<0.01)$ and is indicative of the culture experiencing reduced growth in response to OMV treatment early on.

Comparison of the end-point $\mathrm{OD}_{600}$ values (Fig 14) between control groups \& OMV-treated groups shows a lower $\mathrm{OD}_{600}$ value is reached with a difference between treatment \& control of 0.322, indicating $\mathrm{OMV}_{\text {cip }}$ derived from PAO1 are growth-inhibitory in S. enterica. Student's t-test determined this to be highly significant $(\mathrm{P}<0.001)$. Furthermore, this growth-inhibitory effect can be detected as early as $1 \mathrm{hr}$ into growth (student's t-test $\mathrm{P}<0.01$ ). 


\section{$\underline{3.7 \text { Pyoverdine production analysis }}$}

\subsubsection{OMV $\mathrm{OM}_{\text {cip }}$ induction of pyoverdine production}

Upon completion of a $15 \mathrm{hr}$ PAO1 growth assay with $25 \mu \mathrm{g}$ of OMV cip, a distinct yellow colour was present in the culture supernatant of OMV treated wells. Further examination of the plate under a UV trans-illuminator indicated the presence of the fluorescent P. aeruginosa siderophore, pyoverdine (Fig 16). Treatment with $\mathrm{OMV}_{\text {cip }}$ appeared to stimulate pyoverine production in PAO1.

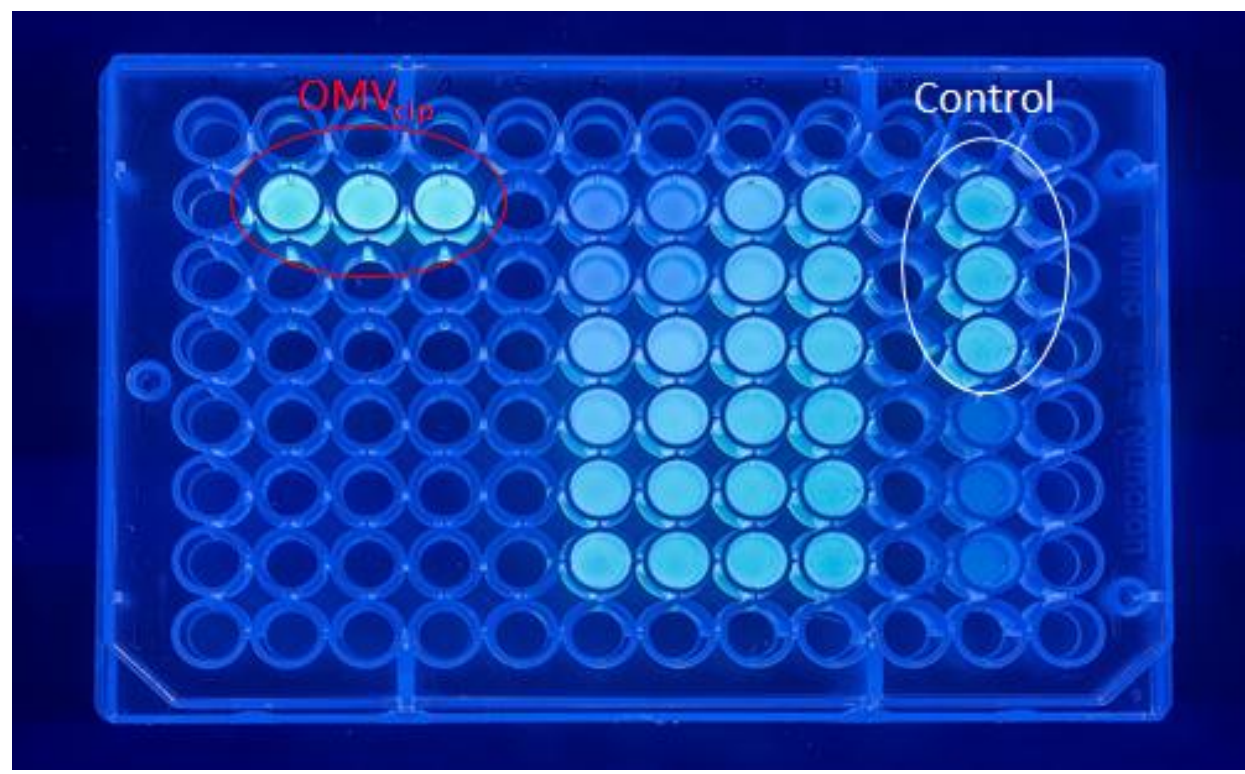

Figure 16: Photo under UV trans-illumination of a 96-well plate containing PAO1 after $16 \mathrm{hrs}$ post-inoculation to visualise pyoverdine production

$25 \mu \mathrm{g} \mathrm{OMV}_{\text {cip }}$ treatment (circled in red) induced pyoverdine production as seen by the blue glow emitted upon UV irradiation. Comparison to the control wells (circled in white) by eye, a significant difference in the amount of pyoverdine present can be seen when compared to cultures treated with $\mathrm{OMV}_{\text {cip }}$

To further investigate the potential for $\mathrm{OMV}_{\text {cip }}$ to induce pyoverdine production, growth assays were paired with excitation/emission readings of 405/455 nm to analyse pyoverdine production during growth (Fig 17). 


\section{Effect of $\mathrm{OMV}_{\text {cip }}$ on Pyoverdine production in PAO1}

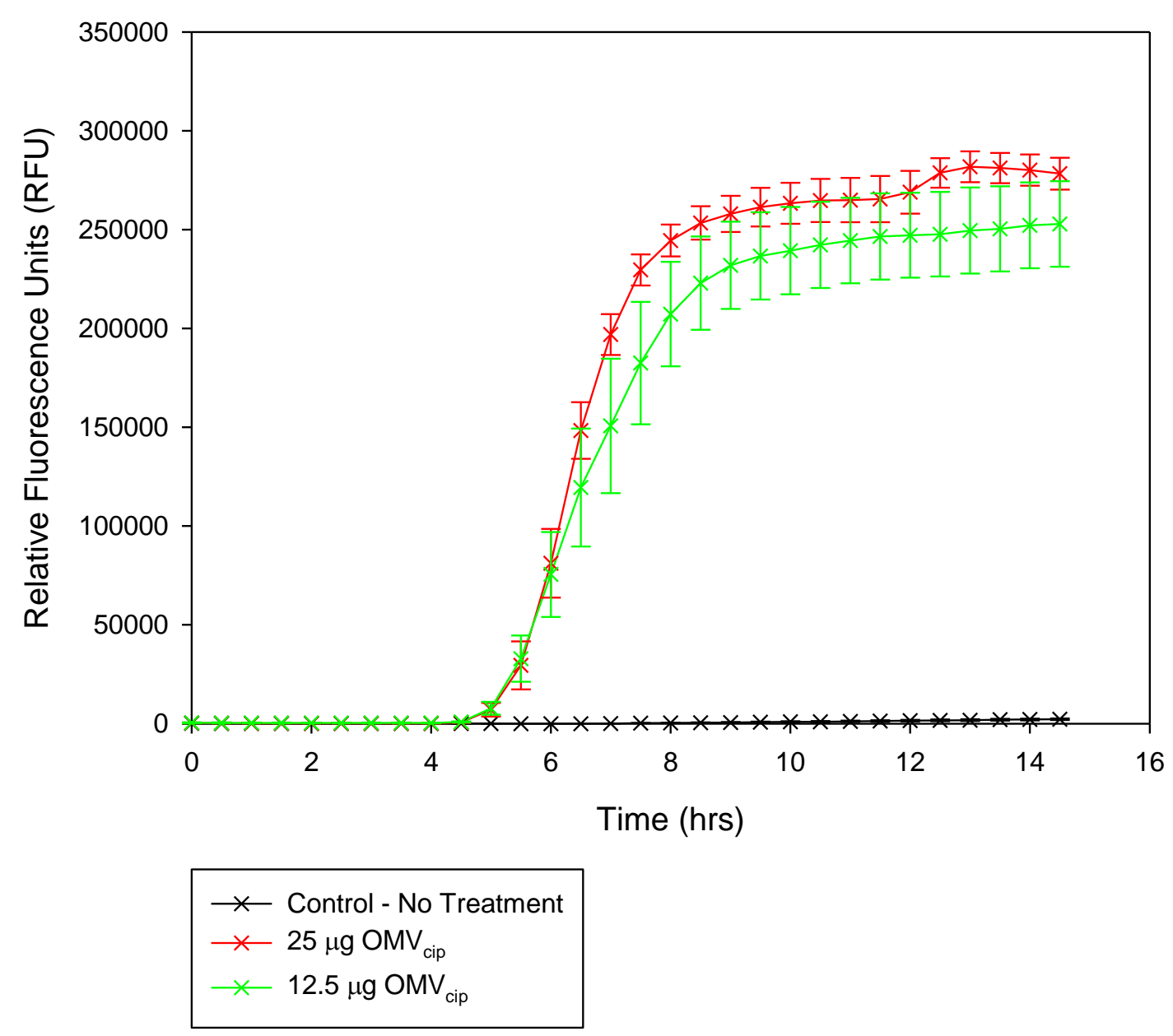

Figure 17: Analysis of pyoverdine production over time in response to $\mathrm{OMV}_{\text {cip }}$ treatment in PAO1

Measurements of pyoverdine production were taken every 30 mins through excitation at $405 \mathrm{~nm}$ and the resulting fluorescence emission at $455 \mathrm{~nm}$ was captured. Treatment with $\mathrm{OMV}_{\text {cip }}$ causes pyoverdine to be produced after $\sim 5 \mathrm{hrs}$. Control wells show little to no pyoverdine production during growth. OMV cip induces pyoverdine production at both 25 $\mu \mathrm{g}$ and $12.5 \mu \mathrm{g}$ doses. A minor decrease in pyoverdine production occurs when the OMV cip dose is halved but this is not statistically significant (student's t-test $\mathrm{P}>0.05$ ). Pyoverdine production is significant compared to controls after $5.5 \mathrm{hrs}$ for both doses of OMV cip (student's t-test, $\mathrm{P}<0.05$ ).

Relative fluorescence unit readings at 14.5 hrs for OMV cip treatment were 278,282 \pm 8088 and $252,810 \pm 21,622$ for doses of $25 \mu \mathrm{g}$ and $12.5 \mu \mathrm{g}$ respectively ( $\mathrm{n}=3$, mean \pm SEM). Controls had RFUs of $2226 \pm 426$ ( $n=3$, mean \pm SEM). Data shown is from 3 independent experiments conducted in triplicate. 


\section{Effect of $\mathrm{OMV}_{\text {cip }}$ on PAO1 Growth \& Pyoverdine production}

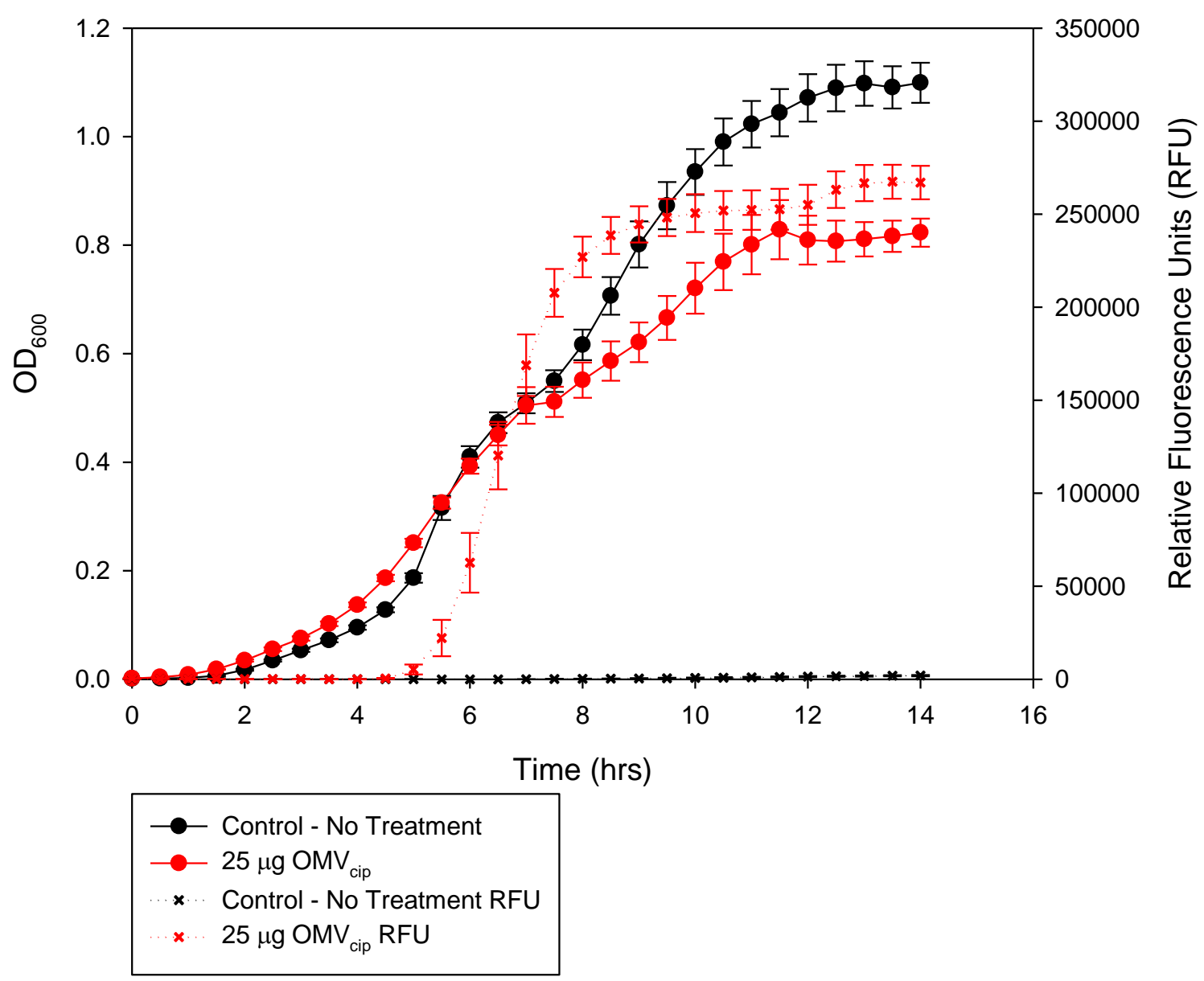

Figure 18: Analysis of pyoverdine production \& growth of PAO1 over time with $O M V_{\text {cip }}$ treatment

Data displayed from Fig $13 \& 17$ in a cumulative graph showing treatment with $25 \mu \mathrm{g}$ OMV cip. The effect of $O M V_{\text {cip }}$ on pyoverdine production can be seen as an increase in pyoverdine production around the 5.5-6 hr mark. Alteration of growth kinetics occurs in the 6-8 $\mathrm{hr}$ window under $\mathrm{OMV}_{\text {cip }}$ treatment. Collectively, the pyoverdine \& growth data indicate a 'signalling window' that occurs in the exponential phase 6-8 hrs into growth, upon which the effects of $O M V_{\text {cip }}$ first become detectable. Growth data is from 4 independent experiments conducted in triplicate. RFU data is from 3 independent experiments conducted in triplicate. 
Pyoverdine production during growth does not significantly differ from beginning values in controls (Fig 17) with control RFU values reaching a maximum of $~ 4000$ RFU in any of the experiments. Groups treated with $\mathrm{OMV}_{\text {cip }}$ at either $12.5 \mu \mathrm{g}$ or $25 \mu \mathrm{g}$, showed a large increase in RFU beginning at the $5.5 \mathrm{hr}$ mark $(12.5 \mu \mathrm{g}=32,900 \pm 11,700 \mathrm{RFU}, 25 \mu \mathrm{g}=29,000 \pm 12,100$ $\mathrm{RFU}, \mathrm{n}=3$, mean $\pm \mathrm{SEM})$. This increase in RFU is indicative of pyoverdine production occurring at this point and is a sign that $O M V_{\text {cip }}$ is exerting its effects at this time point. End-point RFU values at the $14.5 \mathrm{hr}$ mark for the controls were an average $2226 \pm 426 \mathrm{RFU}(\mathrm{n}=3$, mean \pm SEM) compared to OMV cip treatments of $12.5 \mu \mathrm{g} \& 25 \mu \mathrm{g}$ which were $252,800 \pm 21,600 \mathrm{RFU} \&$ $278,200 \pm 8100 \mathrm{RFU}$, respectively ( $\mathrm{n}=3$, mean \pm SEM). OMV $\mathrm{O}_{\text {cip }}$ induces an increase in RFU by over $110 \mathrm{x}$ that of the control by $14.5 \mathrm{hrs}$, indicating a large increase in pyoverdine production over controls.

Combining both $\mathrm{OD}_{600}$ data \& RFU data obtained into one graph (Fig 18), shows a clearly defined period from 6-8 hrs at which the $\mathrm{OMV}_{\text {cip }}$-mediated signalling becomes detectable. A marked increase in pyoverdine occurs first before a reduction in growth rate $\&$ attenuation of growth kinetics occurs, resulting in a significant decrease in final optical density reached. 


\section{$\underline{3.8 \text { Ablation of } O M V_{c i p}}$-mediated effects by heat or chloroform disruption}

Given the magnitude \& replicability of the effects exerted by $O M V_{\text {cip }}$ on both growth kinetics \& pyoverdine production (Fig 18), further investigation into what the possible mechanism by which $O M V_{\text {cip }}$ was mediating these effects was required. Two types of inactivation were attempted to render the effects induced by $\mathrm{OMV}_{\text {cip }}$ ineffective.

Firstly, $25 \mu \mathrm{g}$ samples of $\mathrm{OMV}_{\text {cip }}$ were heated at $75{ }^{\circ} \mathrm{C}$ for $25 \mathrm{~min}$ to denatur any proteins that could be responsible for the modulation of growth kinetics through the action of driving cells into a dormant state. Heating of $O M V_{\text {cip }}$ did not ablate the growth kinetic effect of $O M V_{\text {cip }}$ with both the growth kinetic profile \& final $\mathrm{OD}_{600}$ reached, being insignificantly different from that of the raw $O M V_{\text {cip }}$ isolate treated cuturs as determined by student'\$-test ( $\left.\mathrm{P}>0.05\right)$ (Fig 19). Pyoverdine production of cultures receiving heat-treated $\mathrm{OMV}_{\text {cip }}$ had no reduction in their ability to produce pyoverdine in comparison to cultures that were treated with raw $\mathrm{OMV}_{\text {cip }}$ isolate (Fig 20). This indicates that the effect of $O M V_{\text {cip }}$ on growth and pyoverdine production is not mediated through delivery of inhibitory proteins or proteins that functional as signalling messengers.

Secondly, chloroform was added at $2 \mathrm{x}$ the volume of $\mathrm{OMV}_{\text {cip }}$ sample before being vortexed vigorouly and allowed to dry at $37^{\circ} \mathrm{C}$ for 4 hrs before being re-suspended in LB to disrupt the OMV membranes to investigate whether the mechanism required for effect, requires an intact OMV membrane to function. Any small hydrophilic molecules would be released from the OMV and upon re-suspension in LB, would be in primarily present in the surrounding LB media and would deliver a lower effective concentration of the molecule when OMV fusion to PAO1 occurs. Chloroform-mediated disruption of $\mathrm{OMV}_{\text {cip }}$ caused a small amount of growth inhibition early on (Fig 19). This is likely due to a small amount of residual chloroform being carried over and causing slight growth inhibition/cell death. Chloroform treatment of $\mathrm{OMV}_{\text {cip }}$ did significantly reduce the level of inhibition that raw $O M V_{\text {cip }}$ exerts on growth as end-point $\mathrm{OD}_{600}$ 
values were significantly different from that of cultures that were treated with raw $O M V_{\text {cip }}$ $\left(\mathrm{OMV}_{\text {cip }}=0.601 \pm 0.018\right.$, Chloroform-treated $\mathrm{OMV}_{\text {cip }}=1.027 \pm 0.041(\mathrm{n}=2$, mean $\left.\pm \mathrm{SEM})\right)$ Statistical analysis uing Student's-test determined the difference between $O M V_{\text {cip }} \&$ chloroform-treated $\mathrm{OMV}_{\text {cip }}$ end-points was highly significant $(\mathrm{P}<0.001)$. However, whilst inhibition of growth by $\mathrm{OMV}_{\text {cip }}$ was mostly eliminated by treatment with chloroform, comparison of both control \& chloroform-treated $\mathrm{OMV}_{\text {cip }}$ end-points were still statistically different (student' $\$$-test, $\mathrm{P}<0.01)\left(\right.$ Control $=1.174 \pm 0.022 \mathrm{OD}_{600}$, Chloroform-treated $\mathrm{OMV}_{\text {cip }}$ $=1.027 \pm 0.041 \mathrm{OD}_{600}, \mathrm{n}=2$, mean $\left.\pm \mathrm{SEM}\right)$. This implies that chloroform-treatment of $\mathrm{OMV}_{\text {cip }}$ did not fully ablate growth inhibition. The difference in final $\mathrm{OD}_{600}$ could potentially be due to the residual carry over of chloroform in which case, $\mathrm{OMV}_{\text {cip }}$-induced growth alteration would have been fully ablated.

Analysis of the ability of chloroform-treated $\mathrm{OMV}_{\text {cip }}$ to induce pyoverdine production in $\mathrm{PAO} 1$ (Fig 20) showed chloroform-mediated disruption of $\mathrm{OMV}_{\text {cip }}$, did not significantly alter pyoverdine production compared to raw $\mathrm{OMV}_{\text {cip }}$ (student's-test, $\mathrm{P}>0.05$ ). The variability of the amount of pyoverdine produced by PAO1 in the prescence of the chloroform-treated $\mathrm{OMV}_{\mathrm{cip}}$ did increase however, as seen by the large error bars present. As chloroform treatment of $\mathrm{OMV}_{\text {cip }}$ did not eliminate the induction of pyoverdine production, the signalling component by which pyoverdine production is induced by $O M V_{\text {cip }}$ appears to either be a hydrophobic molecule/lipid \& does not require the OMVs to remain intact to exert its effect. 
PAO1 growth with $\mathrm{OMV}_{\text {cip }}$ inactivation

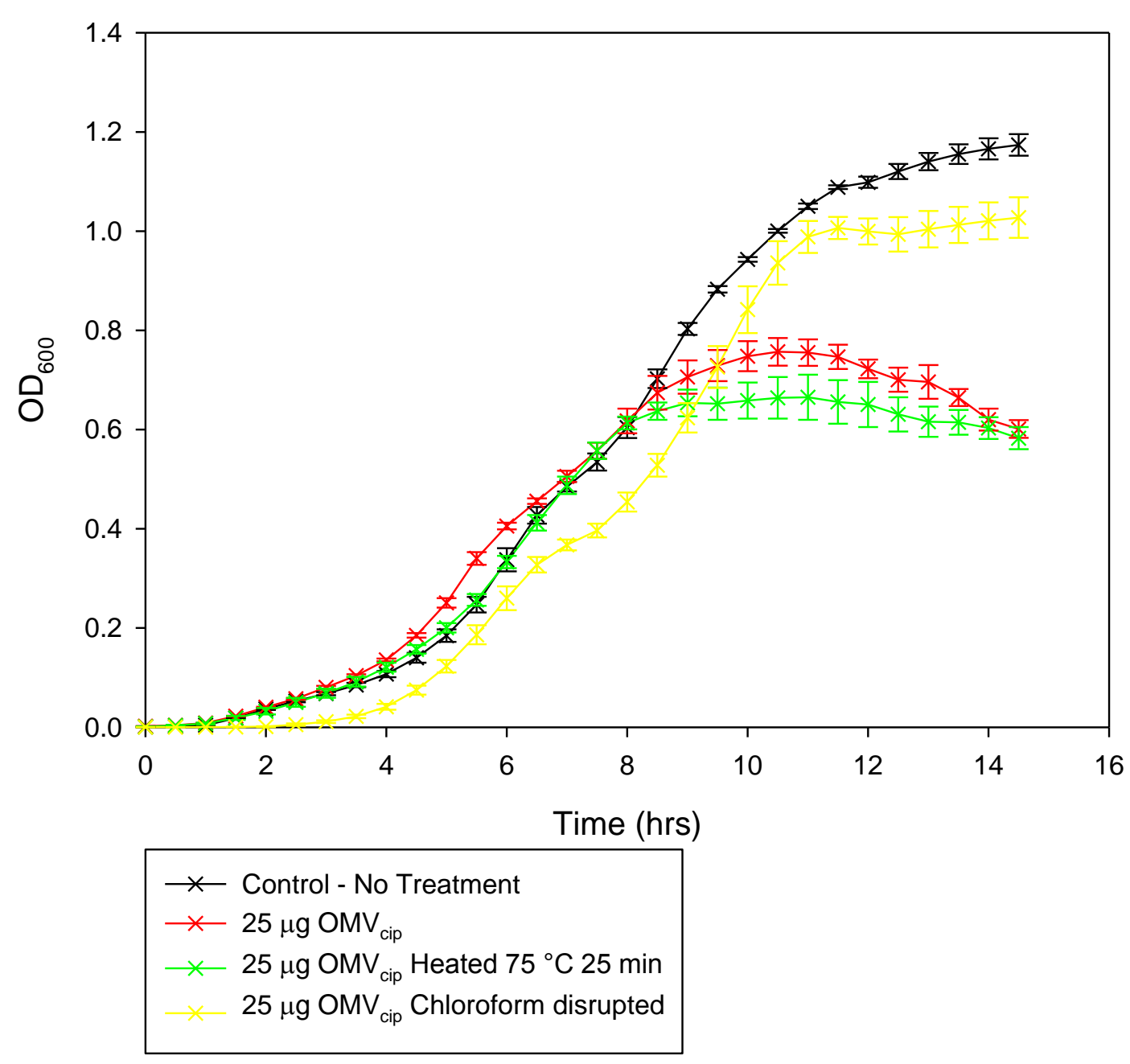

Figure 19: Growth of PAO1 after attempts to inactivate $\mathrm{OMV}_{\text {cip }}$

$25 \mu \mathrm{g}$ of $\mathrm{OMV}_{\text {cip }}$ were subjected to $25 \mathrm{~min}$ of heating at $75{ }^{\circ} \mathrm{C}$ in a heat block to render any proteinbased components inactive to determine whether a protein present was the causative agent for the effects exerted by $O M V_{\text {cip }}$ on growth. Heat-inactivation of $\mathrm{OMV}_{\text {cip }}$ did not significantly alter the growth kinetic pattern from that of non-disrupted $O M V_{\text {cip. }} 25 \mu \mathrm{g}$ of $O M V_{\text {cip }}$ were treated with $2 \mathrm{x}$ the initial volume with chloroform to cause disruption to the membrane and was allowed to evaporate off at $37^{\circ} \mathrm{C}$ for $4 \mathrm{hrs}$ before being re-suspended in the required volume of LB.

Chloroform-treated $\mathrm{OMV}_{\text {cip }}$ mostly ablated the attenuation of growth kinetics caused by $\mathrm{OMV}_{\text {cip. }}$. Final $\mathrm{OD}_{600}$ values of controls were $1.174 \pm 0.022(\mathrm{n}=2$, mean \pm SEM), compared to that of the chloroform disrupted $\mathrm{OMV}_{\text {cip }}$ which had values of $1.027 \pm 0.041(\mathrm{n}=2$, mean $\pm \mathrm{SEM})$. Final $\mathrm{OD}_{600}$ values of $\mathrm{OMV}_{\text {cip }}$ groups were $0.601 \pm 0.018(\mathrm{n}=2$, mean $\pm \mathrm{SEM})$ compared to heat-treated $\mathrm{OMV}_{\text {cip }} 0.583 \pm 0.023$

$(\mathrm{n}=2$, mean $\pm S E M)$. Student's t-test performed on $O M V_{\text {cip }}$ and heat-treated $O M V_{\text {cip }}$ showed difference was not significant $(\mathrm{P}>0.05)$. Data shown is from 2 independent experiments conducted in triplicate. 


\section{PAO1 pyoverdine production with attempts at $\mathrm{OMV}_{\text {cip }}$ inactivation}

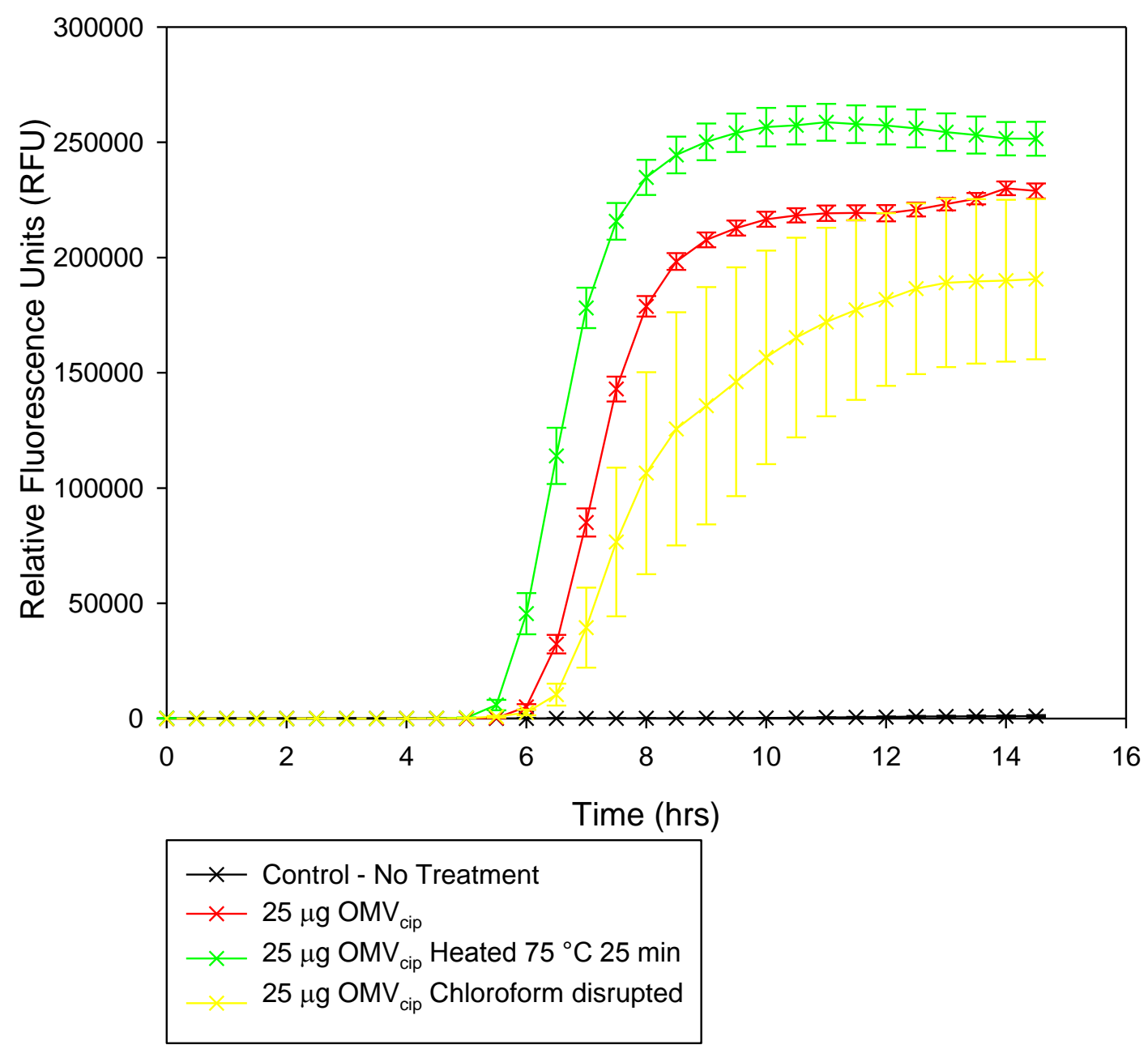

Figure 20: Pyoverdine production in PAO1 after attempts to inactivate $\mathrm{OMV}_{\text {cip }}$

$25 \mu \mathrm{g}$ of $\mathrm{OMV}_{\text {cip }}$ were subjected to $25 \mathrm{~min}$ of heating at $75{ }^{\circ} \mathrm{C}$ in a heat block to render any proteinbased components inactive to determine whether a protein present was the causative agent for the induction of pyoverdine production exerted by $O M V_{\text {cip }}$. Heat-inactivation of $O M V_{\text {cip }}$ caused a $0.5 \mathrm{hr}$ decrease compared to $\mathrm{OMV}_{\mathrm{cip}}$ in the time at which pyoverdine production was inducted when compared to $O M V_{\text {cip. }} 25 \mu \mathrm{g}$ of $O M V_{\text {cip }}$ were treated with $2 \mathrm{x}$ the initial volume with chloroform to cause disruption to the membrane and was allowed to evaporate off at $37^{\circ} \mathrm{C}$ for $4 \mathrm{hrs}$. Chloroform-treated OMV cip still induced pyoverdine production well above the control groups but significant variation of the amount produced between experiments can be seen by the presence of large error bars. Average RFU values at $14.5 \mathrm{hrs}$ for choroform-treated $\mathrm{OMV}_{\text {cip }}$ groups were 190,606 \pm 34,761 RFU ( $\mathrm{n}=2$, mean $\left.\pm \mathrm{SEM}\right)$.

Control groups had final RFU values of $1056 \pm 387 \mathrm{RFU}\left(\mathrm{n}=2\right.$, mean $\pm \mathrm{SEM}$ ). $\mathrm{OMV}_{\text {cip }}$ \& heat-treated $\mathrm{OMV}_{\text {cip }}$ had final RFU values of $228,889 \pm 3263 \mathrm{RFU}(\mathrm{n}=2$, mean \pm SEM) $\& 251,531 \pm 7376 \mathrm{RFU}$ $(\mathrm{n}=2$, mean $\pm \mathrm{SEM})$. Comparison of the end-point $R F U$ values shows heat-inactivation of $O M V_{\text {cip }}$ does not affect $O M V_{\text {cip }}$ ability to initiate pyoverdine production whilst chloroform-mediated disruption of the lipid membrane appears to reduce the extent at which $\mathrm{OMV}_{\text {cip }}$ induces pyoverdine production but still causes significant increases in pyoverdine compared to the control. Data shown is from 2 independent experiments conducted in triplicate. 


\subsection{Pre-incubation with $\mathrm{OMV}_{\text {cip }}$ effect on growth \& pyoverdine production}

The results from previous growth assays (Fig 13) showed that treatment with $O M V_{\text {cip }}$ causes PAO1 to reach a lower final culture density due to premature entry into stationary phase. We hypothesized that the OMVs were programming the cells, imposing a replicative limit which would affect future cellular progeny.

To investigate this, a series of experiments were designed to determine whether $O M V_{\text {cip }}$ is required to be present in the media during growth to exert its effect on growth kinetics \& pyoverdine production in PAO1 or if a short-exposure to OMVs is sufficient to determine the future growth fate and pyoverdine production potential of a culture. PAO1 cells in a $2.5 \mathrm{~mL}$ volume were either pre-incubated with or without an equivalent concentration of $25 \mu \mathrm{g} O M V_{\text {cip }}$ for 2 or 4 hrs before being washed once with LB to remove OMVs and a small $(10 \mu \mathrm{L})$ inoculum from this was used and growth was monitored in a total volume of $250 \mu \mathrm{L}$. For comparison of both the effect on growth \& pyoverdine production, a culture of PAO1 cells was treated with $25 \mu \mathrm{g} O M V_{\text {cip }}$ as per previous growth experiments in section 3.6.2.

PAO1 cells that were pre-incubated with $\mathrm{OMV}_{\text {cip }}$ for 2 or $4 \mathrm{hrs}$ prior to being washed and transferred to fresh media, showed a marked reduction in growth compared to controls (Figs 21 \& 23) which indicates that pre-incubation with $\mathrm{OMV}_{\text {cip }}$ for 2-4 hrs was sufficient to alter growth kinetics. Comparison of the growth curves of PAO1 cells that were pre-incubated with $\mathrm{OMV}_{\text {cip }}$ compared to cells that were grown in the presence of OMV cip in the media, showed a significant increase in the alteration of growth kinetics of cells that were pre-incubated with $O M V_{\text {cip }}$. Two important deviations from the expected growth kinetics profile from PAO1 treatment with $\mathrm{OMV}_{\text {cip }}$ exist.

Firstly, pre-incubation with $O \mathrm{OV}_{\text {cip }}$ caused cells to grow in a linear fashion early on indicating a decreased growth rate early on in growth. Treatment with $\mathrm{OMV}_{\text {cip }}$ in the culture media causes cells to follow a growth trend, entering exponential phase at the 3-4 hr point comparable to that of untreated cultures. Attenuation of growth kinetics mediated by $\mathrm{OMV}_{\text {cip }}$ does not begin to 
occur until the 5-6 hr time point, at which point a decrease in growth rate occurs (Fig 13) before reaching an early plateau, indicating premature entry into stationary-phase. A 4 hr pre-incubation with $\mathrm{OMV}_{\text {cip }}$ did not cause an increase in lag-phase which would be suggestive of cytotoxicity (due to reduced cell numbers), but inhibited cultures from growing in a exponential manner, which would normally occur $\sim 4 \mathrm{hrs}$. Control cultures were treated in the same manner as the cultures that were pre-incubated with $\mathrm{OMV}_{\text {cip }}$ and thus it is highly unlikely the reduction in growth is due to cells being washed out or damaged during the wash phase as the control cultures following the expected growth kinetics of untreated cultures despite use of a small inoculum.

Secondly, pre-incubation with $\mathrm{OMV}_{\text {cip }}$ caused PAO1 cells to enter stationary phase at a lower cell density than cells exposed to $O M V_{\text {cip }}$ in the culture media. Pre-incubation for 4 hrs with $O M V_{\text {cip }}$ caused cells to reach an $\mathrm{OD}_{600}$ after 14 hrs of 0.392 (Fig 21). In contrast, cells cultured in the presence of $\mathrm{OMV}_{\text {cip }}$ which reached an $\mathrm{OD}_{600}$ of 0.755 (Fig 21). The difference in end-point $\mathrm{OD}_{600}$ values between cultures that were pre-incubated for $4 \mathrm{hrs}$ with $\mathrm{OMV}_{\text {cip }}$ to those that were cultured in the presence of $O M V_{\text {cip }}$, is 0.392 . The effect of pre-incubation with $O M V_{\text {cip }}$ on growth is highly significant as determined by student's t-test $(\mathrm{P}<0.001)$.

A similar effect is seen with $2 \mathrm{hr}$ pre-incubation with $\mathrm{OMV}_{\text {cip }}$ (Fig 23) however it is worth noting both the pre-incubated control \& pre-incubated $O M V_{\text {cip }}$ cultures show an increased lag phase which is likely due to loss of cells during the LB wash.

This suggests that a $2 \mathrm{hr}$ pre-incubation of PAO1 with $O M V_{\text {cip }}$, is sufficient for fusion of $O M V_{\text {cip }}$ to deliver signalling components that pre-determines the replicative fate of the cells, resulting in a defined replicative 'limit'.

Analysis of pyoverdine production of PAO1 cells pre-incubated with $\mathrm{OMV}_{\text {cip }}$ for either 2 or 4 hrs (Figs $22 \& 24$ ) showed that removal of $O M V_{\text {cip }}$ from the culture media prevented the induction of pyoverdine production by $\mathrm{OMV}_{\text {cip. }}$ Cultures pre-incubated with $\mathrm{OMV}_{\text {cip }}$ did not 
show significant pyoverdine production compared to the control (student's t-test, $\mathrm{P}>0.05$ ) whilst cultures that were exposed to $\mathrm{OMV}_{\text {cip }}$ during monitored growth followed the expected pyoverdine production as seen in previous experiments (Fig 17). It is possible that that the inhibition of pyoverdine production despite being exposed to $O M V_{\text {cip }}$ is a result of the cultures not reaching a critical population density for the pyoverdine production to be initiated.

These results show that prior exposure to $\mathrm{OMV}_{\text {cip }}$ in PAO1 is sufficient to alter growth kinetics in future progeny. However, presence of $\mathrm{OMV}_{\text {cip }}$ in the culture media is required for OMVmediated pyoverdine production. 


\section{PAO1 growth after $4 \mathrm{hr}$ incubation prior to LB wash}

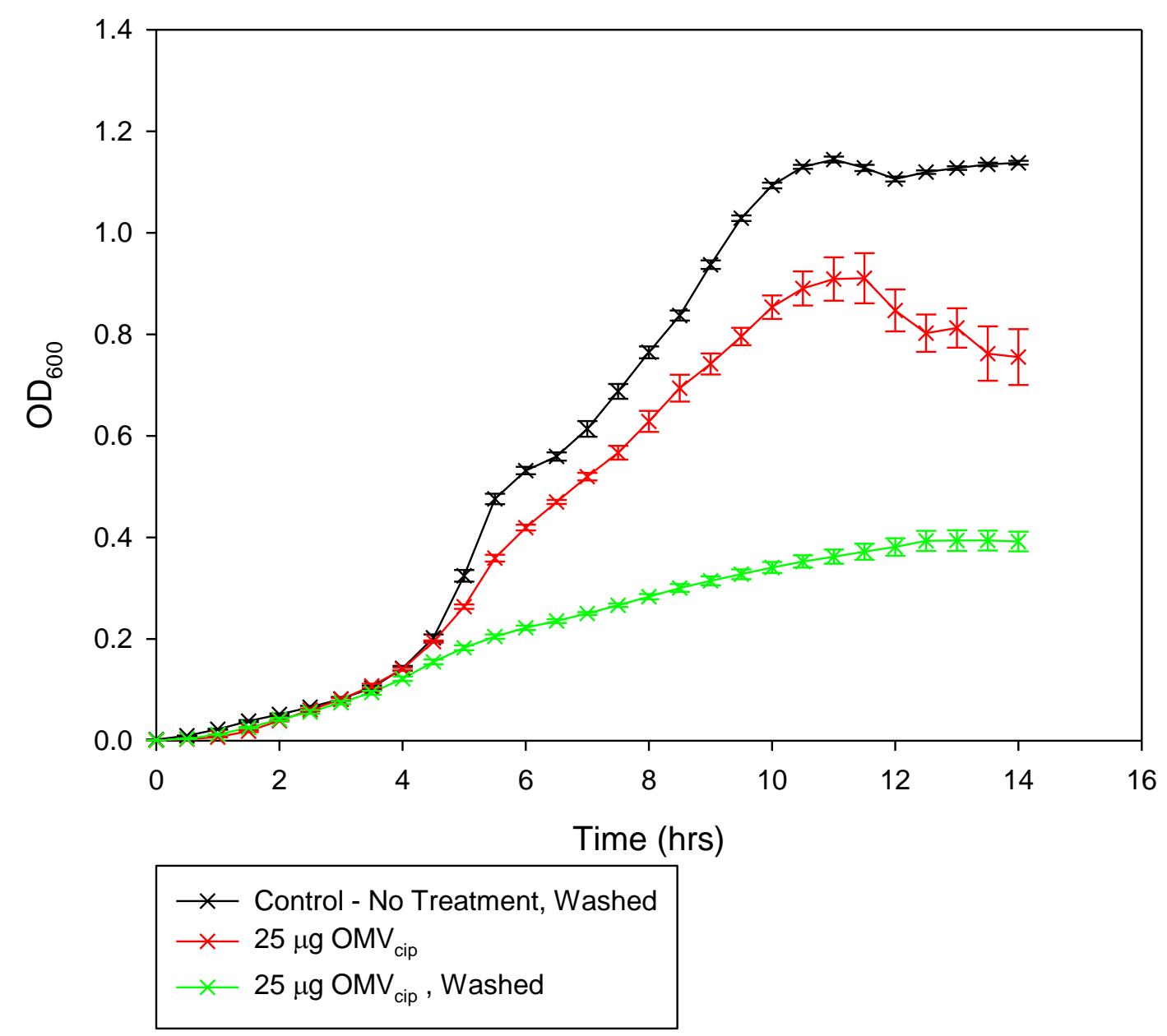

Figure 21: Analysis of PAO1 growth after $4 \mathrm{hr}$ pre-incubation with $25 \mu \mathrm{g} \mathrm{OMV}_{\text {cip }}$ before being washed with $\mathrm{LB}$ to remove $\mathrm{OMV}_{\text {cip }}$

PAO1 cells were pre-incubated for 4 hrs with or without $\mathrm{OMV}_{\text {cip }}$ before being centrifuged for 2 mins at 16,000 $\mathrm{x}$ g and washed with LB. Cells were then re-suspended in $2.5 \mathrm{x}$ the volume of $\mathrm{LB}$ to wash before a $10 \mu \mathrm{L}$ inoculum was seeded into $190 \mu \mathrm{L}$ of LB. A comparative sample with $25 \mathrm{OMV}_{\text {cip }}$ present was included as a reference for $\mathrm{OMV}_{\text {cip }}{ }^{-}$ mediated effects. PAO1 cells pre-incubated with $\mathrm{OMV}_{\text {cip }}$ show a marked decrease in both growth rate \& final $\mathrm{OD}_{600}$ reached at 14 hrs compared to control cells. PAO1 cells that were pre-incubated with $O M V_{\text {cip }}$ compared to those that were exposed to $O M V_{\text {cip }}$ during monitored growth, show a significant decrease in growth rate. End-point $\mathrm{OD}_{600}$ values of $\mathrm{OMV}_{\text {cip }}$ cultures were $0.755 \pm 0.055$, whilst $4 \mathrm{hr}$ pre-incubated $O M V_{\text {cip }}$ cultures were $0.392 \pm 0.019$ ( $\mathrm{n}=2$, mean \pm SEM). The difference of $\mathrm{OD}_{600}$ between pre-incubation with $\mathrm{OMV}_{\text {cip }} \& \mathrm{OMV}_{\text {cip }}$ of 0.363 was highly statistically significant (student's t-test $\mathrm{P}>0.001)$. Data shown is from 2 independent experiments conducted in triplicate. 


\section{PAO1 pyoverdine production after $4 \mathrm{hr}$ incubation prior to LB wash}

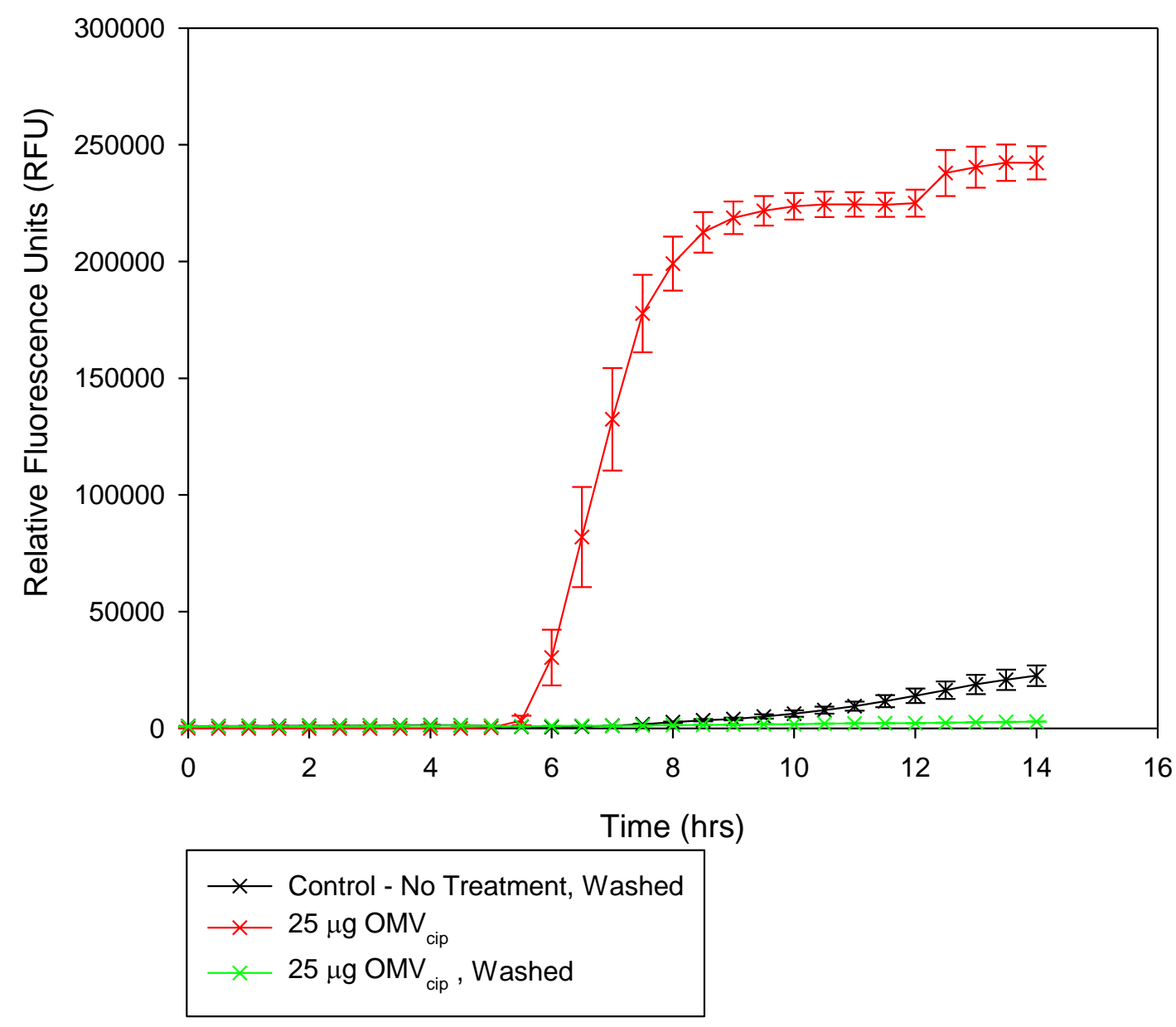

Figure 22: Analysis of PAO1 pyoverdine production after $4 \mathrm{hr}$ pre-incubation with $25 \mu \mathrm{g}$ OMV cip before being washed with LB to remove OMVcip

PAO1 cells were pre-incubated for $4 \mathrm{hrs}$ with or without OMV cip before being centrifuged for 2 mins at 16,000 $\mathrm{x}$ and washed with LB. Cells were then re-suspended in $2.5 \mathrm{x}$ the volume of $\mathrm{LB}$ to wash before a $10 \mu \mathrm{L}$ inoculum was seeded into $190 \mu \mathrm{L}$ of LB. A comparative sample with 25 OMV cip present was included as a reference for OMV cipmediated effects. Pyoverdine production was insignificant in both pre-incubated control \& $O M V_{\text {cip }}$ cultures. Data shown is from 2 independent experiments conducted in triplicate. 


\section{PAO1 growth after $2 \mathrm{hr}$ incubation prior to LB wash}

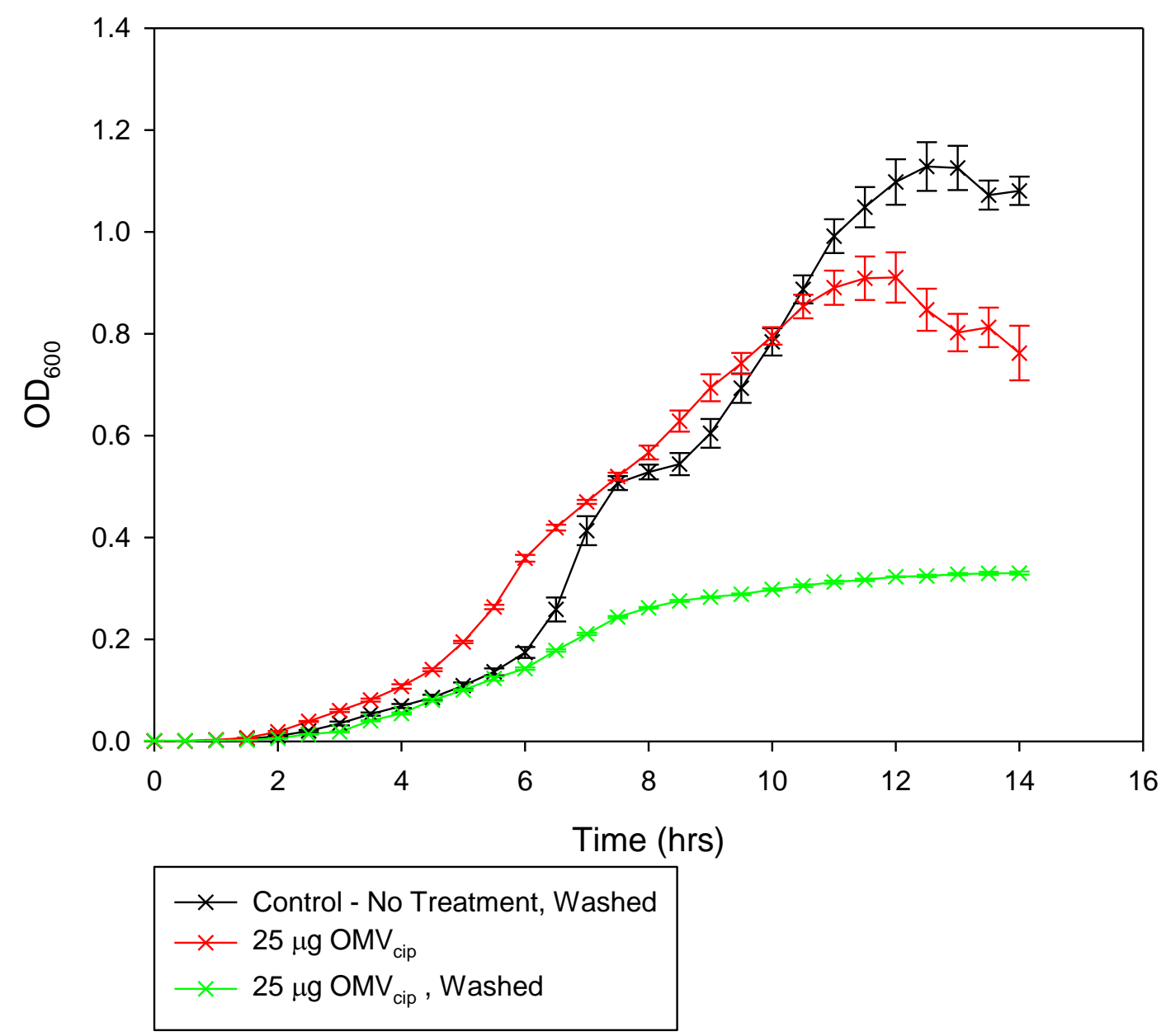

Figure 23: Analysis of PAO1 growth $2 \mathrm{hr}$ pre-incubation with $25 \mu \mathrm{g} \mathrm{OMV}_{\text {cip }}$ before being washed with $\mathrm{LB}$ to remove $\mathrm{OMV}$ cip

PAO1 cells were pre-incubated for 2 hrs with or without $O M V_{\text {cip }}$ before being centrifuged for 2 mins at 16,000 $\mathrm{xg}$ and washed with LB. Cells were then re-suspended in $2.5 \mathrm{x}$ the volume of $\mathrm{LB}$ to wash before a $10 \mu \mathrm{L}$ inoculum was seeded into $190 \mu \mathrm{L}$ of LB. A comparative sample with $25 \mathrm{OMV}_{\text {cip }}$ present was included as a reference for $\mathrm{OMV}_{\text {cip }}{ }^{-}$ mediated effects. PAO1 cells pre-incubated with $\mathrm{OMV}_{\text {cip }}$ show a marked decrease in both growth rate \& final $\mathrm{OD}_{600}$ reached at $14 \mathrm{hrs}$ compared to control cells. Comparison of PAO1 cells that were pre-incubated with $\mathrm{OMV}_{\text {cip }}$ compared to those that were exposed to $\mathrm{OMV}_{\text {cip }}$ during monitored growth, show a significant decrease in growth rate. End-point $\mathrm{OD}_{600}$ values of $\mathrm{OMV}_{\text {cip }}$ cultures were $0.755 \pm 0.055$, whilst $2 \mathrm{hr}$ pre-incubated $\mathrm{OMV}_{\text {cip }}$ cultures were $0.330 \pm 0.03$ ( $\mathrm{n}=2$, mean $\pm \mathrm{SEM}$ ). The difference of $\mathrm{OD}_{600}$ between preincubation with $O M V_{\text {cip }} \& O M V_{\text {cip }}$ of 0.432 was highly statistically significant (student's ttest $\mathrm{P}>0.001)$. Data shown is from 2 independent experiments conducted in triplicate. 
PAO1 pyoverdine production after $2 \mathrm{hr}$ incubation prior to LB wash

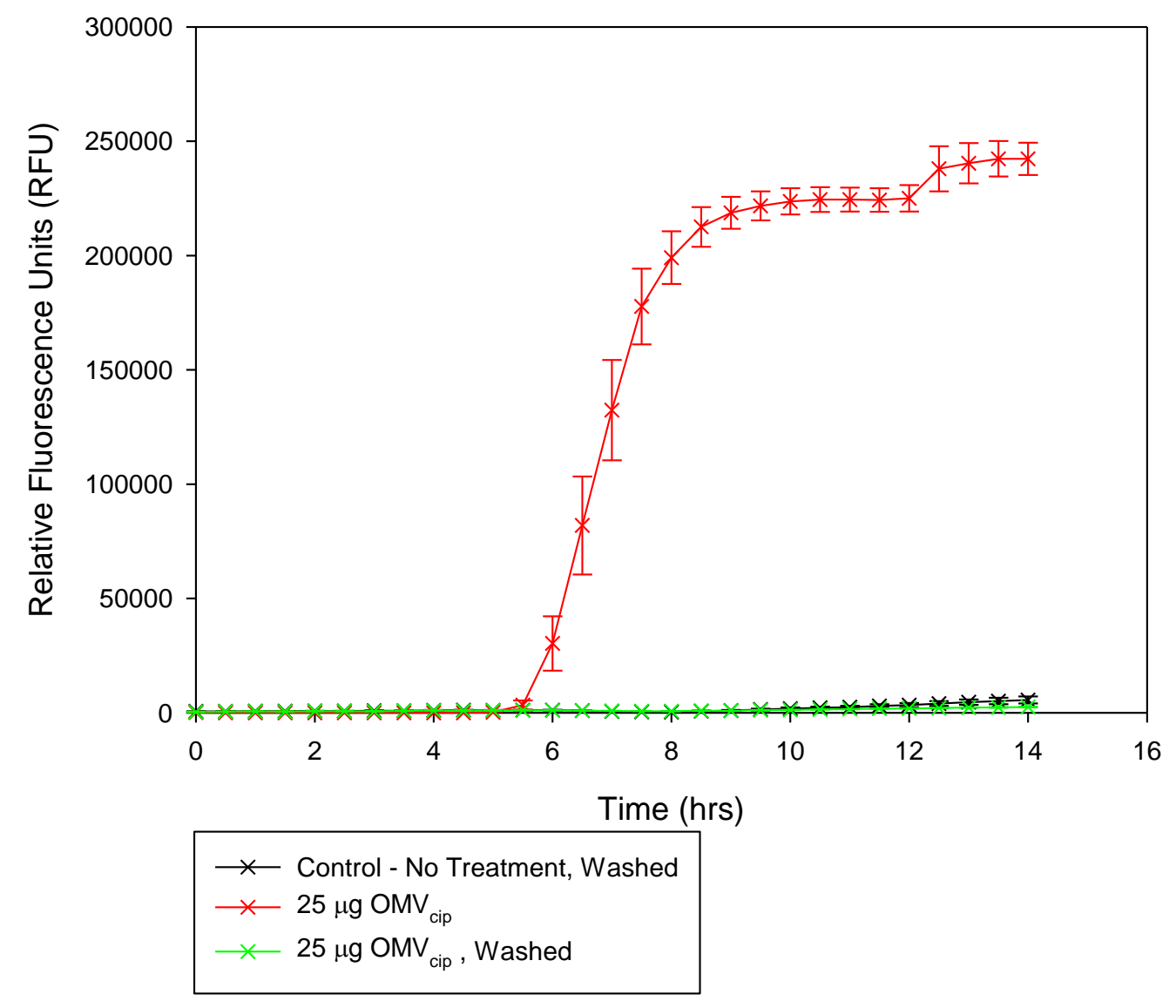

Figure 24: Analysis of PAO1 pyoverdine production after $2 \mathrm{hr}$ pre-incubation with $25 \mu \mathrm{g} O M V_{\text {cip }}$ before being washed with LB to remove OMVcip

PAO1 cells were pre-incubated for 2 hrs with or without OMV cip before being centrifuged for 2 mins at 16,000 $\mathrm{x} g$ and washed with LB. Cells were then re-suspended in $2.5 \mathrm{x}$ the volume of $\mathrm{LB}$ to wash before a $10 \mu \mathrm{L}$ inoculum was seeded into $190 \mu \mathrm{L}$ of LB. A comparative sample with $25 \mathrm{OMV}_{\text {cip }}$ present was included as a reference for OMV cipmediated effects. Pyoverdine production was insignificant in both pre-incubated control \& OMV cip cultures. Data shown is from 2 independent experiments conducted in triplicate. 


\section{$\underline{3.10 \text { Analysis of PI staining of PAO1 cells by flow-analysis }}$}

Results from growth experiments with PAO1 showed that $\mathrm{OMV}_{\text {cip }}$ treatment caused a significant decrease in the final culture density. We hypothesized that this was due to cells entering dormancy and maybe forming persister cells which are characterised as having a decreased pmf due to a lower metabolic state and in theory, persister cells should show increased PI staining. To investigate this analysis by flow cytometry was performed using PI staining to examine the effect $\mathrm{OMV}_{\text {cip }}$ has on PI accumulation. PI is a dye that fluoresces upon intercalation with nucleic acid and is normally excluded by healthy, metabolically active cells due to lack of membrane permeability and efflux pump activity. However upon cell death, decreased efflux activity or depolarisation of the cell membrane, PI can enter the cell and bind nucleic acids (Nebe-vonCaron, Stephens, Hewitt, Powell, \& Badley, 2000).

PAO1 cells were incubated for $2 \& 4$ hrs either in the absence or presence of $125 \mu \mathrm{g} / \mathrm{mL}$ of $\mathrm{OMV}_{\text {cip }}$ (the equivalent concentration used in previous experiments in this study) before being diluted 100-fold in PBS and stained for 5 mins with PI before analysed by flow (Fig 25). A gate (H1) was set that defined the population of cells that were PI negative and a second gate (H2) was set to identify cells which were PI positive. PAO1 cells that did not receive OMV cip treatment showed little to no PI staining as seen by a lack of a peak in H2 (Fig 28). Treatment with $\mathrm{OMV}_{\text {cip }}$ for either $2 \mathrm{hrs}$ or $4 \mathrm{hrs}$ increased the proportion of cells that stained positive for PI which can be detected as the presence of a peak in H2 (Fig 25) which was observed in all cultures treated with $O M V_{\text {cip }}$.

Comparison of the proportion of PAO1 cells that are PI positive to those that are PI negative in control \& treatment cultures, shows an increase in PI staining after treatment with $O M V_{\text {cip }}$ in which $20.8 \%$ and $18.8 \%$ of cells staining positive for PI compared to control cultures which had values of $4.1 \%$ and $3.6 \%$ PI positive, for $2 \mathrm{hrs} \& 4 \mathrm{hrs}$ respectively (Fig 26). The statistical significance of this result could not be determined by student's t-test $(\mathrm{P}>0.05)$ as there was 
significant variation in the level of PI staining between $\mathrm{OMV}_{\mathrm{cip}}$-treated replicates. However, despite this an increase in the proportion of cells that were PI positive was seen in all cultures that were treated with $O M V_{\text {cip }}$ compared to controls indicating that $O M V_{\text {cip }}$ increases PI accumulation in PAO1.

$\mathrm{OMV}_{\text {cip }}$ causes an increase in the number of cells that stain with PI. However, it is unclear whether this is due to OMVs inducing a drop in the PMF or increasing 'leakiness' upon OMV fusion. It is also possible the OMVs are causing cell death, resulting in an increase in cells that are PI positive. 
Control $2 \mathrm{hr}$

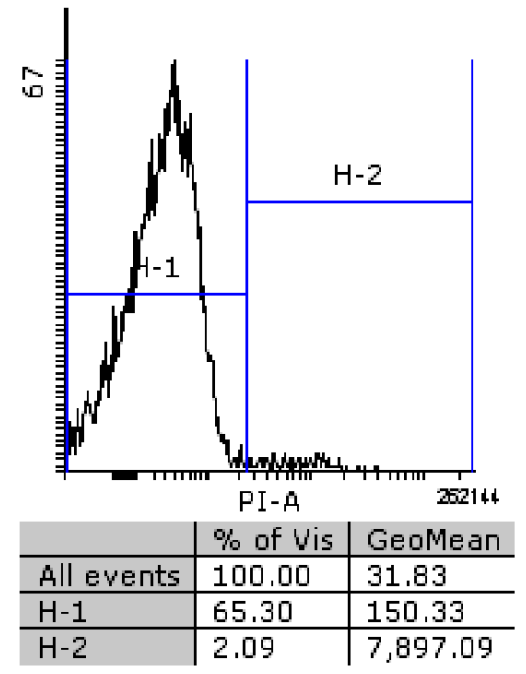

$25 \mu \mathrm{g} O \mathrm{OVV}_{\text {cip }} 2 \mathrm{hr}$

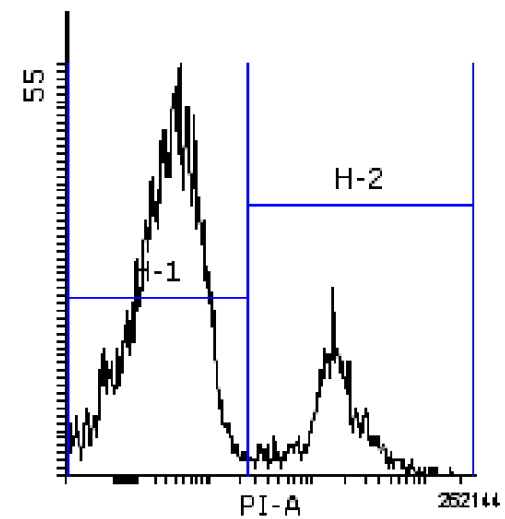

\begin{tabular}{l|l|l} 
& $\%$ of Vis & GeoMean \\
\hline All events & 100,00 & 85,69 \\
\hline $\mathrm{H}-1$ & 57,94 & 177,03 \\
\hline $\mathrm{H}-2$ & 15,01 & $15,792.90$
\end{tabular}

Control $4 \mathrm{hr}$

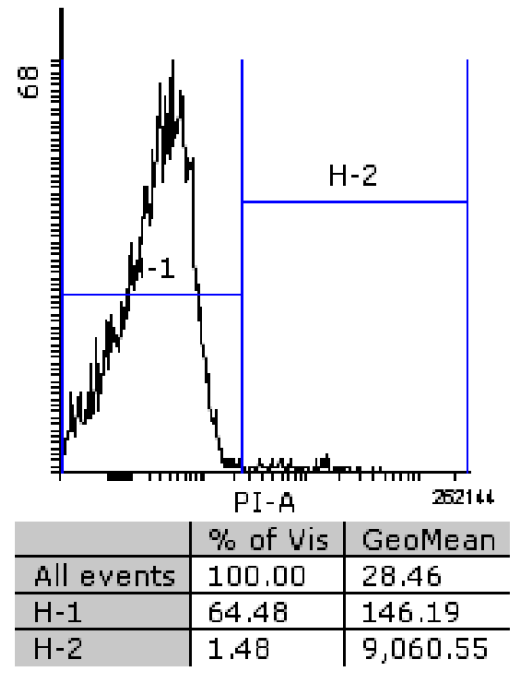

$25 \mu \mathrm{g} \mathrm{OMV}$ cip $4 \mathrm{hr}$

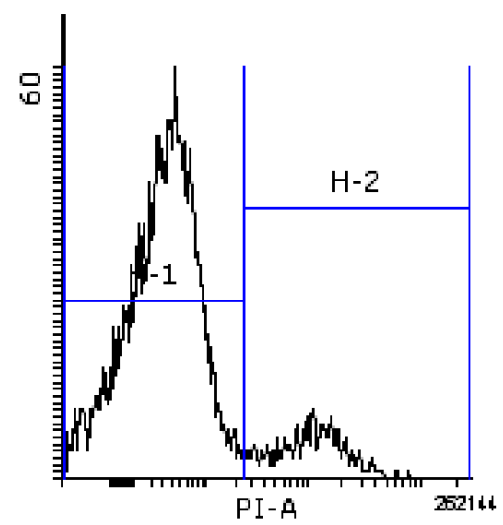

\begin{tabular}{l|l|l} 
& $\%$ of Vis & GeoMean \\
\hline All events & 100,00 & 54,55 \\
\hline $\mathrm{H}-1$ & 61,63 & 173,96 \\
\hline $\mathrm{H}-2$ & 8,87 & $10,292,04$
\end{tabular}

Figure 25: Analysis of PI staining of PAO1

PAO1 cells were incubated with $125 \mu \mathrm{g} / \mathrm{mL}$ of $\mathrm{OMV}_{\text {cip }}$ (concentration equivalent of that used in the growth/pyoverdine assays) for either $2 \mathrm{hrs}$ or $4 \mathrm{hrs}$ at $37^{\circ} \mathrm{C}$ and were paired with a control before being incubated with PI for $5 \mathrm{~min}$ and then flow-analysed. H1 gate determines cells that are PI -ve, H2 gate determines cells that stain PI +ve. Control groups lack a significant peak in the H2 gate set, indicating little to no PI staining present which is due to lack of cell-membrane permeability. Incubation with $\mathrm{OMV}_{\text {cip }}$ causes a peak to appear in the $\mathrm{H} 2$ gate, indicating increased PI staining. Experiment was conducted in triplicate. Data shown is representative of an average result. 


\section{Effect of $\mathrm{OMV}_{\text {cip }}$ on PI staining in PAO1 cells}

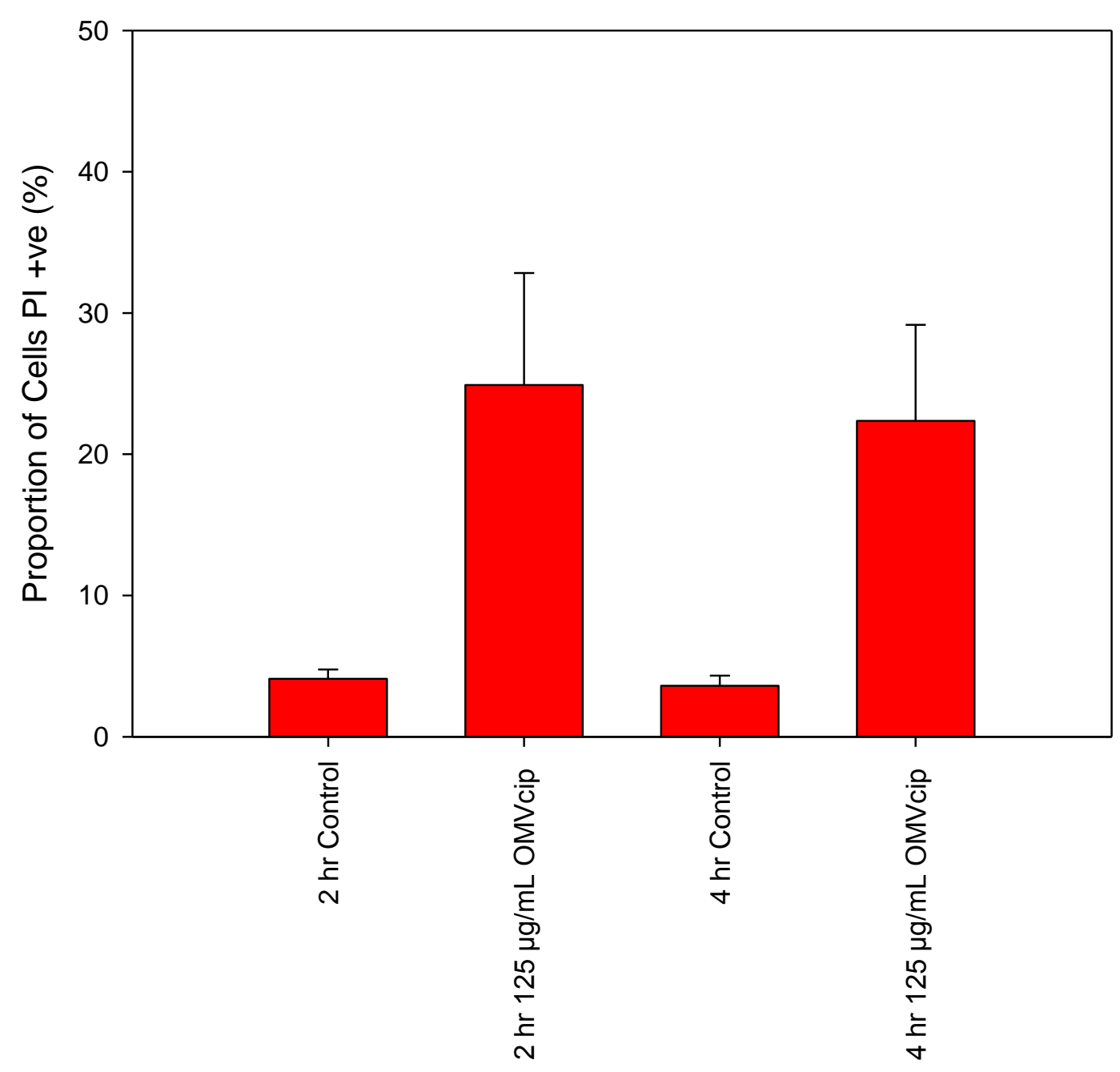

Figure 26: Proportion of PAO1 cells stained PI positive

PAO1 cells were incubated with $125 \mu \mathrm{g} / \mathrm{mL}$ of $\mathrm{OMV}_{\text {cip }}$ (concentration equivalent of that used in the growth/pyoverdine assays) for either $2 \mathrm{hrs}$ or $4 \mathrm{hrs}$ at $37^{\circ} \mathrm{C}$ and were paired with a control before being incubated with PI for $5 \mathrm{~min}$ and then flow-analysed. Cultures incubated for $2 \mathrm{hrs} \& 4 \mathrm{hrs}$ showed an average proportion of PI positive cells of $24.9 \pm$ $7.9 \%$ and $22.4 \pm 6.8 \%$ respectively ( $\mathrm{n}=3$, mean \pm SEM). Control groups of $2 \mathrm{hr} \& 4 \mathrm{hr}$ incubations had an average proportion of PI positive cells of $4.1 \pm 0.7 \%$ and $3.6 \pm 0.7 \%$ $\left(\mathrm{n}=3\right.$, mean \pm SEM). Due to relatively the high level of variation of PI staining in $\mathrm{OMV}_{\text {cip }}$ groups, statistics could not determine whether results are significant (student's t-test, $2 \mathrm{hr} p$ $=0.059,4 \mathrm{hr} \mathrm{p}=0.052$ ), however in all experiments an increase in PI staining was seen in all OMV-treated groups. The difference in proportion of cells that stained positively for PI between controls and OMV-treated cultures were $20.8 \%$ and $18.8 \%$ for $2 \mathrm{hr} \& 4 \mathrm{hr}$ time points respectively. Data shown is from 3 independent experiments. 


\section{$\underline{3.11 \text { Analysis of OMV }}$ ciptreatment on PAO1 colony morphology and antibiotic}

tolerance

The increase in membrane permeability upon treatment of PAO1 cells with $O M V_{\text {cip }}$, suggested potential cell death occurring and did not confirm whether $O M V_{\text {cip }}$ stimulated persister cell formation. To investigate this, PAO1 cells were incubated in the absence or presence of 125 $\mu \mathrm{g} / \mathrm{mL}$ of $\mathrm{OMV}_{\text {cip }}$ for $2 \mathrm{hrs}$ before a sample of the culture was serially diluted and the resulting dilutions were spotted onto a LB agar plate. This was to investigate both the effect $\mathrm{OMV}_{\text {cip }}$ has on colony morphology and as a CFU reference prior to antibiotic treatment. The remaining cultures were then treated with $5 \mu \mathrm{g} / \mathrm{mL}$ of ciprofloxacin for 3 hrs before being washed in LB three times and then serially diluted and plated. This was to identify the presence of any persister cells which would survive the high-dose antibiotic treatment.

Analysis of colonies formed from the cultures prior to ciprofloxacin treatment (Fig 27) showed control cultures forming a uniform 'lawn' with the density of the 'lawn' decreasing in each dilution as expected. Colonies formed from cultures treated with $O M V_{\text {cip }}$ prior to ciprofloxacin treatment formed plaque-like 'lawns' with irregular borders with areas of clearing. These are most evident in dilutions $4,5 \& 6$. The density of the 'lawn' increases with each dilution up until the $7^{\text {th }}$ dilution in the series whereby a decrease in lawn density then begins to occur with each subsequent dilution suggesting there is an initial carry over of $\mathrm{OMV}_{\text {cip }}$ onto the plate.

Both cultures plated out after ciprofloxacin treatment failed to form colonies (Data not shown) in any of the dilutions in both attempts and subsequently analysis of persister formation was unsuccessful. 


\section{Colony morphological analysis of PAO1 after treatment with $\mathrm{OMV}_{\text {cip }}$}

\section{$125 \mu \mathrm{g} / \mathrm{mL} O \mathrm{OMV}_{\text {cip }}$}
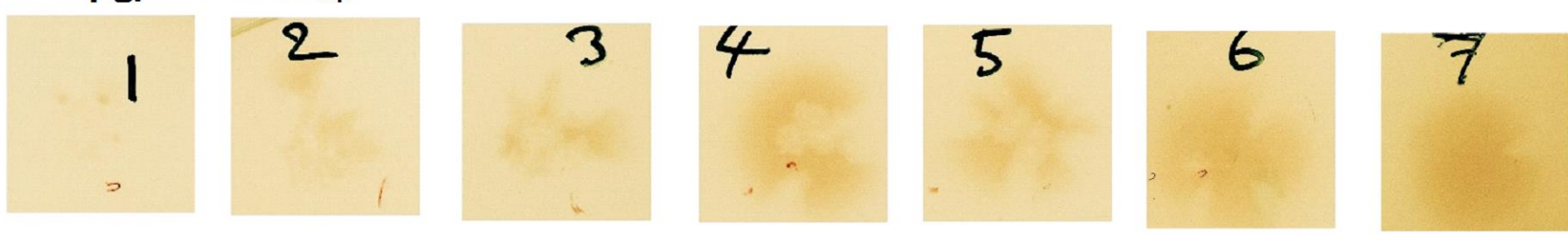

\section{Control - No Treatment}
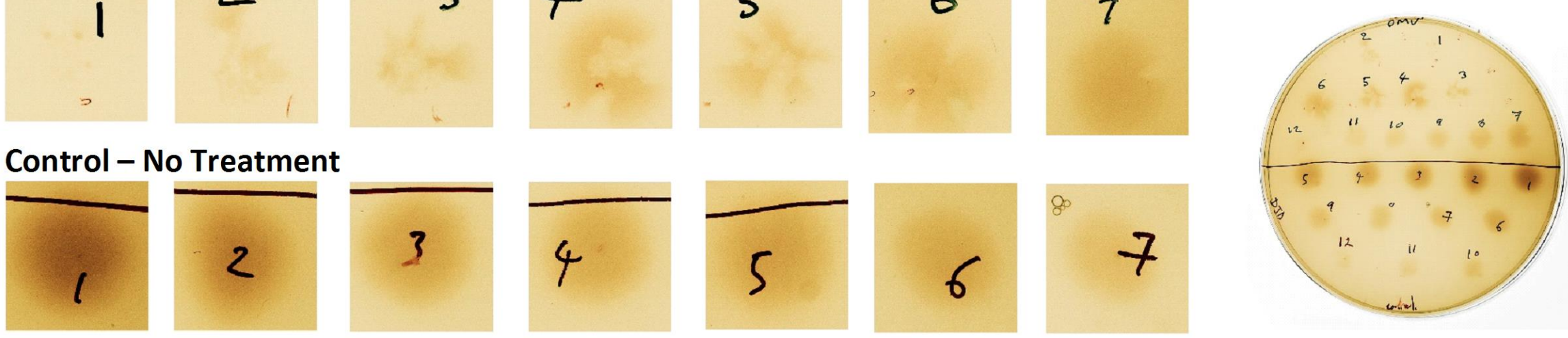

Figure 27: Comparison of colony morphology of PAO1 incubated for 2 hrs with $\mathrm{OMV}_{\text {cip }}$

PAO1 cells were incubated with $125 \mu \mathrm{g} / \mathrm{mL}$ of $\mathrm{OMV}_{\text {cip }}$ (concentration equivalent of that used in the growth/pyoverdine assays) for 2 hrs and was paired with a control (No treatment). Dilution 1 corresponds to a 1 in 100 dilution of the culture and subsequent (dilutions 2-7) represent a two-fold dilution of the previous dilution. $10 \mu \mathrm{L}$ spots of each dilution were dropped onto LB agar and allowed to dry before plates were incubated for 12 hrs at $37^{\circ} \mathrm{C}$ before being photographed. Treatment with $\mathrm{OMV}_{\text {cip }}$ resulted in reduced colony density compared to controls in dilutions 1-6. Colonies treated with $\mathrm{OMV}_{\text {cip }}$ formed plaques with irregular edges. Plate shown is a representative result obtained from 2 independent experiments. Additional plate can be seen in appendix section (Fig 30). 


\section{Discussion}

\subsection{Optimization of OMV Isolation Protocol}

Originally the intended scope of this study was to include comparing the effects of OMVs on growth from those natively produced $\left(\mathrm{OMV}_{\mathrm{n}}\right)$ and those produced under low-dose ciprofloxacin treatment $\left(O M V_{\text {cip }}\right)$. Difficulty in preparing sufficient quantities of $O M V_{n}$ because of the

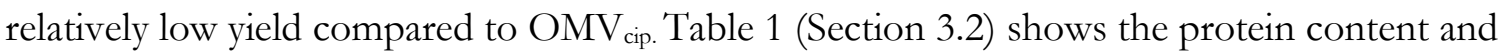
yield of $O M V_{n}$ is significantly less than that obtained from ciprofloxacin treated cultures. Other studies that have struggled to prepare sufficient yields of $O M V_{n}$, have increased the yield through sonification or detergent treatment (Kulp \& Kuehn, 2010). Results from these studies must be interpreted cautiously as these techniques alter the composition of the OMVs and therefore cannot be truly recognised as being natively produced OMVs.

Attempts to scale up the OMV preparations were made by increasing the culture volume from which the OMVs were derived from. Scaling up beyond $250 \mathrm{~mL}$ in a $2 \mathrm{~L}$ conical flask had the effect of reducing OMV yields (data not shown) due to a combination of reduced aeration and increased cell death. After identifying that aeration was a limiting factor, the cultures were scaled back to a maximum of $250 \mathrm{~mL}$ culture per flask and attempted to increase the yield by increasing the incubation period of the culture prior to isolation.

The period within the growth phase at which OMVs are maximally produced, is contensious with some researchers claiming they are predominately produced in the exponential phase (Schwechheimer \& Kuehn, 2013) whilst others claim that this occurs in the stationary phase (McCaig et al, 2013). No studies to date have compared OMV yields between species during the various phases of growth and thus the growth phase which OMVs are predominately produced could possibly vary amongst species. It is also worth noting that the composition of OMVs produced in log-phase compared to that in stationary phase is distinctly different (Tashiro et al., 2010). In addition to this, OMV isolations obtained from stationary- 
phase cultures are more likely to include components of lysed bacteria such as pili, flagella or genomic DNA (Kadurugamuwa \& Beveridge, 1995).

Isolation of OMVs from P. aeruginosa cultures grown for 36 or 48 hrs (stationary phase reached $\sim 18 \mathrm{hr}$ ) was attempted to try and increase OMV yield, however increasing the culture growth time led to an increase in lysed bacteria that made the cell-free supernatants difficult to filter through $0.45 / 022 \mu \mathrm{m}$ membranes. Long culture times ( $>24 \mathrm{hrs}$ ) were abandoned even though it appeared to increase OMV yield, as longer culture times also increased the amount of lysed bacterial components present.

Quantification and subsequent standardization of OMV isolates is important when examining the biological properties to ensure the phenomena observed are robust and repeatable. Unfortunately, each methodology for standardizing OMV preparations presents its own unique set of problems. In this study, OMV preparations were initially standardized relative to the culture volumes they were derived from. However, due to variation between independent preparations, some OMV preparations showed greater biological activity than other preparations, thus a need for a direct measurement of what was in the isolate was required to enable consistent reproducible results. Standardization of OMV preparations is typically done by either protein quantification (such as Bradfords or BCA assay) (Parker et al, 2010) or various lipid quantification assays (such as total lipid quantification by lipophilic fluorescent probes or by $\mathrm{O}$ band antigen quantification) (MacDonald \& Kuehn, 2013).

A nile red assay was utilized with a bacterial lysate standard as a cheap, high-throughput alternative to $\mathrm{O}$ band antigen quantification for lipid quantification (Genicot et al, 2005). However, the nile red assay was not sufficiently sensitive to detect samples if they were not sufficiently concentrated and thus was unsuitable. As BCA protein quantification is highly sensitive $(2 \mu \mathrm{g} / \mu \mathrm{L}$ to $25 \mathrm{ng} / \mu \mathrm{L}$ of protein) it seemed appropriate to use protein quantification for standardization purposes. OMVs contain redox-active components 
such as PQS which initially were a problem as these compounds function as reducing agents in the assay and cause a falsely strong signal to be detected. To combat this, chloroform-methanol protein extractions were performed on samples to achieve accurate readings of the protein content present. OMV protein/lipid ratio can be vastly different depending on the conditions under which it was generated from and therefore, standardizing by protein or lipid is not the most optimal method. If possible, a direct measurement of the number of particles present would be the most appropriate methodology to standardize between preparations. This could be achieved through rigorous counting of samples under EM or through use of a conductive nano pore machine such as the qNano. 


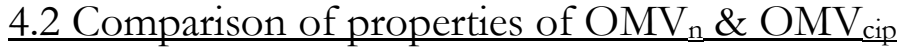

Size comparison by DLS of $\mathrm{OMV}_{\mathrm{n}} \& \mathrm{OMV}_{\text {cip }}($ Fig 6A) suggested that there was no significant difference in size between the two OMV subtypes which was unexpected. Previous studies had reported that antibiotic treatment increases both OMV yield and size (Nguyen et al., 2003). Both the size of the pores \& type of membrane used to filter the culture supernatants, can affect the OMV yield and thus it is important to select a pore size that will exclude bacteria but will not exclude a large proportion of the OMVs produced. Development of OMV-based vaccines has shed light on what components of the isolation process can affect the resulting OMV isolate.

Due to the ability of OMVs to form aggregates in suspension, a significant decrease $(\sim 50 \%)$ in yield has been seen when attempting to use a $0.22 \mu \mathrm{m}$ pore size instead of $0.45 \mu \mathrm{m}$ or larger in the production of a OMV-based meningococcal vaccine (Gorringe et al., 2005). We hypothesized that the lack of size difference between $\mathrm{OMV}_{\mathrm{n}}$ \& $O M V_{\text {cip }}$ seen in Fig 6A, was a result of larger OMVs or OMV aggregates being excluded from the filtrate as the filters used were $0.22 \mu \mathrm{m}$. Thus the protocol was optimized to use $0.45 \mu \mathrm{m}$ filters which both increased the yield of OMVs \& allowed us to detect the size difference between $O M V_{n} \& O M V_{\text {cip }}($ Fig 6B). However, the caveat of this optimization is the $0.45 \mu \mathrm{m}$ syringe filters used to sterilely process the OMV samples in the final step, had significant retention of $O M V_{n}$ samples which was noted due to staining of the filter membrane upon processing the isolate (Fig 29 in Appendix).

Further optimization of the isolation protocol is needed if a further study into $\mathrm{OMV}_{\mathrm{n}}$ is to be conducted in future as the combination of extremely low yields (as detected by protein content via $\mathrm{BCA}$ assay) \& filter retention make it unfeasible to produce sufficient quantities of $O M V_{\mathrm{n}}$ to analyse in many biological assays. 


\section{$\underline{4.3}$ Presence of cytochrome $\mathrm{c}$ in $\mathrm{OMV}_{\text {cip }}$}

Analysis of the absorption spectra of $O M V_{\text {cip }}$ showed two peaks of 520 and $550 \mathrm{~nm}$ (Fig 8) that could upon addition of the oxidizer APS, decreased the peak intensity after $10 \mathrm{~min}$. This confirmed that the peak signature was due to the presence of cytochrome c. Furthermore, SDSPAGE analysis of $\mathrm{OMV}_{\text {cip }}$ (Fig 11) yielded two protein bands of $\sim 20-25 \mathrm{kDa}$ and $\sim 15-20 \mathrm{kDa}$ that upon reference to previous studies, are likely to be pseudomonas cytochrome c proteins (Pettigrew \& Moore, 1987). Interestingly, the cytochrome c bands were not present in $\mathrm{OMV}_{\mathrm{n}}$ isolates.

This shows that OMVs can contain functional proteins that may be able to be delivered to recipient cells. The biological significance of the presence of cytochrome $\mathrm{c}$ in $\mathrm{OMV}_{\text {cip }}$ is currently unknown but we speculate it may be incorporated into the OMVs as a virulence factor by mimicking mitochondrial cyt $\mathrm{c}$ release in eukaryotic cells upon fusion, which initiates the caspase pathway inducing apoptosis (Jiang \& Wang, 2004). 


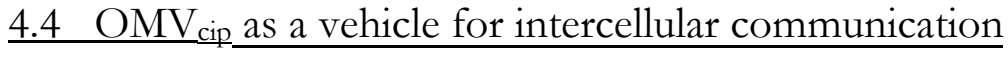

Previous studies have identified quorum sensing molecules in OMV preparations from P. aeruginosa such as PQS (along with other similar quinone compounds) with trace amounts of the acyl-HSL molecules 3OC12-HSL and C4-HSL (Mashburn \& Whiteley, 2005).

Mashburn \& Whiteley used the P. aeruginosa deletion strain $p q s H$ to investigate the presence of quorum sensing molecules in OMVs. The $p q s H$ mutant is deficient in the enzyme required for catalysis in the final step of PQS biosynthesis and as PQS regulates transcription of genes required for production of pyocyanin, the $p q s H$ mutant is deficient in pyocyanin production unless PQS is added from an external source. Mashburn \& Whiteley found that OMVs induced pyocyanin production in the $p q s H$ mutant at comparable levels to when exogenous synthetic PQS was added to the culture thus concluding that the delivery of PQS present in OMVs, is sufficient to induce a physiological response and as such, OMVs could potentially serve as vehicles for intercellular communication.

In this study, $\mathrm{OMV}_{\text {cip }}$ was shown to reduce $\mathrm{PAO} 1$ growth rate causing cultures to achieve a significantly lower cell density in stationary phase (14hr) (Fig 13). This ability for OMV cip to significantly alter the growth kinetics of PAO1 is characteristic of a 'switch' being inducted through a signalling mechanism present on or within the OMV itself. In addition to this, $O M V_{\text {cip }}$ induced production of the siderophore, pyoverdine in PAO1 (Fig 17).

The production of pyoverdine by $P$. aeruginosa is highly correlated to a state of iron-starvation (Visca et al, 2007) and has so far, not been recorded to have a role in communicating growth arrest in P. aeruginosa. Thus, although both early growth arrest and pyoverdine production occur in PAO1 cultures in the presence of $\mathrm{OMV}_{\text {cip }}$, it is highly unlikely that the production of pyoverdine is the causative agent for the growth arrest but rather an indication that a signal has been delivered to the culture by $\mathrm{OMV}_{\text {cip. }}$ 
Pyocyanin is well-documented for its role as a virulence factor where it functions as a redox agent that can generate high levels of reactive oxygen species (Hassett et al, 1992; Kerr et al., 1999; Lau et al, 2004). Additionally, pyocyanin functions as a signalling molecule in P. aeruginosa by activating transcription of a set of genes called the PYO stimulon (Nadal Jimenez et al., 2012). Functional roles of these genes range from involvement of redox activities, efflux pump regulation, iron acquisition (Nadal Jimenez et al., 2012) and key genes involved in the regulatory network of PQS and phenazine biosynthesis (Déziel et al., 2005). The complex relationship between PQS, OMVs \& pyocyanin made pyocyanin seem a potential candidate for the putative signalling mechanism seen with $\mathrm{OMV}_{\text {cip }}$ so attempts were made in this study to determine the effect a. crude organic extract of pyocyanin from conditioned growth media, would have on the growth kinetics of PAO1. However, issues with quantifying the amount of pyocyanin present as well as the crude nature of the extract meant multiple non-polar molecules would be present in the isolated organic phase would make interpretation impossible and thus was abandoned early on in the study.

Further investigation into potential mechanisms were carried out by attempts to 'inactivate' $\mathrm{OMV}_{\text {cip. }} O \mathrm{OMV}_{\text {cip }}$ was heated at $75{ }^{\circ} \mathrm{C}$ for 25 mins to denature proteins potentially involved in mediating the effects seen from $\mathrm{OMV}_{\text {cip. }}$ Toxin-antitoxin systems have been well-characterised in P. aeruginosa and have roles that regulate gene expression, persister formation and programmed cell arrest (F. Hayes, 2003; Wang \& Wood, 2011) and it was possible that OMV cip could be acting through delivery of a toxin-type protein that could programme cell arrest. However, this is unlikely as no reduction in the effect of $\mathrm{OMV}_{\text {cip }}$ to alter growth kinetics or pyoverdine production was seen after heat treatment (Fig $19 \& 20$ ), suggesting a small molecule or non-heat labile factor to be involved in mediating the effects of $\mathrm{OMV}_{\text {cip }}$ and unlikely to be a protein-based messenger. 
Disruption of $O M V_{\text {cip }}$ membranes was carried out through the addition of chloroform to disrupt the OMV membrane which would cause hydrophilic contents to become unpackaged and therefore in theory, less effective as the effective concentration delivered to cells would be much lower. Chloroform disruption was mostly successful at preventing the effects of $O M V_{\text {cip }}$ on growth, with only a slight decrease in final culture density that could potentially be for the aforementioned reasons (less effect due to signalling molecule being hydrophilic and thus at a lower effective concentration) or possibly due to residual chloroform present which may have been slightly bacteriostatic.

Interestingly however, chloroform disruption of $\mathrm{OMV}_{\text {cip }}$ did not prevent the induction of pyoverdine during growth. This suggests that two separate mechanisms are at play and that the effect of $\mathrm{OMV}_{\text {cip }}$ on growth kinetics and induction of pyoverdine production may not be intrinsically linked by the same signalling messenger delivered by the OMVs. Membranedisruption eliminated most of the effect of $\mathrm{OMV}_{\text {cip }}$ on growth whilst heat inactivation did not, suggesting a hydrophilic molecule or membrane-bound complex, is responsible for attenuation of growth kinetics but conversely, both heat-inactivation \& chloroform disruption failed to prevent the induction of pyoverdine production. This suggests that the signalling messenger responsible for the induction of pyoverdine production is likely to either be a hydrophobic molecule or fatty acid.

As previously mentioned, trace amounts of the hydrophobic quorum molecule family, acyl-HSL, have been detected in OMVs produced by P. aeruginosa (Mashburn \& Whiteley, 2005). Of the acyl-HSL family, C4-HSL \& 3-oxo-C12-HSL are the most well characterised in P. aeruginosa. Studies have shown a reasonable proportion of the P. aeruginosa genome (2-10\% of total genes) are regulated by acyl-HSL dependent quorum-sensing control (Sio et al., 2006). The $P$. aeruginosa gene $p v d Q$ has encodes a periplasmic protein that functions as an acylase, capable of degradation of acyl-HSL molecules causing quorum-quenching (Huang et al, 2003) 
and also plays a key role in the biosynthesis of pyoverdine by hydrolysis of the fatty acid tail in the final steps (Kem \& Butler, 2015). A study utilizing a mutant P. aeruginosa promoterless lac $Z$ transposon library showed acyl-HSL induction of $p v d \mathrm{Q}$, indicating a role in quorum sensing of acyl-HSL (Whiteley, Lee, \& Greenberg, 1999).

The autoinducer molecule, Pseudomonas quinolone signal (PQS) is present in high concentrations in P. aeruginosa OMVs (Mashburn \& Whiteley, 2005) as PQS both facilitates its own insertion into the outer-membrane and increases OMV production by causing an increase in membrane curvature (Schwechheimer \& Kuehn, 2015). Furthermore, PQS induces pyoverdine production when added to growth media containing $P$. aeruginosa by stimulating upregulation of the pyoverdine regulation \& biosynthesis genes $p v d S$, $p v d A \& p v d E$ (Diggle et al., 2007). PQS is also a hydrophobic moiety and would retain activity upon chloroform-mediated membrane disruption given the likelihood of the $\mathrm{OMV}_{\text {cip }}$-mediated induction of pyoverdine production being a hydrophilic molecule and the link between pyoverdine production, the enzyme PvdQ \& its role in quorum sensing of acyl-HSL \& the interplay between PQS and pyoverdine production it is possible that an acyl-HSL compound or PQS is responsible for this.

A speculative mechanism by which $\mathrm{OMV}_{\text {cip }}$ induces pyoverdine production in $P$. aeruginosa is either through delivery of acyl-HSL or PQS quorum molecules, initiating increased expression of pyoverdine regulatory \& biosynthesis genes which then subsequently degrades the OMV-derived acyl-HSL to produce pyoverdine or by directly increasing the level of enzymes required for pyoverdine synthesis in the case of PQS. Although Mashburn \& Whiteley concluded levels of acyl-HSL moieties were extremely low in the OMVs they derived from P. aeruginosa and thus mainly focused on PQS, they generated their OMVs natively. Whereas the OMVs used in the pyoverdine studies within this thesis, were generated under ciprofloxacin treatment.

As shown in this study, the difference in lipid composition of $O M V_{n}$ between $O M V_{\text {cip }}$ can be seen both by eye (yellow vs orange/brown colouration) when the OMV pellets are isolated and 
under EM, with OMV cip having a 'ruffled' appearance around their outer-membrane. Therefore, it is possible that the OMVs generated under treatment of ciprofloxacin contain a higher concentration of acyl-HSL compounds compared to natively produced OMVs as well as having an increase concentration of PQS from induction of the SOS response from the sub-lethal ciprofloxacin treatment. This would explain why OMV-mediated pyoverdine production does not occur when PAO1 cells were pre-incubated with OMVs and only occurs when the OMVs are present in the culture media (Fig $22 \& 24)$. 


\subsection{A role for OMVs in cell fate determination}

It is generally accepted that bacteria exhibit the ability to replicate continuously if sufficient nutrients are present, compared to non-cancerous mammalian cells that display a limited capacity to divide, entering into senescence as they reach the hayflick limit. However, bacterial growth can be inhibited in a similar manner to cellular senescence by the accumulation of the toxin component of TA modules. The toxin component is considered stable whilst the anti-toxin component is unstable. The anti-toxin is required to be constitutively produced in sufficient quantities to prevent the toxin from inhibiting targets involved in cellular processes such as DNA translation \& synthesis and biosynthetic pathways (Bernard \& Couturier, 1992; Gerdes, 2000). Upon cell division, if the daughter cells do not inherit the genes required to produce the antitoxin, growth is inhibited and potentially cell death can occur (Hayes \& Sauer, 2003). This phenomenon is known as post-segregationally killing (PSK). Treatment of PAO1 cultures with $O M V_{\text {cip }}$ resulted in significantly reduced culture density after 14 hrs indicating that $O M V_{\text {cip }}$ cause growth inhibition (Fig 13). There was no change in the lag phase experienced in OMV-treated cultures which suggested that $\mathrm{OMV}_{\text {cip }}$ is not immediately killing PAO1 cells and that a form of PSK may be occurring or a decrease in growth efficiency upon OMV fusion.

Furthermore, pre-incubation of PAO1 with $\mathrm{OMV}_{\text {cip }}$ followed by washing and dilution to remove OMVs still present in the culture medium, caused the growth inhibition effect of OMV cip to be have a greater effect resulting in a final culture density lower than that of cultures grown in the presence of OMVs in the culture media (Fig $21 \& 23$ ). No increase in the lag-phase was noted compared to control cultures that were washed in the same manner, which means the same inoculum size was used post-washing. Pre-treated cultures plateaued at a lower cell density than both controls and cultures grown in the presence of $\mathrm{OMV}_{\text {cip }}$ in the culture media. This shows that $\mathrm{OMV}_{\text {cip }}$ is not required to be present in the culture medium during growth to alter the 
growth kinetics of the culture and that a $2 \mathrm{hr}$ incubation with $\mathrm{OMV}_{\text {cip }}$ is sufficient to cause attenuation of growth. It is assumed that OMV fusion with cells occurred within this period.

We hypothesize that the starting inoculum from PAO1 cells that had been pre-incubated with $O M V_{\text {cip }}$ would have initially a greater proportion of the population that had fused with $O M V_{\text {cip }}$ compared to cells that had OMV cip present in the culture media.

If $\mathrm{OMV}_{\text {cip }}$ were delivering a factor that acted in a manner that predetermined a replicative limit in future progeny, this would result in a reduction in cell growth and subsequent final culture density similar to that seen in this study (Fig 13, 21, 23). Pre-incubation with $\mathrm{OMV}_{\text {cip }}$ would have an initial increase in the proportion of cells that have received the inhibitory factor compared to cells that experience OMV fusion in the culture media during growth, causing all cells in the preincubatory culture to have a pre-set division limit. This would cause a greater proportion of cells to experience growth inhibition and would result in a much lower culture density due to entry into stationary-phase earlier.

Cultures that were exposed to OMV cip in the culture media would show a level of growth inhibition but it would not be as great, as the growth of cells that have not fused with OMVs may be able to outpace the increase in cells that have received the inhibitory factor from $O M V_{\text {cip }}$ and thus although the proportion of cells that have received the inhibitory factor may increase as time progresses throughout growth, at any given point in time the proportion of these cells will be much less than those that were pre-incubated with OMVs.

These results show that OMVs are capable of attenuating growth on a population-wide scale and may serve as a mechanism for fate-programming, imposing a division limit on cells analogous to the eukaryotic Hayflick limit. As this is a newly discovered phenomenon, we have coined this as the 'Dayflick limit' after my supervisor, Dr D J Day. 
However, further investigation is required to determine whether cells that fuse with OMVs are still replicative and/or have altered growth kinetics and if they are programmed by OMV fusion, how many subsequent divisions occur before 'senescence' is achieved. It is also not clear what the duration of this effect is and how the programming is erased, to allow resumption of growth when more favourable growth condition are encountered. The benefit of producing vesicles that inhibit or limit population growth would seem to be a disadvantageous but may represent a communal/altruistic behaviour for the greater good that benefits the population. The senescentlike phenotype described in this thesis has much in common with the persister phenotype which many bacteria induce as a putative mechanism from environmental stressors such as antibiotic treatment. The reduced metabolic activity and decreased pmf of persister cells, is similar to that seen in this study and may be the same as the senescent phenotype described in this thesis.

Evidence of altruistic behaviours in bacteria that benefit the bacterial community, can be seen by the formation of persister cells which is mediated by stochastic mechanisms in which fluctuations in gene expression causes a subpopulation of genetically identical cells to enter a temporary transient growth-arrested state (Veening et al., 2008) and represents a bet-hedging strategy. Cells can switch from persister phenotype to resume normal growth and vice versa. The benefit conferred from this to the population, becomes apparent in the presence of an environmental stressor such as nutrient deprivation or antibiotic exposure.

Cells exhibiting the persister phenotype can survive high concentrations of antibiotics for extended periods of time due to their slow/lack of growth, in conjuncture with other cellular changes such as upregulation of efflux pumps. Actively growing cells are killed by antibiotic, whereas persister cells utilize a waiting strategy, in which growth can be resumed under more favourable conditions. Consistent with previous reports that have shown that stimulating OMV production in $P$. aeruginosa, is markedly increased in response to exposure of sub-MIC concentrations of an antibiotic (i.e. ciprofloxacin) or stressor. We speculate that the OMVs 
$\left(\mathrm{OMV}_{\text {cip }}\right)$ fuse with naïve $P$. aeruginosa bacteria to deliver a signal that communicates previous growth in a hostile environment to the bacterium to prepare for a harsh environment, thereby limiting cell growth or inducing persister formation to increase the survival odds of the population as a whole.

Further elucidation of OMV-mediated growth inhibition is needed to understand the mechanisms at play and the physiological relevance of stress-induced OMVs in $P$. aeruginosa. It is not yet apparent whether OMVs produced by a stressor are unique in their effect on growth or whether a sufficiently high concentration of OMVs produced by early stationary phase cultures under normal growth, will achieve a similar result. Previous studies have shown that bacteria become slow-growing and antibiotic tolerant when left in extended periods of time in stationaryphase and require being sub-cultured multiple times to obtain a culture which is low in slowgrowing/dormant bacteria (Brauner et al, 2016). We speculate that this phenomenon is due to OMV-mediated programming, similar to that seen in this study. Whilst it is possible $O \mathrm{OV}_{\mathrm{n}}$ could produce similar effects, poor yields of $O M V_{n}$ compared to $O M V_{\text {cip }}$ make experimenting with $\mathrm{OMV}_{\mathrm{n}}$ difficult. 


\subsection{Modulation of colony morphology \& biofilm formation by OMV $\underline{\text { cip }}$}

Treatment of $P$. aeruginosa cultures with $\mathrm{OMV}_{\text {cip }}$ caused the formation of irregular shaped colonies with the appearance of plaque formation occurring compared to control colonies (Fig 27). The irregular appearance of the colonies became less pronounced with each subsequent dilution of the culture, suggesting that the carryover of $\mathrm{OMV}_{\text {cip }}$ was responsible for the modulation of colony appearance.

Zones of clearing were present in the $\mathrm{OMV}_{\text {cip }}$-treated colonies, this is a typical of colonies experiencing either bacterial lysis (D'Argenio et al, 2002) or swarming type behaviour (Overhage et al, 2008) noted in other studies of P. aeruginosa. We speculate that the irregularity of these colonies is not due to bacterial lysis as suggested in previous studies, but is due to a mixed population of slow and fast growing bacteria. The zones of clearing would be the region which are occupied by slow-growing bacteria, whilst the visible colony regions are made up of fast-growing bacteria.

OMVs have shown to increase biofilm formation in Helicobacter pylori (Yonezawa et al., 2009) and have also been shown to increase cellular aggregation and subsequent biofilm formation aiding in the development of dental plaques in the bacterium Porphyromonas gingivalis (Grenier \& Mayrand, 1987). Currently, there is a lack of studies investigating the role of OMVs in promoting biofilm formation in $P$. aeruginosa, apart from studies indicating that there is a significant prescence of OMVs associated with the biofilm matrix in P. aeruginosa (Schooling \& Beveridge, 2006). The role of OMVs in stimulating biofilm formation in bacteria is commonplace in bacteria and such, it is almost certain the $P$. aeruginosa-derived OMVs would likely increase biofilm formation but has not been confirmed.

Studies have shown P. aeruginosa mutants that over-express PQS, readily form wrinkled colonies whilst mutants with reduced PQS production show a reduction in bacterial lysis, resulting in regular colony morphology being restored (D'Argenio et al., 2002). Wrinkled colony formation 
was found to be consistent with increased cellular aggregation due to increased production of fimbrial adhesion proteins initiated by PQS-mediated up-regulation of genes that are controlled by the regulatory gene, $W s p R$. $W s p R$ encodes a diguanylate cyclase and subsequent activation of WspR results in increased biofilm formation in P. aeruginosa (Ryder et al, 2007). Given the similarity between studies showing irregular colony morphology \& the colonies formed in this study with treatment of $\mathrm{OMV}_{\text {cip }}$, it is possible that the colony morphology can be explained by the induction of increased cellular aggregation by an autoinducer such as PQS that is present in the OMVs.

The bacteriolytic potential of OMVs derived from P. aeruginosa has previously been demonstrated in OMVs generated in the presence of the antibiotic aminoglycoside, gentamicin $\left(\mathrm{OMV}_{\mathrm{g}}\right)$. The presence of autolysins is present in both $\mathrm{OMV}_{\mathrm{n}} \& \mathrm{OMV}_{\mathrm{g}}$ and is capable of hydrolysing the cell walls of both Gram-positive and Gram-negative bacteria leading to bacteriolysis (Kadurugamuwa \& Beveridge, 1996). The presence of autolysins in $\mathrm{OMV}_{\text {cip }}$ is likely and as such, may explain why a reduced colony size is present in the dilutions plated with the highest bacteria concentration.

Single-point mutations in the gene LasR (transcriptional regulatory gene stimulated by the presence of quorum-sensing molecules) creates $P$. aeruginosa mutants that are resistant to bacterial lysis that would normally occur in stationary-phase (Heurlier et al., 2005) and thus indicates the activation of genes under quorum-sensing regulation by acyl-HSL or PQS, plays a role in modulating cell death.

Given the roles of quorum sensing molecules like PQS in being able to both induce swarming behaviour and cause plaque formation through cellular aggregation and cell death, it is difficult to distinguish whether the reduced colony size and irregular morphology could be due to the presence of quorum-sensing molecules or autolysins. 


\subsection{Growth Inhibition of S. enterica by OMV cip $_{\text {}}$}

Cultures of $S$. enterica grown in the presence of $P$. aeruginosa-derived $\mathrm{OMV}_{\text {cip }}$, experienced a reduced growth rate and achieved a lower final cell density after 14 hrs which indicates that $\mathrm{OMV}_{\text {cip }}$ inhibits growth of $S$. enterica (Fig $\left.14 \& 15\right)$. OMV fusion to bacteria occurs both intraspecially and intraspecially, as well being able to mammalian cells to deliver virulence factors and modulate host-immune cell function (Bomberger et al., 2009; Kulp \& Kuehn, 2010; Schwechheimer \& Kuehn, 2015).

Fusion of OMVs-derived from one species of bacteria to another species has been shown to facilitate killing of the recipient bacteria (Li et al., 1998) through delivering virulence factors such as hydrolytic enzymes present in the OMVs as mentioned in section 4.4. Zymogram analysis of OMVs derived from 15 different Gram-negative bacteria, found OMVs derived from PAO1 had the highest level of lytic activity, indicating the potential for $P$. aeruginosa to act in an offensive manner against other bacteria. Fusion of $P$. aeruginosa-derived OMVs has been observed in E. coli and $S$. aureus bacteria, leading to disintegration of the cell wall (Kadurugamuwa \& Beveridge, 1996) and subsequent cell death.

The reduced growth seen in S. enterica cultures treated with OMVs (Fig $14 \& 15$ ) is consistent with the OMVs inhibiting growth of $S$. enterica and the final cell density is reduced similarly to that seen with PAO1 (Fig 13). We speculate that the OMV signalling component causing this may be active across multiple bacterial species and as such examining this phenomenon across multiple bacterial species may aid in future studies to determine the exact mechanism. 


\subsection{Induction of the persister phenotype by OMVs}

Due to the mounting evidence indicate that OMVs act as intercellular messengers and that increased production of OMVs is a response to environmental stressors, it seemed plausible that intraspecies fusion of OMVs generated under stress may induce persister formation. Persister cells are dormant cells that are genetically identical to the rest of the population and stochastically form in a bacterial population. They display a high level of antibiotic tolerance and are implicated in the resurgence of chronic infections (Lewis, 2010). As persister cells have a decreased metabolism they have a decreased pmf (Wood et al, 2013). PI was used in this study to assess whether OMV treatment caused a decrease in pmf resulting in increases in PI staining.

PAO1 cultures treated with $\mathrm{OMV}_{\text {cip }}$ showed an increase in PI staining compared to control cells, in all the experimental replicates (Fig 26) potentially suggesting that OMVs are capable of causing a drop in pmf or increase in membrane permeability. This evidence alone is insufficient to conclude whether OMVs are capable of mediating the formation of persister cells as increased PI staining of cells can be due to a number of reasons.

PI is predominantly used in microbiology as a cell viability dye, as viable cells are assumed to have intact cell membranes and are capable of excluding PI, whereas dead cells have impaired membrane integrity and display increased membrane permeability which allows PI to enter and stain nucleic acids within the cell (Stiefel et al, 2015). This could mean that the increase in PI staining of cells treated with $\mathrm{OMV}_{\text {cip }}$ could be due to cell death. There is also the possibility the increase in PI staining could be caused by OMV fusion inducing temporary 'leakiness' in bacterial cell membranes, allowing PI to enter the cell, however this study has no evidence to support this.

Plating of PAO1 cultures treated with $\mathrm{OMV}_{\text {cip }}$ to identify whether the increase in PI staining was due to cell death showed that although colony morphology was distinctly different to that of the 
control, colonies formed from all dilutions that produced colonies in the control cultures. This suggests that $\mathrm{OMV}_{\text {cip }}$ is not causing cell death. Treatment of PAO1 with 5x MIC of ciprofloxacin caused failure of any colonies to form in both the control and OMV-treated cultures and as such, the capacity for OMVs to mediate persister formation remains unverified. 


\section{$\underline{\text { 5. Future Directions }}$}

This study confirmed a role for OMVs in inter-cellular signalling in P. aeruginosa, capable of mediating synchronised behaviour through programming. However a number of questions remain unanswered about OMV-mediated bacterial programming and as such, further studies are required to fully understand this phenomenon.

$\mathrm{OMV}_{\text {cip }}$ caused PAO1 cells to enter an early senescent period, marked by a lower final culture density reached. The duration of this programming effect is unclear and warrants further investigation. This could be studied by re-culturing cells derived from an OMV-treated culture and tracking growth compared to control cultures. A dilution series of bacteria should be made of each culture ranging from 100,000 bacteria to a single bacterium per inoculum in each well and all growth tracked on the same 96-well plate. The time between readings should be decreased from 30 mins to $2-3$ mins, as this will enhance the resolution of the data obtained and will enable robust growth kinetic analyses to be performed. Previous studies conducted by the Day lab, have confirmed the utility of this methodology in estimating growth rates \& doubling time through growth kinetic analysis (Dr D Day, Personal Communication). If growth resumes in OMVtreated cultures during the course of the experiment, the number of generations required to 'erase' the programming can be determined by comparison of the culture to the control culture dilution series. Furthermore, slope comparison of OMV-treated cultures to control cultures can be used to determine whether OMVs cause a decrease in growth efficiency by determining doubling time during the exponential phase.

Validation of the proposed model for OMV-mediated programming of bacterial populations is required to explain the growth inhibitory effects seen. To examine this further, growth assays should be repeated with a dilution series of PAO1, ranging from a relatively high-concentration inoculum to a low-concentration inoculum. All cultures will be exposed to the same concentration of OMV, which will theoretically cause the lower-concentration inoculums to 
achieve near 100\% saturation of the bacterial population with OMVs. This will confirm whether the difference between final culture density is dependent on the ratio of OMV-fused bacteria vs OMV-naïve bacteria.

OMV treated cultures prematurely entered stationary-phase resulting in a lower final culture density. As the culture does not resume growth once it has entered the premature stationaryphase, $100 \%$ of the bacteria are growth-inhibited and have entered a 'senescent' state.

This study has postulated potential signalling elements in $O M V_{\text {cip }}$ based on the current literature, however this is speculative at best and requires further work to identify the components responsible for the effects seen. Fractionation of the OMVs by high-performance liquid chromatography (HPLC) would separate the OMV components, allowing each fraction to be assayed for bioactivity (induction of pyoverdine production and growth inhibition) of that seen in this study. Bioactive fractions can then be analysed by Matrix-assisted desorption/ionization (MALDI), to identify the biomolecule or protein responsible.

The PI data in this study, showed that OMVs increase PI staining but it was unclear as to the cause of this and plating of cells following high-concentration ciprofloxacin treatment failed to produce any results, leaving the question of whether OMVs can induce persister formation unanswered. In future studies, experiments should be performed examining the metabolic state of PAO1 cells after OMV treatment using another fluorescent dye such as rhodamine 123 to determine whether cells display a lower metabolic state, reflective of a persister-like phenotype. As the ability to produce pyoverdine has been correlated to increased virulence in $P$. aeruginosa, future experiments should also examine if OMV-treated $P$. aeruginosa bacteria, are more virulent and cause a higher mortality in a waxworm model (Galleria mellonella). This could shed light on the clinical relevance of OMV production in human infections (i.e. CF patients). 


\section{Conclusion}

In conclusion, many previous studies have confirmed the role of OMVs in a wide-range of biological functions and play an important role in mediating virulence in pathogenic bacteria such as P.aeruginosa. P.aeruginosa OMVs generated in response to an environmental stressor (i.e. ciprofloxacin treatment) are both produced in greater quantities and have a distinctly different composition to OMVs produced during stationary phase growth. This suggested a plausible role for OMVs to aid survival of bacteria exposed to antibiotic.

Treatment of PAO1 with $\mathrm{OMV}_{\text {cip }}$ caused early entry into stationary phase with cells exhibiting a senescent-like state. Furthermore, pre-incubation of PAO1 with $\mathrm{OMV}_{\text {cip }}$ determined that priorparental exposure to $\mathrm{OMV}_{\text {cip }}$ was sufficient to program the fate of subsequent progeny to enter stationary phase prematurely. $\mathrm{OMV}_{\text {cip }}$ induces pyoverdine production in PAO1 but unlike the growth effect, is required to be present in the culture media to achieve this.

The effects of $O M V_{\text {cip }}$ could not be prevented by heat inactivation. OMV membrane disruption by chloroform however, ablated the modulation of growth by $\mathrm{OMV}_{\text {cip }}$ but did not alter the ability for $\mathrm{OMV}_{\text {cip }}$ to induce pyoverdine production. This suggests that OMV-mediated growth effects and OMV-mediated pyoverdine production are due to two separate signals present on/in the OMV, both of which are unlikely to be a protein but potentially a lipid or small hydrophobic molecule.

OMVs appear to act as a vehicle for signalling between bacteria and communicate the conditions of the environment from one cell to another. OMVs generated by bacteria in the presence of antibiotic can program naïve cells to enter a dormant-state, potentially causing them to become antibiotic-tolerant, aiding in survival. 


\section{References}

Ackermann, M., Stearns, S. C., \& Jenal, U. (2003). Senescence in a bacterium with asymmetric division. Science, 300(5627), 1920-1920.

Aizenman, E., Engelberg-Kulka, H., \& Glaser, G. (1996). An Escherichia coli chromosomal "addiction module" regulated by guanosine [corrected] 3',5'-bispyrophosphate: a model for programmed bacterial cell death. Proceedings of the National Academy of Sciences, 93(12), 6059-6063.

Andrews, S. C., Robinson, A. K., \& Rodríguez-Quiñones, F. (2006). Bacterial iron homeostasis. FEMS Microbiology Reviews, 27(2-3), 215-237.

Balaban, N. Q., Merrin, J., Chait, R., Kowalik, L., \& Leibler, S. (2004). Bacterial persistence as a phenotypic switch. Science, 305(5690), 1622-1625.

Bauernfeind, A., \& Petermüller, C. (1983). In vitro activity of ciprofloxacin, norfloxacin and nalidixic acid. European Journal of Clinical Microbiology, 2(2), 111-115.

Bauman, S. J., \& Kuehn, M. J. (2006). Purification of outer membrane vesicles from Pseudomonas aeruginosa and their activation of an IL-8 response. Microbes Infect, 8(9-10), 2400-2408.

Bernard, P., \& Couturier, M. (1992). Cell killing by the F plasmid CcdB protein involves poisoning of DNA-topoisomerase II complexes. Journal of Molecular Biology, 226(3), 735-745.

Bielig, H., Dongre, M., Zurek, B., Wai, S. N., \& Kufer, T. A. (2011). A role for quorum sensing in regulating innate immune responses mediated by Vibrio cholerae outer membrane vesicles (OMVs). Gut Microbes, 2(5), 274-279.

Bomberger, J. M., MacEachran, D. P., Coutermarsh, B. A., Ye, S., O'Toole, G. A., \& Stanton, B. A. (2009). Long-distance delivery of bacterial virulence factors by Pseudomonas aeruginosa outer membrane vesicles. PLoS Pathog, 5(4), e1000382.

Brantl, S. (2012). Bacterial type I toxin-antitoxin systems. RNA Biology, 9(12), 1488-1490.

Brauner, A., Fridman, O., Gefen, O., \& Balaban, N. Q. (2016). Distinguishing between resistance, tolerance and persistence to antibiotic treatment. Nat Rev Micro, 14(5), 320-330.

Campisi, J. (1999). Cancer, aging and cellular senescence. In vivo (Athens, Greece), 14(1), 183-188.

Casadesús, J., \& Low, D. (2006). Epigenetic Gene Regulation in the Bacterial World. Microbiology and Molecular Biology Reviens, 70(3), 830-856.

Costerton, J. W., Lewandowski, Z., Caldwell, D. E., Korber, D. R., \& Lappin-Scott, H. M. (1995). Microbial biofilms. Annual Reviews in Microbiology, 49(1), 711-745.

D'Argenio, D. A., Calfee, M. W., Rainey, P. B., \& Pesci, E. C. (2002). Autolysis and Autoaggregation in Pseudomonas aeruginosa Colony Morphology Mutants. Journal of bacteriology, 184(23), 6481-6489.

Dalebroux, Z. D., \& Swanson, M. S. (2012). ppGpp: magic beyond RNA polymerase. Nat Rev Micro, 10(3), 203-212.

Dao, K.-H. T., Hamer, K. E., Clark, C. L., \& Harshman, L. G. (1999). Pyoverdine production by Pseudomonas aeruginosa exposed to metals or an oxidative stress agent. Ecological Applications, 9(2), 441-448. 
Darby, B. L., Auguié, B., Meyer, M., Pantoja, A. E., \& Le Ru, E. C. (2016). Modified optical absorption of molecules on metallic nanoparticles at sub-monolayer coverage. Nat Photon, 10(1), 40-45.

Déziel, E., Gopalan, S., Tampakaki, A. P., Lépine, F., Padfield, K. E., Saucier, M., . . Rahme, L. G. (2005). The contribution of MvfR to Pseudomonas aeruginosa pathogenesis and quorum sensing circuitry regulation: multiple quorum sensing - regulated genes are modulated without affecting lasRI, rhIRI or the production of N - acyl - 1 - homoserine lactones. Molecular Microbiology, 55(4), 998-1014.

Diggle, S. P., Matthijs, S., Wright, V. J., Fletcher, M. P., Chhabra, S. R., Lamont, I. L., . . Williams, P. (2007). The Pseudomonas aeruginosa 4-Quinolone Signal Molecules HHQ and PQS Play Multifunctional Roles in Quorum Sensing and Iron Entrapment. Chemistry \& Biology, 14(1), 87-96.

Drlica, K., \& Zhao, X. (1997). DNA gyrase, topoisomerase IV, and the 4-quinolones. Microbiology and Molecular Biology Reviews, 61(3), 377-392.

Ellis, T. N., Leiman, S. A., \& Kuehn, M. J. (2010). Naturally produced outer membrane vesicles from Pseudomonas aeruginosa elicit a potent innate immune response via combined sensing of both lipopolysaccharide and protein components. Infection and immunity, 78(9), 3822-3831.

Emmerson, A. M., \& Jones, A. M. (2003). The quinolones: decades of development and use. Journal of Antimicrobial Chemotherapy, 51 (suppl 1), 13-20.

Fauvart, M., De Groote, V. N., \& Michiels, J. (2011). Role of persister cells in chronic infections: clinical relevance and perspectives on anti-persister therapies. Journal of medical microbiology, 60(6), 699-709.

Fernández-Piñar, R., Cámara, M., Dubern, J.-F., Ramos, J. L., \& Espinosa-Urgel, M. (2011). The Pseudomonas aeruginosa quinolone quorum sensing signal alters the multicellular behaviour of Pseudomonas putida KT2440. Research in microbiology, 162(8), 773-781.

Folk, R. L. (1993). SEM imaging of bacteria and nannobacteria in carbonate sediments and rocks. Journal of Sedimentary Research, 63(5), 990-999.

Fulsundar, S., Harms, K., Flaten, G. E., Johnsen, P. J., Chopade, B. A., \& Nielsen, K. M. (2014). Gene Transfer Potential of Outer Membrane Vesicles of Acinetobacter baylyi and Effects of Stress on Vesiculation. Applied and Environmental Microbiology, 80(11), 3469-3483.

Genicot, G., Leroy, J. L., Soom, A. V., \& Donnay, I. (2005). The use of a fluorescent dye, Nile red, to evaluate the lipid content of single mammalian oocytes. Theriogenology, 63(4), 1181-1194.

Gerdes, K. (2000). Toxin-Antitoxin Modules May Regulate Synthesis of Macromolecules during Nutritional Stress. Journal of bacteriology, 182(3), 561-572.

Gerdes, K., \& Maisonneuve, E. (2012). Bacterial Persistence and Toxin-Antitoxin Loci. Annual review of microbiology, 66(1), 103-123.

Goldburg, W. (1999). Dynamic light scattering. American Joumal of Physics, 67(12), 1152-1160.

Gorringe, A., Halliwell, D., Matheson, M., Reddin, K., Finney, M., \& Hudson, M. (2005). The development of a meningococcal disease vaccine based on Neisseria lactamica outer membrane vesicles. Vaccine, 23(17-18), 2210-2213.

Grenier, D., \& Mayrand, D. (1987). Functional characterization of extracellular vesicles produced by Bacteroides gingivalis. Infection and immunity, 55(1), 111-117. 
Hallett, F., Watton, J., \& Krygsman, P. (1991). Vesicle sizing: number distributions by dynamic light scattering. Biophysical joumal, 59(2), 357.

Harrison, F., Browning, L. E., Vos, M., \& Buckling, A. (2006). Cooperation and virulence in acute Pseudomonas aeruginosa infections. BMC Biology, 4(1), 21.

Hassett, D., Charniga, L., Bean, K., Ohman, D., \& Cohen, M. S. (1992). Response of Pseudomonas aeruginosa to pyocyanin: mechanisms of resistance, antioxidant defenses, and demonstration of a manganese-cofactored superoxide dismutase. Infection and immunity, 60(2), 328-336.

Hayes, C. S., \& Sauer, R. T. (2003). Toxin-Antitoxin Pairs in Bacteria: Killers or Stress Regulators? Cell, 112(1), 2-4.

Hayes, F. (2003). Toxins-antitoxins: plasmid maintenance, programmed cell death, and cell cycle arrest. Science, 301(5639), 1496-1499.

Hensler, P. J., \& Pereira-Smith, O. M. (1995). Human replicative senescence. A molecular study. The American journal of pathology, 147(1), 1.

Heurlier, K., Dénervaud, V., Haenni, M., Guy, L., Krishnapillai, V., \& Haas, D. (2005). Quorum-SensingNegative (lasR) Mutants of Pseudomonas aeruginosa Avoid Cell Lysis and Death. Journal of bacteriology, 187(14), 4875-4883.

Huang, J. J., Han, J.-I., Zhang, L.-H., \& Leadbetter, J. R. (2003). Utilization of Acyl-Homoserine Lactone Quorum Signals for Growth by a Soil Pseudomonad and Pseudomonas aeruginosa PAO1. Applied and Environmental Microbiology, 69(10), 5941-5949.

Itah, A. Y., \& Essien, J. P. (2005). Growth Profile and Hydrocarbonoclastic Potential of Microorganisms Isolated from Tarballs in the Bight of Bonny, Nigeria. World Journal of Microbiology and Biotechnology, 21(6), 1317-1322.

Janion, C. (2001). Some aspects of the SOS response system—a critical survey.

Jiang, X., \& Wang, X. (2004). Cytochrome C-mediated apoptosis. Annu Rev Biochem, 73, 87-106.

Jolivet-Gougeon, A., \& Bonnaure-Mallet, M. (2014). Biofilms as a mechanism of bacterial resistance. Drug Discovery Today: Technologies, 11, 49-56.

Kadurugamuwa, J. L., \& Beveridge, T. J. (1995). Virulence factors are released from Pseudomonas aeruginosa in association with membrane vesicles during normal growth and exposure to gentamicin: a novel mechanism of enzyme secretion. Journal of bacteriology, 177(14), 3998-4008.

Kadurugamuwa, J. L., \& Beveridge, T. J. (1996). Bacteriolytic effect of membrane vesicles from Pseudomonas aeruginosa on other bacteria including pathogens: conceptually new antibiotics. Journal of bacteriology, 178(10), 2767-2774.

Kaufmann, B. B., Yang, Q., Mettetal, J. T., \& van Oudenaarden, A. (2007). Heritable stochastic switching revealed by single-cell genealogy. PLOS Biol, 5(9), e239.

Kem, M. P., \& Butler, A. (2015). Acyl peptidic siderophores: structures, biosyntheses and post-assembly modifications. BioMetals, 28(3), 445-459.

Kerr, J., Taylor, G., Rutman, A., Høiby, N., Cole, P., \& Wilson, R. (1999). Pseudomonas aeruginosa pyocyanin and 1-hydroxyphenazine inhibit fungal growth. Journal of clinical pathology, 52(5), 385387. 
Khan, M. Y., Gruninger, R. P., Nelson, S. M., \& Klicker, R. E. (1982). Comparative in vitro activity of norfloxacin (MK-0366) and ten other oral antimicrobial agents against urinary bacterial isolates. Antimicrobial Agents and Chemotherapy, 21(5), 848-851.

Klimentová, J., \& Stulík, J. (2015). Methods of isolation and purification of outer membrane vesicles from gram-negative bacteria. Microbiological Research, 170, 1-9.

Kulp, A., \& Kuehn, M. J. (2010). Biological functions and biogenesis of secreted bacterial outer membrane vesicles. Annual review of microbiology, 64, 163.

Labrie, S. J., Samson, J. E., \& Moineau, S. (2010). Bacteriophage resistance mechanisms. Nat Rev Micro, $8(5), 317-327$.

Lau, G. W., Hassett, D. J., Ran, H., \& Kong, F. (2004). The role of pyocyanin in Pseudomonas aeruginosa infection. Trends in molecular medicine, 10(12), 599-606.

Lee, E. Y., Choi, D. Y., Kim, D. K., Kim, J. W., Park, J. O., Kim, S., . . Kim, K. P. (2009). Gram positive bacteria produce membrane vesicles: Proteomics - based characterization of Staphylococcus aureus - derived membrane vesicles. Proteomics, 9(24), 5425-5436.

Lewis, K. (2010). Persister Cells. Annual review of microbiology, 64(1), 357-372.

Li, Z., Clarke, A. J., \& Beveridge, T. J. (1998). Gram-Negative Bacteria Produce Membrane Vesicles Which Are Capable of Killing Other Bacteria. Journal of bacteriology, 180(20), 5478-5483.

MacDonald, I. A., \& Kuehn, M. J. (2013). Stress-Induced Outer Membrane Vesicle Production by Pseudomonas aeruginosa. Journal of bacteriology, 195(13), 2971-2981.

Maredia, R., Devineni, N., Lentz, P., Dallo, S. F., Yu, J., Guentzel, N., .. Weitao, T. (2012). Vesiculation from Pseudomonas aeruginosa under SOS. The Scientific World Journal, 2012.

Mashburn, L. M., \& Whiteley, M. (2005). Membrane vesicles traffic signals and facilitate group activities in a prokaryote. Nature, 437(7057), 422-425.

McCaig, W. D., Koller, A., \& Thanassi, D. G. (2013). Production of Outer Membrane Vesicles and Outer Membrane Tubes by Francisella novicida. Journal of bacteriology, 195(6), 1120-1132.

Metruccio, M. M. E., Evans, D. J., Gabriel, M. M., Kadurugamuwa, J. L., \& Fleiszig, S. M. J. (2016). Pseudomonas aeruginosa Outer Membrane Vesicles Triggered by Human Mucosal Fluid and Lysozyme Can Prime Host Tissue Surfaces for Bacterial Adhesion. Frontiers in Microbiology, 7, 871.

Meyer, J. M., Neely, A., Stintzi, A., Georges, C., \& Holder, I. A. (1996). Pyoverdin is essential for virulence of Pseudomonas aeruginosa. Infection and immunity, 64(2), 518-523.

Miller, M. B., \& Bassler, B. L. (2001). Quorum sensing in bacteria. Annual Reviews in Microbiology, 55(1), 165-199.

Minandri, F., Imperi, F., Frangipani, E., Bonchi, C., Visaggio, D., Facchini, M., . . Visca, P. (2016). Role of Iron Uptake Systems in Pseudomonas aeruginosa Virulence and Airway Infection. Infection and immunity, 84(8), 2324-2335.

Nadal Jimenez, P., Koch, G., Thompson, J. A., Xavier, K. B., Cool, R. H., \& Quax, W. J. (2012). The Multiple Signaling Systems Regulating Virulence in Pseudomonas aeruginosa. Microbiology and Molecular Biology Reviens, 76(1), 46-65. 
Nebe-von-Caron, G., Stephens, P. J., Hewitt, C. J., Powell, J. R., \& Badley, R. A. (2000). Analysis of bacterial function by multi-colour fluorescence flow cytometry and single cell sorting. Journal of Microbiological Methods, 42(1), 97-114.

Nguyen, T. T., Saxena, A., \& Beveridge, T. J. (2003). Effect of surface lipopolysaccharide on the nature of membrane vesicles liberated from the Gram - negative bacterium Pseudomonas aeruginosa. Journal of Electron Microscopy, 52(5), 465-469.

O'Toole, G. A., \& Kolter, R. (1998). Flagellar and twitching motility are necessary for Pseudomonas aeruginosa biofilm development. Molecular Microbiology, 30(2), 295-304.

Overhage, J., Bains, M., Brazas, M. D., \& Hancock, R. E. W. (2008). Swarming of Pseudomonas aeruginosa Is a Complex Adaptation Leading to Increased Production of Virulence Factors and Antibiotic Resistance. Journal of bacteriology, 190(8), 2671-2679.

Park, A. J., Murphy, K., Surette, M. D., Bandoro, C., Krieger, J. R., Taylor, P., \& Khursigara, C. M. (2015). Tracking the Dynamic Relationship between Cellular Systems and Extracellular Subproteomes in Pseudomonas aeruginosa Biofilms. Journal of Proteome Research, 14(11), 45244537.

Park, K.-S., Choi, K.-H., Kim, Y.-S., Hong, B. S., Kim, O. Y., Kim, J. H., . . Gho, Y. S. (2010). Outer membrane vesicles derived from Escherichia coli induce systemic inflammatory response syndrome. PLoS One, 5(6), e11334.

Parker, H., Chitcholtan, K., Hampton, M. B., \& Keenan, J. I. (2010). Uptake of Helicobacter pylori outer membrane vesicles by gastric epithelial cells. Infection and immunity, 78(12), 5054-5061.

Pearson, J. P., Passador, L., Iglewski, B. H., \& Greenberg, E. P. (1995). A second N-acylhomoserine lactone signal produced by Pseudomonas aeruginosa. Proceedings of the National Academy of Sciences, 92(5), 1490-1494.

Pesci, E. C., Milbank, J. B. J., Pearson, J. P., McKnight, S., Kende, A. S., Greenberg, E. P., \& Iglewski, B. H. (1999). Quinolone signaling in the cell-to-cell communication system of Pseudomonas aeruginosa. Proceedings of the National Academy of Sciences, 96(20), 11229-11234.

Petersen, U., Grohe, K., Zeiler, H. J., \& Metzger, K. G. (1985). 1-Cyclopropyl-6-fluoro-1,4-dihydro-4oxo-7-[4-(oxo-alkyl)-1-piperazinyl] quinoline-3-carboxylic acids and their derivatives, and antibacterial agents containing them: Google Patents.

Pettigrew, G. W., \& Moore, G. R. (1987). Cytochromes c: biological aspects: Springer-Verlag.

Rainey, P. B., Beaumont, H. J., Ferguson, G. C., Gallie, J., Kost, C., Libby, E., \& Zhang, X.-X. (2011). The evolutionary emergence of stochastic phenotype switching in bacteria. Microbial cell factories, 10(1), 1.

Rivera, J., Cordero, R. J., Nakouzi, A. S., Frases, S., Nicola, A., \& Casadevall, A. (2010). Bacillus anthracis produces membrane-derived vesicles containing biologically active toxins. Proceedings of the National Academy of Sciences, 107(44), 19002-19007.

Ryder, C., Byrd, M., \& Wozniak, D. J. (2007). Role of polysaccharides in Pseudomonas aeruginosa biofilm development. Current opinion in microbiology, 10(6), 644-648.

Schalk, I. J., \& Guillon, L. (2013). Pyoverdine biosynthesis and secretion in Pseudomonas aeruginosa: implications for metal homeostasis. Environmental microbiology, 15(6), 1661-1673. 
Schertzer, J. W., \& Whiteley, M. (2013). Bacterial Outer Membrane Vesicles in Trafficking, Communication and the Host-Pathogen Interaction. Journal of Molecular Microbiology and Biotechnology, 23(1-2), 118-130.

Schobert, M., \& Jahn, D. (2010). Anaerobic physiology of Pseudomonas aeruginosa in the cystic fibrosis lung. International Journal of Medical Microbiology, 300(8), 549-556.

Schooling, S. R., \& Beveridge, T. J. (2006). Membrane Vesicles: an Overlooked Component of the Matrices of Biofilms. Journal of bacteriology, 188(16), 5945-5957.

Schooling, S. R., Hubley, A., \& Beveridge, T. J. (2009). Interactions of DNA with biofilm-derived membrane vesicles. Journal of bacteriology, 191(13), 4097-4102.

Schuster, M., Lostroh, C. P., Ogi, T., \& Greenberg, E. P. (2003). Identification, Timing, and Signal Specificity of Pseudomonas aeruginosa Quorum-Controlled Genes: a Transcriptome Analysis. Journal of bacteriology, 185(7), 2066-2079.

Schuster, M., \& Peter Greenberg, E. (2006). A network of networks: Quorum-sensing gene regulation in Pseudomonas aeruginosa. International Journal of Medical Microbiology, 296(2-3), 73-81.

Schwechheimer, C., \& Kuehn, M. J. (2013). Synthetic Effect between Envelope Stress and Lack of Outer Membrane Vesicle Production in Escherichia coli. Journal of bacteriology, 195(18), 4161-4173.

Schwechheimer, C., \& Kuehn, M. J. (2015). Outer-membrane vesicles from Gram-negative bacteria: biogenesis and functions. Nat Rev Micro, 13(10), 605-619.

Shay, J. W., \& Wright, W. E. (2000). Hayflick, his limit, and cellular ageing. Nat Rev Mol Cell Biol, 1(1), 7276.

Silby, M. W., Winstanley, C., Godfrey, S. A. C., Levy, S. B., \& Jackson, R. W. (2011). Pseudomonas genomes: diverse and adaptable. FEMS Microbiology Reviews, 35(4), 652-680.

Sio, C. F., Otten, L. G., Cool, R. H., Diggle, S. P., Braun, P. G., Bos, R., . . Quax, W. J. (2006). Quorum Quenching by an N-Acyl-Homoserine Lactone Acylase from Pseudomonas aeruginosa PAO1. Infection and immunity, 74(3), 1673-1682.

Stiefel, P., Schmidt-Emrich, S., Maniura-Weber, K., \& Ren, Q. (2015). Critical aspects of using bacterial cell viability assays with the fluorophores SYTO9 and propidium iodide. BMC Microbiol, 15, 36.

Tashiro, Y., Ichikawa, S., Shimizu, M., Toyofuku, M., Takaya, N., Nakajima-Kambe, T., . . Nomura, N. (2010). Variation of Physiochemical Properties and Cell Association Activity of Membrane Vesicles with Growth Phase in Pseudomonas aeruginosa. Applied and Environmental Microbiology, 76(11), 3732-3739.

Totter, J. R., \& Moseley, F. T. (1953). INFLUENCE OF THE CONCENTRATION OF IRON ON THE PRODUCTION OF FLUORESCIN BY PSEUDOMONAS AERUGINOSA. Journal of bacteriology, 65(1), 45-47.

Toyofuku, M., Roschitzki, B., Riedel, K., \& Eberl, L. (2012). Identification of proteins associated with the Pseudomonas aeruginosa biofilm extracellular matrix. Journal of Proteome Research, 11(10), 49064915.

Tsokos, C. G., \& Laub, M. T. (2012). Polarity and cell fate asymmetry in Caulobacter crescentus. Current opinion in microbiology, 15(6), 744-750. 
Van Delden, C., \& Iglewski, B. H. (1998). Cell-to-cell signaling and Pseudomonas aeruginosa infections. Emerging infectious diseases, 4(4), 551.

Van Melderen, L., \& Saavedra De Bast, M. (2009). Bacterial Toxin-Antitoxin Systems: More Than Selfish Entities? PLOS Genetics, 5(3), e1000437.

Vandewalle, P. L., \& Petersen, N. O. (1987). Oxidation of reduced cytochrome c by hydrogen peroxide. FEBS Letters, 210(2), 195-198.

Veening, J.-W., Smits, W. K., \& Kuipers, O. P. (2008). Bistability, epigenetics, and bet-hedging in bacteria. Annu. Rev. Microbiol., 62, 193-210.

Venturi, V. (2006). Regulation of quorum sensing in Pseudomonas. FEMS Microbiology Reviews, 30(2), 274291.

Visca, P., Imperi, F., \& Lamont, I. L. (2007). Pyoverdine siderophores: from biogenesis to biosignificance. Trends in microbiology, 15(1), 22-30.

Wagner, V. E., Bushnell, D., Passador, L., Brooks, A. I., \& Iglewski, B. H. (2003). Microarray analysis of Pseudomonas aeruginosa quorum-sensing regulons: effects of growth phase and environment. Journal of bacteriology, 185(7), 2080-2095.

Wang, X., \& Wood, T. K. (2011). Toxin-Antitoxin Systems Influence Biofilm and Persister Cell Formation and the General Stress Response. Applied and Environmental Microbiology, 77(16), $5577-$ 5583.

Waters, C. M., \& Bassler, B. L. (2005). Quorum sensing: cell-to-cell communication in bacteria. Annu. Rev. Cell Dev. Biol., 21, 319-346.

Whiteley, M., Lee, K. M., \& Greenberg, E. P. (1999). Identification of genes controlled by quorum sensing in Pseudomonas aeruginosa. Proceedings of the National Academy of Sciences, 96(24), 1390413909.

Wood, T. K., Knabel, S. J., \& Kwan, B. W. (2013). Bacterial Persister Cell Formation and Dormancy. Applied and Environmental Microbiology, 79(23), 7116-7121.

Yonezawa, H., Osaki, T., Kurata, S., Fukuda, M., Kawakami, H., Ochiai, K., . . Kamiya, S. (2009). Outer membrane vesicles of Helicobacter pylori TK1402 are involved in biofilm formation. BMC Microbiol, 9, 197.

Zhao, K., Deng, X., He, C., Yue, B., \& Wu, M. (2013). Pseudomonas aeruginosa outer membrane vesicles modulate host immune responses by targeting the Toll-like receptor 4 signaling pathway. Infection and immunity, 81(12), 4509-4518. 


\section{Appendix}

\section{$\underline{6.1 \text { Media and Solution Recipes }}$}

\section{$\underline{\text { LB media }}$}

- $10 \mathrm{~g} / \mathrm{L}$ Bacto-Tryptone (Oxo)

- $5 \mathrm{~g} / \mathrm{L}$ Bacto-Yeast extract (Oxo)

- $10 \mathrm{~g} / \mathrm{L} \mathrm{NaCl}$ (BD bioscience)

- $1 \mathrm{~L} \mathrm{ddH} \mathrm{H}_{2} \mathrm{O}$

$\mathrm{LB}$ was made up to $1 \mathrm{~L}$ with $\mathrm{ddH}_{2} \mathrm{O}$ and was $\mathrm{pH}$ corrected to 7.0 with $10 \mathrm{M} \mathrm{NaOH}$ prior to sterilization by autoclaving.

\section{LB Agar}

- $10 \mathrm{~g} / \mathrm{L}$ Bacto-Tryptone (Oxo)

- $5 \mathrm{~g} / \mathrm{L}$ Bacto-Yeast extract (Oxo)

- $10 \mathrm{~g} / \mathrm{L} \mathrm{NaCl}$ (BD bioscience)

- $15 \mathrm{~g} / \mathrm{L}$ Agar (BD bioscience)

- $1 \mathrm{~L} \mathrm{ddH}_{2} \mathrm{O}$

LB was made up to $1 \mathrm{~L}$ with $\mathrm{ddH}_{2} \mathrm{O}$ and was $\mathrm{pH}$ corrected to 7.0 with $10 \mathrm{M} \mathrm{NaOH}$ prior to sterilization by autoclaving. Plates were poured in a biosafety cabinet after autoclaving and stored at $4^{\circ} \mathrm{C}$ until use.

\section{$\underline{10 x \text { PBS }}$}

- $80 \mathrm{~g} / \mathrm{L} \mathrm{NaCl}$

- $2 \mathrm{~g} / \mathrm{L} \mathrm{KCl}$

- $26.8 \mathrm{~g} / \mathrm{L} \mathrm{Na}_{2} \mathrm{HPO}_{4}-7 \mathrm{H}_{2} \mathrm{O}$

- $2.4 \mathrm{~g} / \mathrm{L} \mathrm{KH}_{2} \mathrm{PO}_{4}$

- $1 \mathrm{~L} \mathrm{ddH}_{2} \mathrm{O}$

PBS was made up to $1 \mathrm{~L}$ with $\mathrm{ddH}_{2} \mathrm{O}$ and $\mathrm{pH}$ was adjusted to 7.4 using $\mathrm{HCl}$ and was then sterilized by autoclaving. 1x PBS was made from this solution by diluting 1 part 10x PBS in 9 parts $\mathrm{ddH}_{2} \mathrm{O}$. This solution was sterilised by $0.22 \mu \mathrm{m}$ filtration or by autoclaving. 


\section{1x TE buffer}

- $10 \mathrm{~mL} 1 \mathrm{M}$ Tris

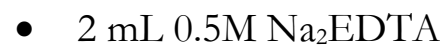

- $1 \mathrm{~L} \mathrm{ddH}_{2} \mathrm{O}$

TE buffer was sterilized by autoclaving

\section{$\underline{5 x \text { SDS Reducing buffer }}$}

- $25 \mathrm{~mL} 1.5 \mathrm{M}$ Tris

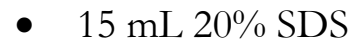

- $75 \mathrm{~mL}$ Glycerol

- $4.5 \mathrm{mg}$ bromophenol blue

- $100 \mathrm{~mL} \mathrm{ddH}_{2} \mathrm{O}$

SDS Reducing buffer was made as described above and frozen in aliquots at $-20^{\circ} \mathrm{C} .10 \% \beta$ mercaptoethanol was added fresh prior to mixing sample.

\section{$\underline{1 \mathrm{x} \text { SDS running buffer }}$}

- $1 \mathrm{~g}$ SDS

- $3.03 \mathrm{~g}$ Tris

- 14.41 g glycine

- $1 \mathrm{~L} \mathrm{ddH}_{2} \mathrm{O}$

\section{$\underline{1 \%}$ Coomassie Blue staining solution}

- $10 \mathrm{~g}$ Coomassie Brillant Blue

- $450 \mathrm{~mL}$ methanol

- $100 \mathrm{~mL}$ glacial acetic acid

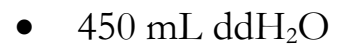

\section{Destaining solution}

- $450 \mathrm{~mL}$ methanol

- $100 \mathrm{~mL}$ glacial acetic acid

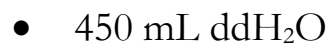




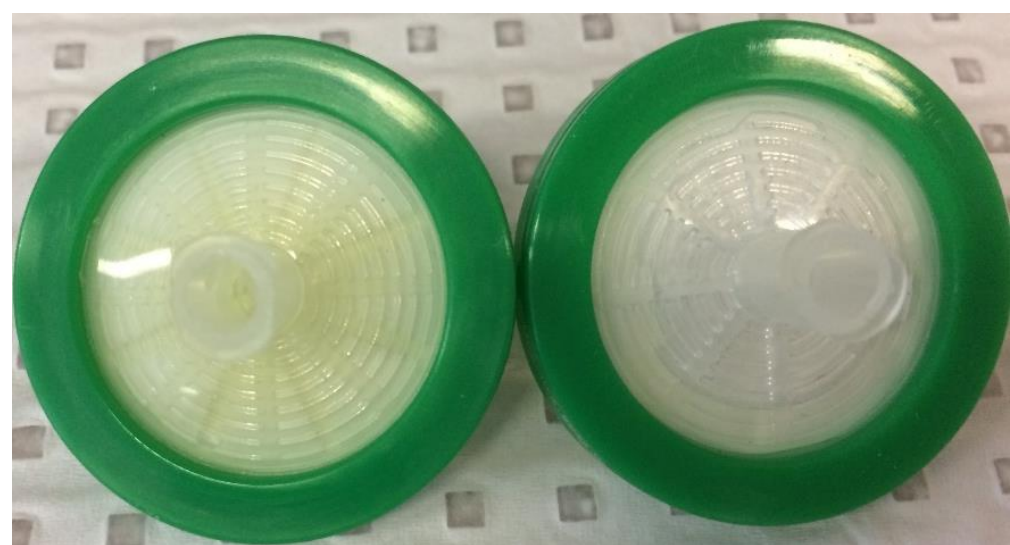

Figure 28: Example of retention of OMV samples on $0.45 \mu \mathrm{m}$ filters used.

Left filter $=\mathrm{OMV}_{\mathrm{n}}$

Right filter $=\mathrm{OMV}_{\mathrm{n}}$

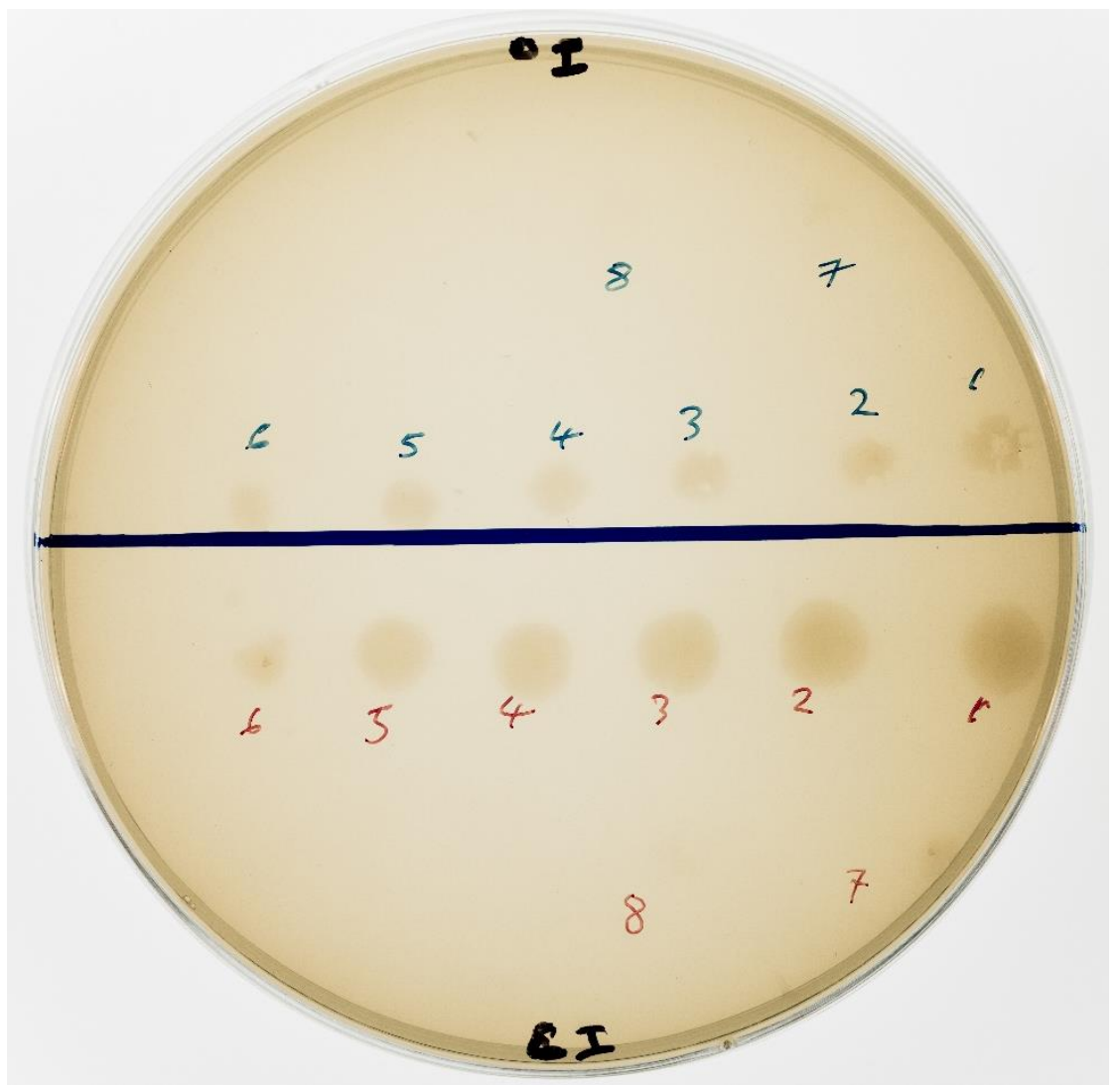

Figure 28: Additional PAO1 plate

Blue numbers $=\mathrm{OMV}_{\text {cip }}$ treated culture

Red numbers $=$ Control - no treatment 